\title{
Calcium Carbonate Particle Size Effects on Titanium Dioxide Light Scattering in Coatings
}

\author{
A Project Report \\ presented to \\ the Faculty of California Polytechnic State University, \\ San Luis Obispo
}

\author{
In Partial Fulfillment \\ of the Requirements for the Degree \\ Master of Science in Polymers and Coatings
}

by

Jason Wai Pan Boke

June 2013 
(C) 2013

Jason Wai Pan Boke

ALL RIGHTS RESERVED 
TITLE:

AUTHOR:

DATE SUBMITTED:

COMMITTEE CHAIR:

COMMITTEE MEMBER:

COMMITTEE MEMBER:
Calcium Carbonate Particle Size Effects on Titanium Dioxide Light Scattering in Coatings

Jason Wai Pan Boke

June 2013

Dr. Raymond H. Fernando, Professor Chemistry Department

Dr. Michael P. Diebold, Research Fellow E.I. du Pont de Nemours and Company

Dr. Kevin Kingsbury, Professor Chemistry \& Biochemistry Department 


\begin{abstract}
Calcium Carbonate Particle Size Effects on Titanium Dioxide Light Scattering in Coatings

Jason Wai Pan Boke
\end{abstract}

Titanium dioxide $\left(\mathrm{TiO}_{2}\right)$ is an essential component in a white paint formulation due to its excellent light scattering ability. $\mathrm{TiO}_{2}$ also happens to make up most of the raw materials cost. Viable replacements to $\mathrm{TiO}_{2}$ do not currently exist in a feasible manner. Rising costs in the recent $\mathrm{TiO}_{2}$ supply shortage have forced coatings formulators to find a balance between cost and performance. One method includes partial substitution of $\mathrm{TiO}_{2}$ with cheaper material such as calcium carbonate $\left(\mathrm{CaCO}_{3}\right)$, which serves to occupy volume.

The purpose of this study was to compare the coating spread rate of paints with varying $\mathrm{TiO}_{2}$ and $\mathrm{CaCO}_{3}$ pigment volume concentration (PVC). Different sized $\mathrm{CaCO}_{3}$ particles were used in this study. A series of PVC ladder studies were performed at keeping $\mathrm{CaCO}_{3}$ PVC constant. Paints were formulated at the same volume solids to minimize variability. Weighed coating draw-downs were prepared to measure the contrast ratio. The coating spread rates were obtained with the DuPont Spread Rate program, which relies on Kubelka-Munk relationships, which takes into account the physical properties of the paint. These spread rate values were compared to one another across type and size to find common trends. Critical pigment volume concentration (CPVC) values were determined through regression of the spread rate values and compared to oil absorption tests. 
It was found that replacement of up to $20 \mathrm{PVC}$ of $\mathrm{TiO}_{2}$ with $\mathrm{CaCO}_{3}$ could marginally increase the spread rate, thus increasing the efficiency of $\mathrm{TiO}_{2}$. The spread rate increased modestly as similarly sized extender particles were initially introduced, then dropped at higher extender levels. Data analysis revealed that CPVC was influenced based on the size and amount of the extender particle present, which can be used to predict resin demand of a paint system.

Keywords: titanium dioxide, light scattering, spread rate, calcium carbonate, particle size, contrast ratio, pigment volume concentration (PVC) 


\section{ACKNOWLEDGMENTS}

I would like to thank E. I. du Pont de Nemours and Company, particularly Dr. Michael Diebold for the opportunity as well as introducing me to the wonderful world of white pigment technology. I also thank Dr. Raymond Fernando for his support when I first learned about the Polymers and Coatings Program as well as Dr. Kevin Kingsbury for serving on my advisory committee. Finally, I want to thank the Bill Moore Fellowship Fund for financial support and the Polymers and Coatings Program for making everything possible. 


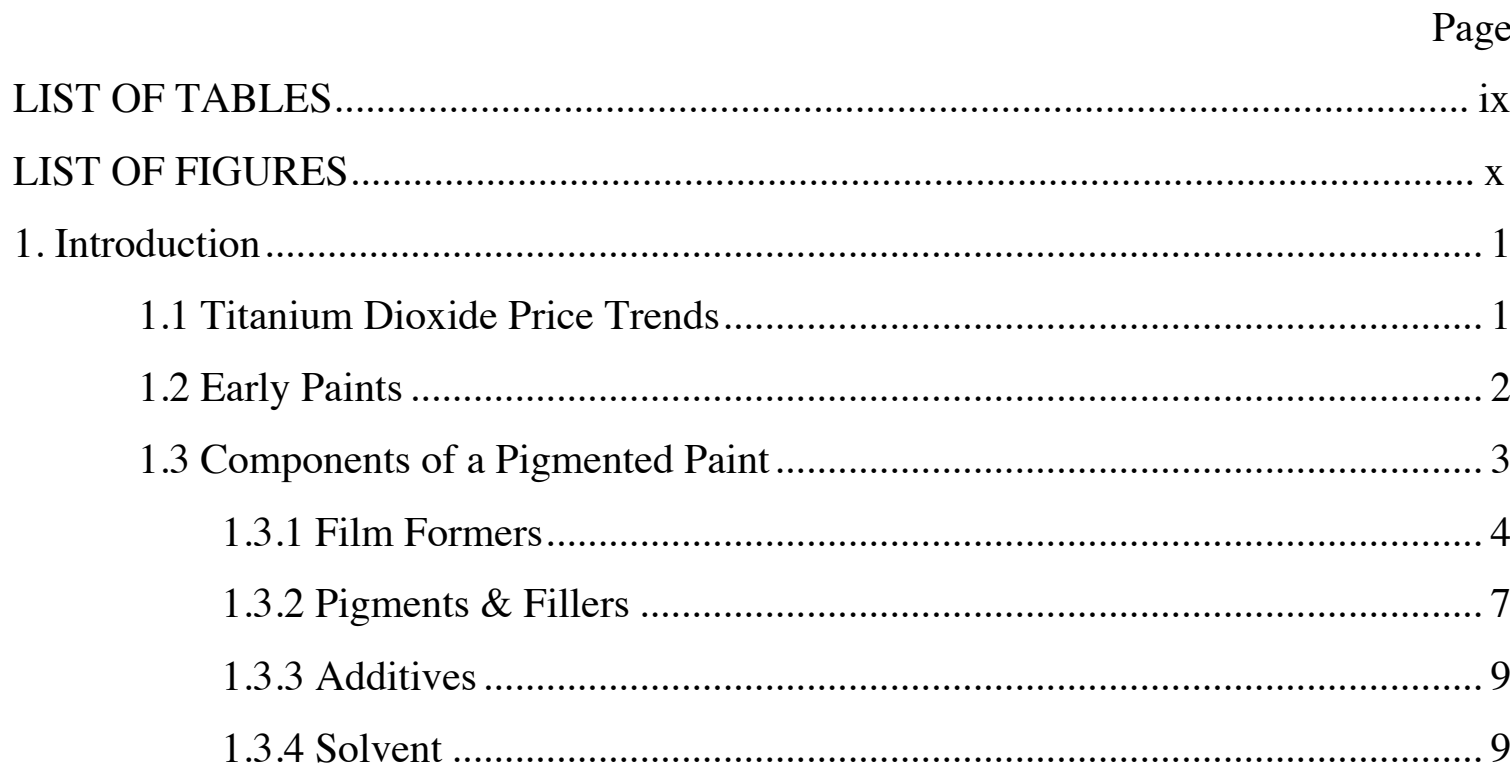

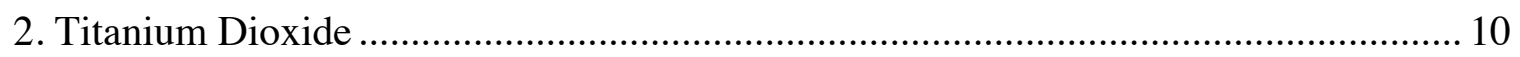

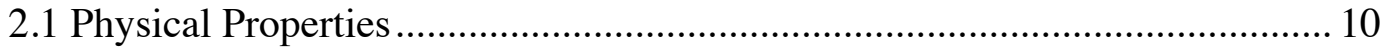

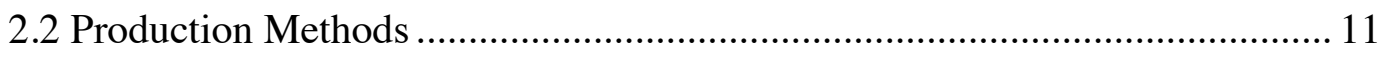

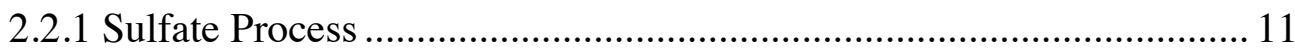

2.2.2 Chloride Process ......................................................................... 12

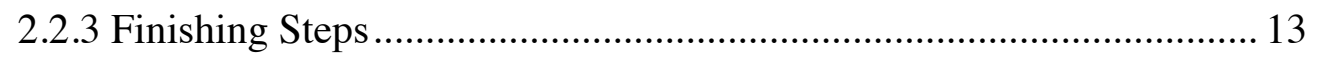

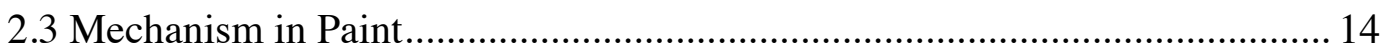

2.4 Benefits in Paint ................................................................................... 15

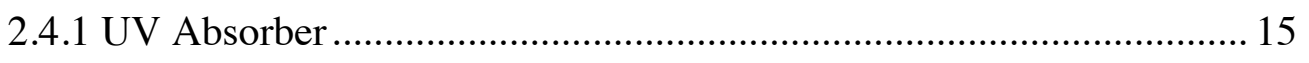

2.4.2 Antimicrobial Properties .................................................................. 16

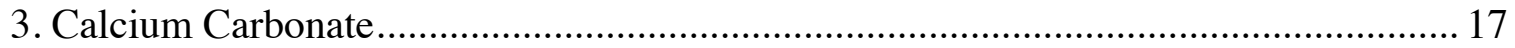

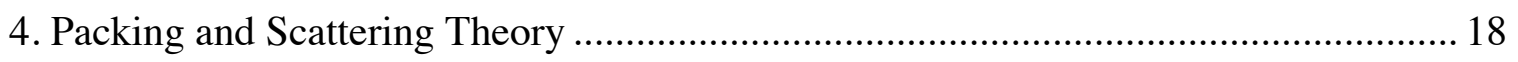

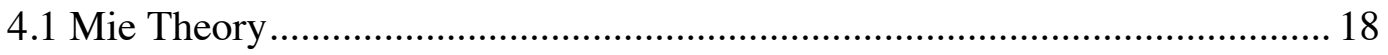

4.2 Kubelka-Munk Theory........................................................................ 20

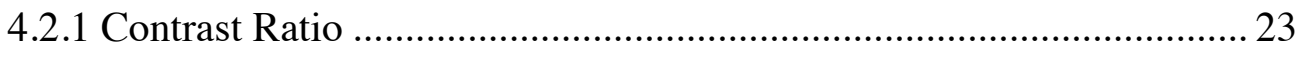

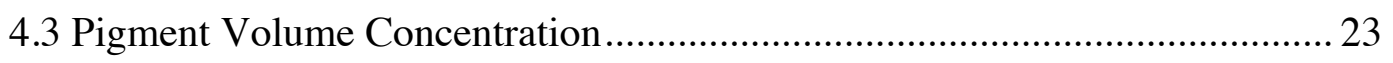

4.3.1 Oil Absorption ………………………………................................ 27

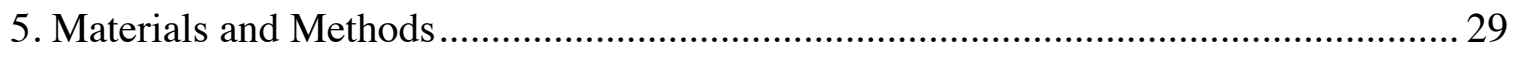




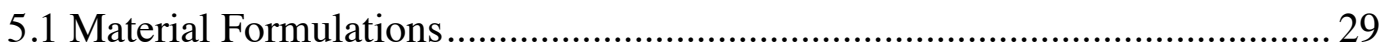

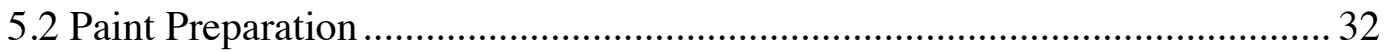

5.3 Spread Rate Procedure .......................................................................... 33

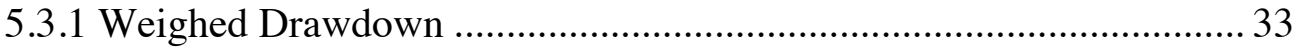

5.3.2 Contrast Ratio Measurements ......................................................... 34

5.3.2 Spread Rate Calculation................................................................. 35

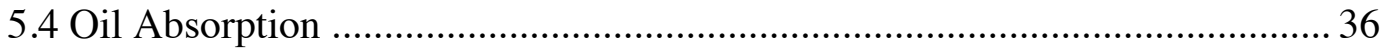

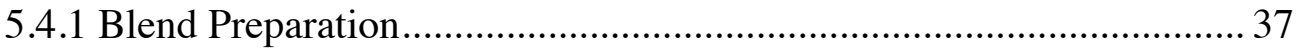

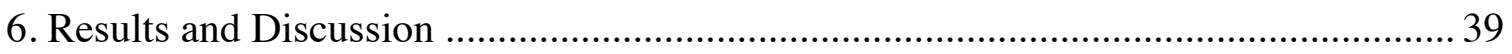

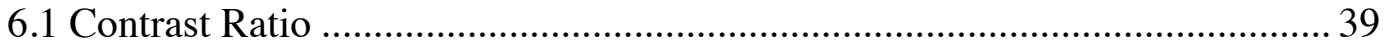

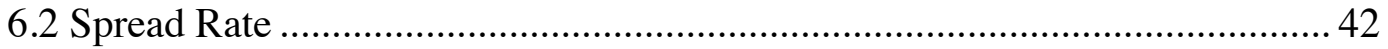

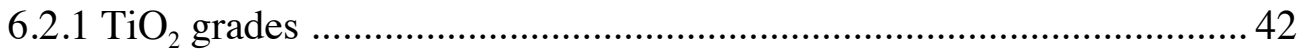

6.2.2 Total PVC - Omyacrab 15 ......................................................... 44

6.2.2 Total PVC - Omyacrab UF ........................................................ 46

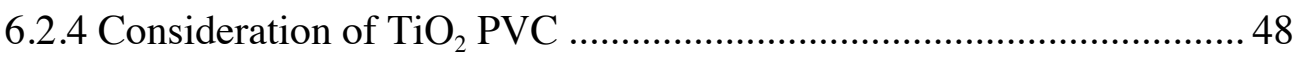

6.2.5 Particle Size Effects on Resin Demand ........................................... 50

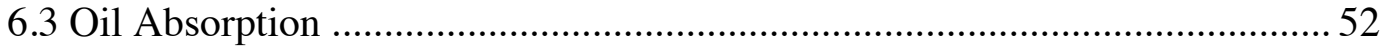

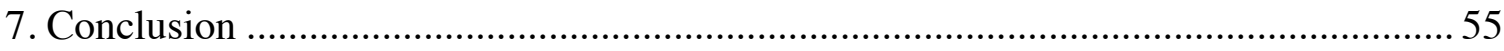

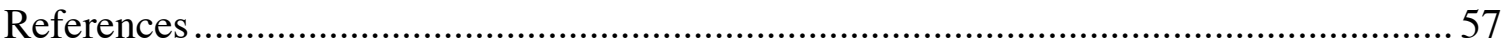

Appendices

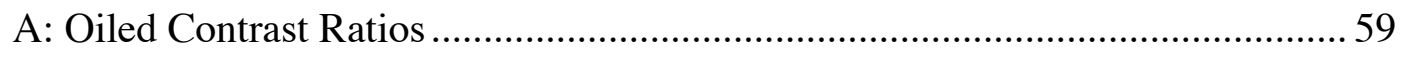

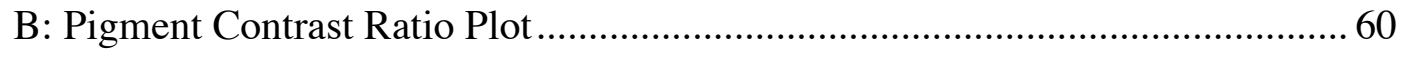

C: Comparison of Spread Rate Plots with Omyacarb Grades ............................. 61

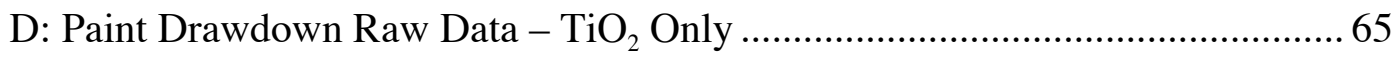

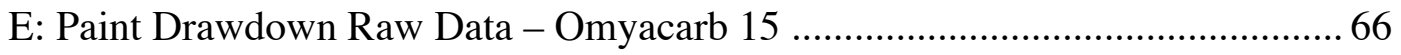

F: Paint Drawdown Raw Data - Omyacarb UF............................................. 72 


\section{LIST OF TABLES}

Page

Table 1: Typical Composition of Various Coating Systems .......................................... 4

Table 2: Differences between step-growth and chain-growth polymerization .................. 6

Table 3: Comparison between inorganic and organic pigments .................................... 7

Table 4: Physical Property Differences Between $\mathrm{TiO}_{2}$ crystal structures ........................ 10

Table 5: Classification of dry $\mathrm{TiO}_{2}$ pigments according to ASTM D476 ....................... 13

Table 6: Refractive Index (R.I.) of Common Materials in Paint .................................... 14

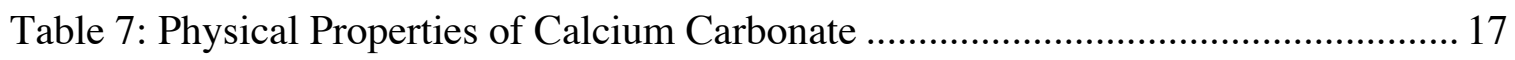

Table 8: Physical Properties of Pigments and Extenders used in this Study ................... 29

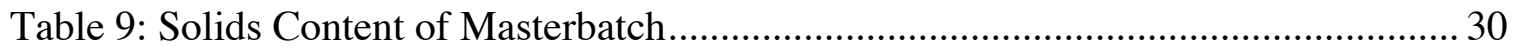

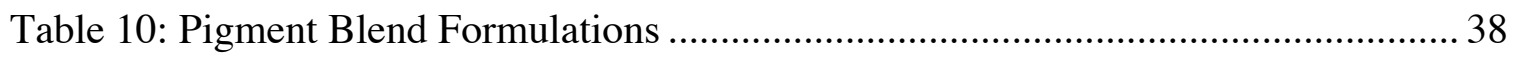

Table 11: Averaged Contrast Ratio - Omyacarb 15 (a) and Omyacarb UF (b) .............. 39

Table 12: Omyacarb 15 Replacement CPVC Values .................................................. 46

Table 13: Omyacarb UF Replacement CPVC Values .................................................. 48

Table 14: Spread Rate Values - Omyacarb 15 (a) and Omyacarb UF (b) ...................... 49

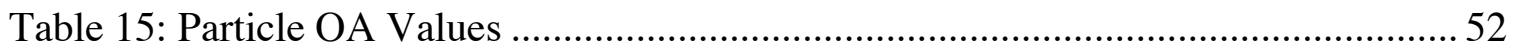




\section{LIST OF FIGURES}

Page

Figure 1: North America historical average and forecast price of $\mathrm{TiO}_{2}($ Fasano, 2010) .... 1

Figure 2: Photocatalytic Reaction on $\mathrm{TiO}_{2}$ surface ..................................................... 11

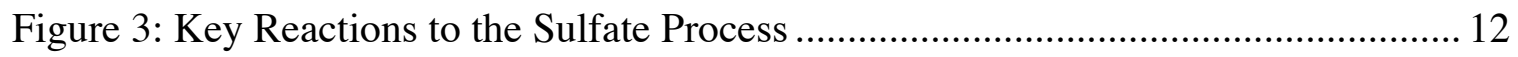

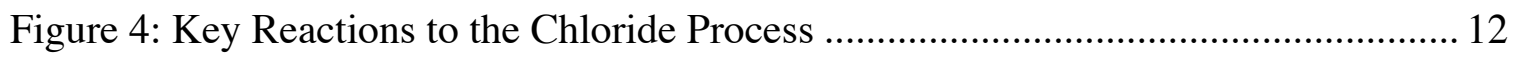

Figure 5: Reflectance of $\mathrm{TiO}_{2}$ Pigment at Various Wavelengths (DuPont, 2007) ........... 16

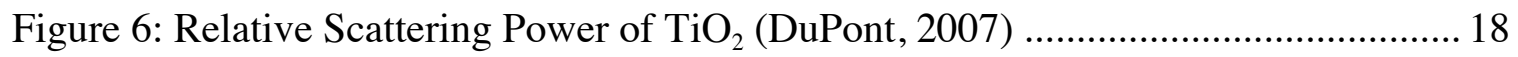

Figure 7: Model of Scattering Loss of Rutile $\mathrm{TiO}_{2}$ (E. S. Thiele \& French, 1998) .......... 19

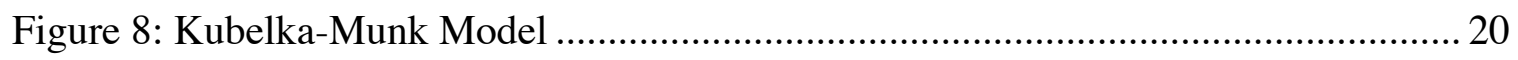

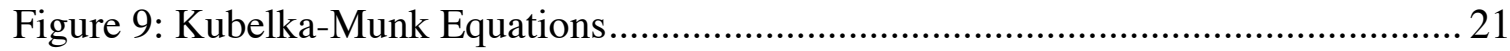

Figure 10: Kubelka-Munk Opacity Chart (Hunter \& Harold, 1987) .............................. 22

Figure 11: Model of System with Increasing PVC ........................................................ 23

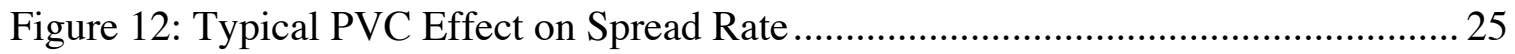

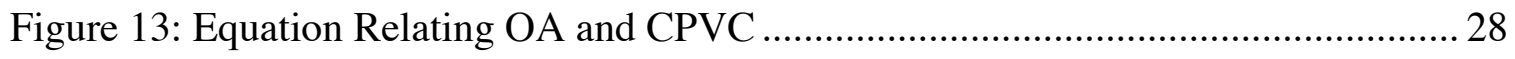

Figure 14: Visual Representation of Paint Samples Made ........................................... 32

Figure 15: Spread Rate Program v.2.1 (DuPont) Screenshot ...................................... 36

Figure 16: Contrast Ratios with Paints containing Omyacarb 15 ............................... 41

Figure 17: Spread Rate Comparison between $\mathrm{TiO}_{2}$ grades ......................................... 43

Figure 18: Spread Rate of PVC Ladders containing Omyacarb 15 .............................. 45

Figure 19: Spread Rate of PVC Ladders containing Omyacarb UF .............................. 47

Figure 20: Omyacarb 15 Spread Rate Ternary Plot .................................................... 50

Figure 21: Omyacarb UF Spread Rate Ternary Plot ............................................... 51

Figure 22: Pigment Blend OA Values ............................................................... 53 


\section{Introduction}

\subsection{Titanium Dioxide Price Trends}

Titanium dioxide $\left(\mathrm{TiO}_{2}\right)$ follows an uneven market cycle with short periods of a supply crunch and longer periods of oversupply. Factors include procurement of ore, plant operation, as well as financial and economic effects. Regardless of the factors, the price of $\mathrm{TiO}_{2}$ is relatively stable with the exception of the supply crunch periods. Shown in Figure 1 is the historical and forecast price of $\mathrm{TiO}_{2}$ from 1990 to 2015 (Fasano \& Adamson, 2012).

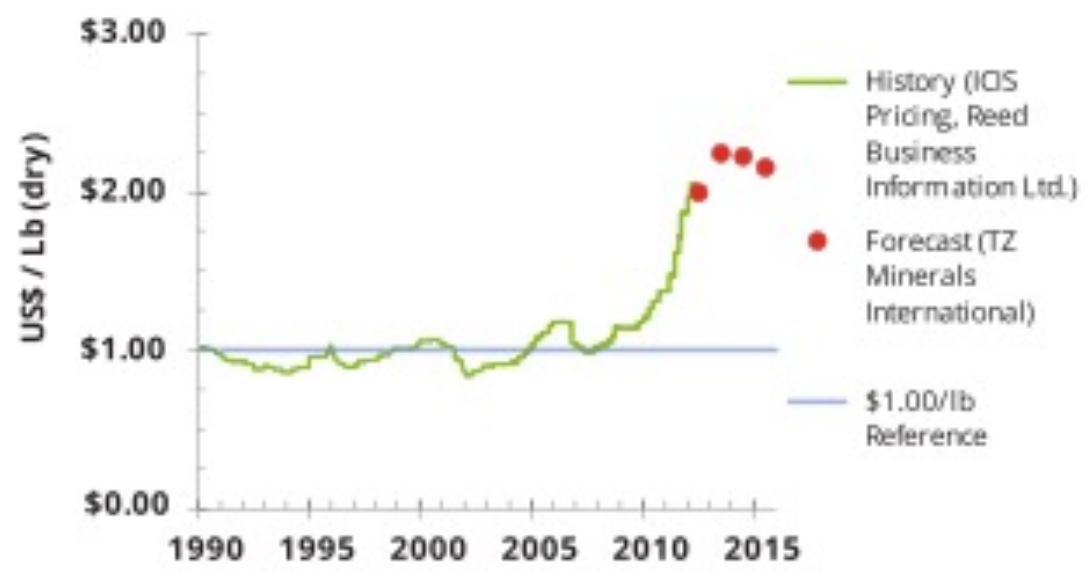

Figure 1: North America historical average and forecast price of $\mathrm{TiO}_{2}($ Fasano, 2010)

The latest $\mathrm{TiO}_{2}$ supply shortage started in 2010 where the average price increased from $\$ 1$ to over $\$ 2$ per pound (Fasano \& Adamson, 2012). The price hike is especially significant because $\mathrm{TiO}_{2}$ makes up anywhere from a third to a half of the raw material costs (Cardinal, Francis, \& Scriven, 2009). Due to market competition, the price increase is not completely passed onto the end consumer (Cardinal et al., 2009). As a result, paint formulators have been forced to reevaluate their paint systems in a manner to reduce 
costs without compromised paint properties. One common method involves partial substitution or replacement of $\mathrm{TiO}_{2}$ with a cheaper mineral. It is however important to mention that material costs are not limited to $\mathrm{TiO}_{2}$ as there are other ingredients common in paint.

\subsection{Early Paints}

The earliest known use of paints dates back more than 30,000 years to cave paintings in Spain (Brock, Groteklaes, \& Mischke, 2010). These paints were simply mixtures of colored earth, soot, grease, and other natural substances. The ancient Greeks, Romans, and Egyptians used natural resins and raw materials to decorate and identify statues, tools, vessels, and buildings (Brock et al., 2010; Goldschmidt \& Streitberger, 2007). These natural ingredients include vegetable gums, starches, and amber. In China and India, shellac resins and beeswax were used over 2000 years ago as a decorative coating which also doubled as a protective function (Gennadios, Hanna, \& Kurth, 1997). The earliest paint formulation dates back roughly 900 years to a German goldsmith and monk, Rodgerus von Helmershausen (Brock et al., 2010; Goldschmidt \& Streitberger, 2007). His formulation described the manufacturing of paint by mixing linseed oil and amber, referred to as paint boiling, which was further refined and developed into the Industrial Revolution (Brock et al., 2010; Goldschmidt \& Streitberger, 2007). The demand for paints dramatically increased into the Industrial Revolution. As the amount of iron used for making goods and buildings increased, the concern for rust quickly followed. Additionally, as sea-trade increased, the demand for marine coatings followed. The earliest paint factories appeared as early as 1790 in England and quickly spread to Holland and Germany (Brock et al., 2010). 
It is important to note that the most of the raw materials in paints and coatings made into the early 1900s were of natural origins. Synthetic materials were not yet introduced aside from a few pigments. Downfalls to paints at this time include extended drying time due to the use of the oil-based paints. This time also marked the start of the first continuous production line by Henry Ford as cars were being mass-produced. The result was a move to spray coating of a quick drying nitrocellulose based paint with solvent contents as high as 80\% (Brock et al., 2010; Goldschmidt \& Streitberger, 2007). Synthetic polymer chemistry also developed at this time with Carothers and others in the 1920s (Painter \& Coleman, 2000). Numerous resin systems were developed in succession from one another from the 1930s to 1940s. Included are vinyls, ureas, alkyds, acrylics, polyurethanes, melamines, and epoxy based resins. Changes to paint technology in the past 40 years have focused on reducing solvent content in paint formulations. This is due to increased regulation of volatile organic compounds (VOCs) in paint formulation. Primary developments in paint technology today include further reduction of VOCs for environmental benefits and optimizing paint formulations for specific functions.

\subsection{Components of a Pigmented Paint}

Paints and coatings are typically synonymous in colloquial speech. The accepted definition of a coating is a product based on organic binders, which provides a cohesive, non-absorbent, protective film (Brock et al., 2010). Differences in the composition of the various coatings systems are presented in Table 1. Common to all three coating systems are the resin and additive. Clear coats are optically inactive; therefore pigments and fillers are not present. Powder coatings are not in a liquid medium; therefore a solvent is not present. Paints are liquid materials that are optically opaque coatings that form when 
applied by brushing, rolling or spraying (Brock et al., 2010; Goldschmidt \& Streitberger, 2007). In other words, paints are a type of coating that cover up a background, but it is important to note that not all coatings are paints. Paints are composed of ingredients that can be put into one of four categories: film formers, pigments and fillers, additives, and solvents. Factors that are considered in a paint formulation include its ability to flow, mechanical properties, as well as appearance when prepared, during, and post application of the coating.

Table 1: Typical Composition of Various Coating Systems

\begin{tabular}{|c|c|c|c|c|}
\hline & \multicolumn{3}{|c|}{ Coating Type } \\
\hline & & $\begin{array}{c}\text { Pigmented } \\
\text { Paint }\end{array}$ & $\begin{array}{l}\text { Powder } \\
\text { Coating }\end{array}$ & $\begin{array}{l}\text { Clear } \\
\text { Coat }\end{array}$ \\
\hline \multirow{4}{*}{ 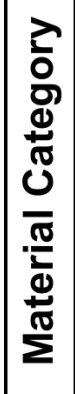 } & Resin & Yes & Yes & Yes \\
\hline & Additive & Yes & Yes & Yes \\
\hline & Solvent & Yes & No & Yes \\
\hline & $\begin{array}{c}\text { Pigment \& } \\
\text { Extender }\end{array}$ & Yes & Yes & No \\
\hline
\end{tabular}

\subsubsection{Film Formers}

Resins are the precursors to binders, which result in film formation in a paint system. In this context, resins, binders, and film formers can be though of as the same material category. The technical definition of a binder is the non-volatile part of a paint excluding the pigments and filler, which includes the non-volatile additives (Brock et al., 2010). These film formers contain macromolecule-forming substances, or polymers as well as oligomers. Examples include acrylics, alkyds, amino resins, cellulose derivatives, epoxies, polyesters, urethanes, polyvinyl acetates, and polyvinyl chlorides. The purpose 
of the film former is to provide a cohesive coating on a substrate, holding together the other non-volatile components. These film-formers are typically categorized into natural or synthetic substances.

Natural substances for use as film formers include natural resins and oils. Colophony is a natural resin extracted from pine trees as balsam and fractionally distilled, isolating abietic acid (Brock et al., 2010). The presence of a conjugated double bond and carboxyl group is an important chemical feature. Colophony is rarely used as is due to poor natural resistance to yellowing, water resistance, and compatibility. Natural oils or fatty oils were important film forming agents which were able to convert a low viscosity liquid into a solid (Goldschmidt \& Streitberger, 2007). These naturally occurring oils are triglycerides, triesters of glycerol and fatty acids. The drying and hardening process is the result of autoxidation and crosslinks.

Some of these natural substances have been chemically modified to optimize their coating properties. Cellulose derived compounds are an example of natural substances that are modified for use as film formers. Cellulose is widely present in plants, but cannot be used directly due to poor solubility in water. Modification of the hydroxyl groups enables solubility in water to act as a film former. Use of natural rubber as a film former is possible after chemical modification due to brittleness resulting from oxidation and insolubility in coating solvents (Brock et al., 2010). 
Table 2: Differences between step-growth and chain-growth polymerization

\begin{tabular}{|l|l|}
\hline \multicolumn{1}{|c|}{$\begin{array}{c}\text { Step-growth } \\
\text { Polymerization }\end{array}$} & \multicolumn{1}{c|}{$\begin{array}{c}\text { Chain-growth } \\
\text { Polymerization }\end{array}$} \\
\hline Slow polymerization rate & Fast polymerization rate \\
\hline $\begin{array}{l}\text { Rapid loss of monomer } \\
\text { early in the reaction }\end{array}$ & $\begin{array}{l}\text { Some monomer remains } \\
\text { even at long reaction times }\end{array}$ \\
\hline $\begin{array}{l}\text { Similar steps repeated } \\
\text { throughout reaction process }\end{array}$ & Three distinct reactions \\
\hline $\begin{array}{l}\text { Molecular weight increases } \\
\text { slowly initially }\end{array}$ & $\begin{array}{l}\text { Molecular weight increases } \\
\text { rapidly initially }\end{array}$ \\
\hline $\begin{array}{l}\text { Bonds formed by functional } \\
\text { groups }\end{array}$ & Carbon-carbon bonds \\
\hline No initiator needed & Initiator needed \\
\hline
\end{tabular}

Synthetic resins came about in the 1920s with the advancements in polymer chemistry. The primary benefits of synthetic resins are that products can be tailored with specific properties with nearly unlimited availability. The different resin systems are mentioned above, all of which are either step-growth or chain-growth polymerization (Wicks, Jones, Pappas, \& Wicks, 2007). Chain-growth reactions typically have three reactions - initiation, propagation, and termination. Step-growth polymerizations are reactions between bifunctional or multifunctional monomers without an initiation or termination step. Key differences between step-growth and chain growth polymerization are presented in Table 2.

Polymers dispersions are created through emulsion polymerization. Polymer dispersions are transparent white liquids low in viscosity. This system contains spherical polymer particles generally referred to as latex particles. Emulsion polymerization involves addition of slightly soluble monomers and water-soluble initiators in an aqueous media. 


\subsubsection{Pigments \& Fillers}

Pigments are particles that are used for their ability to impart color in a coating material. Characteristics common in pigments include extreme optical characteristics, particles smaller than $10 \mu \mathrm{m}$, being insoluble in water and most organic solvents, and being chemically inert or chemically stable (J. H. Braun, 1993). Pigments and dyes are both colorants - the difference being that pigments are insoluble whereas dyes are soluble in the application medium. Fillers are also particles that are insoluble in a paint system, but are purposed to increase volume in a paint system. Fillers are also commonly referred to as extenders and function as inert pigments. Fillers are significantly cheaper than pigments and contribute little to no optical properties.

Table 3: Comparison between inorganic and organic pigments

\begin{tabular}{|l|l|l|}
\hline Property & Inorganic Pigment & Organic Pigment \\
\hline Particle Size & Larger & Smaller \\
\hline Scattering Power & Higher & Lower \\
\hline Color Intensity & Lower & Higher \\
\hline Surface Characteristic & Hydrophilic & Hydrophobic \\
\hline Heat Resistance & Higher & Lower \\
\hline
\end{tabular}

Pigments can be categorized as being white, black, colored inorganic, and colored organic. Additionally, there are specialty functional pigments for corrosion protection. The most important white pigment is titanium dioxide $\left(\mathrm{TiO}_{2}\right)$, which will be discussed in further detail in Chapter 2. Other white pigments are considered less important as their optical performance is inferior. Black pigments include carbon black. Colored pigments operate by absorbing and scattering light at different intensities at different wavelengths. Colored inorganic pigments are typically variants of iron oxides (Goldschmidt \& Streitberger, 2007). Use of colored organic pigments has grown due to the presence of 
heavy metals in their inorganic counterparts. Organic pigments have much more distinct colors with a higher color purity. A comparison between the organic and inorganic pigments is presented in Table 3 (Brock et al., 2010). Organic pigments are usually azo based, polycyclic based, or metal-complex based. Benefits of the inorganic pigments include stability and chemical resistance.

Fillers can come from a variety of materials, in different shapes and sizes. Shapes vary from blocks to rods and can be smooth or porous. Their sizes can vary anywhere from nanometers to microns depending upon the application and requirements in the paint system. The majority of filler materials are natural in origin, which helps to reduce cost. Fillers can also be used to improve tensile strength and/or control the degree of gloss of coatings. Common filler materials include carbonates, silicon dioxide, silicic acids, silicates, and sulfates (Brock et al., 2010; Goldschmidt \& Streitberger, 2007; Wicks et al., 2007).

These pigments and extenders are commercially available in solid or slurry form. Slurry is an aqueous solution that contains dispersed pigments or extenders. In a paint application, the pigment and extenders are eventually dispersed in some sort of medium. The dispersion process involves 3 steps - wetting, separation, and stabilization (Wicks et al., 2007). It is important that particles are separated because aggregation and flocculation of these particles result in diminished optical properties due to the decrease surface area exposure. 


\subsubsection{Additives}

An additive is a substance added to a coating material in small quantities in order to impart specific properties to the coating material. Additives can be thought of as an alternative to hasten the film forming system and/or pigment system in most cases for compatibility. Additives are divided into various groups, catering to a specific function. A few specific examples include defoaming agents, wetting and dispersing agents, surfactants, flatting agents, rheology modifiers, corrosion inhibitors, light stabilizers, and biocides. Some additives serve multiple functions and can influence multiple properties.

\subsubsection{Solvent}

Solvents are liquids that comprise one or more components that are volatile under specified drying conditions that dissolve film-forming agents without chemical reaction. Additionally, the solvent lowers the viscosity of a paint formulation for easier application. The term solvent can also be thought of as a vehicle used to apply a coating material, as there is a movement to reduce VOCs in current paint formulations. Most coatings, including waterborne coatings still contain some volatile solvents. 


\section{Titanium Dioxide}

World production of titanium dioxide $\left(\mathrm{TiO}_{2}\right)$ is over 4 million tons per year, most of which is used in coatings applications (Brock et al., 2010). As mentioned earlier, $\mathrm{TiO}_{2}$ is used as white pigment in paint application. To date, a better white pigment has not been discovered as a replacement or alternative to $\mathrm{TiO}_{2}$. Production of $\mathrm{TiO}_{2}$ pigments started in the 1920s and rose dramatically in the 1930s replacing lithopone, zinc oxide, and lead containing compounds as some examples. The Chloride Process was introduced in the 1950 s, producing pure rutile $\mathrm{TiO}_{2}$. Production of $\mathrm{TiO}_{2}$ in aqueous dispersions started in the 1970 s for better incorporation into waterborne coatings. Current trends in $\mathrm{TiO}_{2}$ technology have involved surface treatment to minimize crowding effects for better efficiency.

\subsection{Physical Properties}

Table 4: Physical Property Differences Between $\mathrm{TiO}_{2}$ crystal structures

\begin{tabular}{|l|r|r|r|}
\hline Property & Anatase & Brookite & \multicolumn{1}{c|}{ Rutile } \\
\hline Crystal System & tetragonal & tetragonal & tetragonal \\
\hline Point Symmetry & $\mathrm{D}_{4 \mathrm{~h}}$ & $\mathrm{D}_{2 \mathrm{~h}}$ & $\mathrm{D}_{4 \mathrm{~h}}$ \\
\hline Refractive Index & 2.5 & 2.6 & 2.7 \\
\hline Density $\left(\mathbf{g} / \mathbf{c m}^{3}\right)$ & $3.8-3.9$ & $3.9-4.1$ & $4.2-4.3$ \\
\hline Mohs' hardness $^{3}$ & $5.5-6.0$ & $5.5-6.0$ & $6.5-7.0$ \\
\hline Melting Point ( $\left.{ }^{\circ} \mathbf{C}\right)$ & $915^{*}$ & $750^{*}$ & 1830 \\
\hline
\end{tabular}

There are three main crystal structures associated with $\mathrm{TiO}_{2}$ - anatase, brookite, and rutile. Brookite is rare and unstable. Differences between the three crystal structures affect various physical properties, some of which are summarized in Table 4. Rutile $\mathrm{TiO}_{2}$ is commonly used in coatings application due to improved optical properties. Anatase $\mathrm{TiO}_{2}$ use includes paper pulp due to lower hardness for processing. Brookite $\mathrm{TiO}_{2}$ is rare 
in nature and typically rearranges to the rutile crystal structure (Davis, 1982). This naturally occurring oxide of titanium is mined and processed to make $\mathrm{TiO}_{2}$ particles.

$$
\mathrm{H}_{2} \mathrm{O}+\mathrm{O}_{2} \stackrel{\mathrm{hv} / \mathrm{TiO}_{2}}{\longrightarrow} \cdot \mathrm{OH}+\mathrm{HO}_{2} \bullet
$$

\section{Figure 2: Photocatalytic Reaction on $\mathrm{TiO}_{2}$ surface}

It is important to note that $\mathrm{TiO}_{2}$ particles are surface treated, usually with alumina and/or silica. $\mathrm{TiO}_{2}$ can generate radicals in the presence of UV light, shown in Figure 2, which can degrade the paint or coating (J. Braun, Baidins, \& Marganski, 1992). The surface serves as a barrier to prevent the generation of these radicals. As a result, commercially available $\mathrm{TiO}_{2}$ particles are typically not pure. Surface treatment can account for as much as $20 \%$ of a $\mathrm{TiO}_{2}$ product.

\subsection{Production Methods}

There are two methods for producing titanium dioxide pigments - the Sulfate Process and the Chloride Process. The Sulfate Process dates back to the early 1900s and is the older process that employs aqueous chemistry, whereas the chloride process is the newer process, commercialized by DuPont in the 1950s (J. Braun et al., 1992; Hanna, 2009). Following the different manufacturing processes, the $\mathrm{TiO}_{2}$ particles undergo finishing steps, depending on their desired quality.

\subsubsection{Sulfate Process}

The sulfate process can produce anatase and rutile titanium dioxide. Manufacturing steps include digestion, clarification, hydrolysis, and calcination (J. Braun et al., 1992; Hanna, 2009). Ore is used as a starting material that must be broken down. Clarification is the process of removing impurities. Hydrolysis involves the use of water 
to break apart bonds in a chemical reaction. Calcination is a thermal treatment of a material, hydrous titanium dioxide in this case, to create titanium dioxide. Key reactions are depicted in Figure 3. Titanium bearing ore such as ilmenite $\left(\mathrm{FeTiO}_{3}\right)$ is dissolved in sulfuric acid. The iron sulfates are removed and remaining solution dissolved in water. The remaining solution is heated and precipitated as hydrous titanium dioxide and grown to proper particle size and surface treated as necessary (J. Braun et al., 1992; Davis, 1982; Hanna, 2009). Rutile pigments are produced with rutile seed crystals added during the hydrolysis step (J. Braun et al., 1992).

$\mathrm{FeTiO}_{3}+2 \mathrm{H}_{2} \mathrm{SO}_{4} \rightarrow \mathrm{FeSO}_{4}+\mathrm{TiO} \bullet \mathrm{SO}_{4}+2 \mathrm{H}_{2} \mathrm{O}+\mathrm{H}_{2}$
$\mathrm{TiO} \cdot \mathrm{SO}_{4}+2 \mathrm{H}_{2} \mathrm{O} \rightarrow \mathrm{TiO}_{2} \bullet \mathrm{H}_{2} \mathrm{O}+\mathrm{H}_{2} \mathrm{SO}_{4}$
$\mathrm{TiO}_{2} \bullet \mathrm{H}_{2} \mathrm{O} \stackrel{\text { heat }}{\longrightarrow} \mathrm{TiO}_{2}+\mathrm{H}_{2} \mathrm{O}$

Figure 3: Key Reactions to the Sulfate Process

\subsubsection{Chloride Process}

$3 \mathrm{TiO}_{2}$ (ore) $+4 \mathrm{C}+6 \mathrm{Cl}_{2} \rightarrow 3 \mathrm{TiCl}_{4}$ (gas) $+2 \mathrm{CO}_{2}+2 \mathrm{CO}$
$\mathrm{TiCl}_{4}$ (gas) $\rightarrow \mathrm{TiCl}_{4}$ (liquid)
$\mathrm{TiCl}_{4}$ (gas) $+\mathrm{O}_{2} \rightarrow \mathrm{TiO}_{2}$ (solid) $+2 \mathrm{Cl}_{2}$

Figure 4: Key Reactions to the Chloride Process

The chloride process offers waste disposal, energy, and quality advantages over the sulfate process (J. Braun et al., 1992). Examples include production of rutile pigments having narrow particle size distributions. Additionally, there is material efficiency as chlorine can be recycled in the reaction. Key manufacturing processes in the chloride process includes chlorination, purification, and oxidation. Key reactions to the chloride 
process are presented in Figure 4. Titanium ore is heated up with chlorine gas and coke to produce titanium tetrachloride, or 'tickle', and other metal chlorides, which are then fractionally distilled, which is purified, converting the gas to a liquid (J. Braun et al., 1992; Davis, 1982; Hanna, 2009). The purified titanium tetrachloride is then vaporized and reacted with air to form $\mathrm{TiO}_{2}$ and chlorine.

\subsubsection{Finishing Steps}

Table 5: Classification of dry $\mathrm{TiO}_{2}$ pigments according to ASTM D476

\begin{tabular}{|c|c|c|c|c|c|c|c|}
\cline { 2 - 8 } \multicolumn{1}{c|}{} & Type I & Type II & Type III & Type IV & Type V & Type VI & Type VII \\
\hline structure & anatase & rutile & rutile & rutile & rutile & rutile & rutile \\
\hline $\begin{array}{c}\text { Typical } \\
\text { application }\end{array}$ & $\begin{array}{l}\text { white } \\
\text { exterior } \\
\text { house } \\
\text { paint and } \\
\text { interior } \\
\text { uses }\end{array}$ & $\begin{array}{l}\text { low- } \\
\text { medium } \\
\text { percent } \\
\text { PVC }\end{array}$ & $\begin{array}{l}\text { high } \\
\text { percent } \\
\text { PVC }\end{array}$ & $\begin{array}{l}\text { exterior } \\
\text { coatings } \\
\text { requiring } \\
\text { high } \\
\text { durability }\end{array}$ & $\begin{array}{l}\text { exterior } \\
\text { coatings } \\
\text { requiring } \\
\text { high } \\
\text { durability } \\
\text { with high } \\
\text { gloss }\end{array}$ & $\begin{array}{l}\text { medium- } \\
\text { high } \\
\text { percent } \\
\text { PVC }\end{array}$ & $\begin{array}{l}\text { low-high } \\
\text { percent } \\
\text { PVC }\end{array}$ \\
\hline $\begin{array}{c}\text { Min. TiO } 2 \\
\text { content, \% }\end{array}$ & 94 & 92 & 80 & 80 & 90 & 90 & 92 \\
\hline $\begin{array}{l}\text { Min. moisture } \\
\text { content when } \\
\text { packed, \% }\end{array}$ & 0.7 & 0.7 & 1.5 & 1.5 & 1 & 0.7 & 0.7 \\
\hline Specific gravity & $3.8-4.0$ & $4.0-4.3$ & $3.6-4.3$ & $3.6-4.3$ & $3.6-4.3$ & $3.6-4.3$ & $4.0-4.3$ \\
\hline
\end{tabular}

Production of $\mathrm{TiO}_{2}$ particles doesn't stop at the chloride and sulfate process.

There are more than 400 different types of $\mathrm{TiO}_{2}$ pigments commercially available (Brock et al., 2010). ASTM D476 describes and classifies seven types of dry $\mathrm{TiO}_{2}$ products, taking composition, end application, and performance properties into account, which is presented in Table 5.

As mentioned previously, $\mathrm{TiO}_{2}$ particles are typically not sold as pure compounds due to their surface treatments. $\mathrm{TiO}_{2}$ particles are coated in water by precipitation or adsorption techniques onto the surface, with silica and alumina being the most common 
inorganic oxides used. These oxides come in a variety of sizes and shapes, which cater the $\mathrm{TiO}_{2}$ particle to specific applications, such as altering surface roughness, which affects gloss. Additional finishing steps may include further grinding to prevent aggregation of particles for optimal $\mathrm{TiO}_{2}$ performance. If prepared as slurry, additives are used to ensure a dispersed and stable medium for the $\mathrm{TiO}_{2}$ particles.

\subsection{Mechanism in Paint}

Pigments are effective due to their unique optical properties. In the case of white pigments, the 'whiteness' is due to the scattering of light by the pigment. The light scattering is the mechanism that contributes to hiding and can be explained from optical theories. White pigments are unique in that the appearance of white is due only to scattering, whereas colored pigments may also rely on selective scattering as well as absorption of light.

Table 6: Refractive Index (R.I.) of Common Materials in Paint

\begin{tabular}{|l|l|l|l|}
\hline Pigments & R.I. & Media & R.I. \\
\hline Silica* & 1.49 & Vacuum & 1.00 \\
\hline Calcium Carbonate & 1.63 & Air* & 1.00 \\
\hline Clay & 1.65 & Water & 1.33 \\
\hline Lithopone & 1.84 & Polyvinyl acetate resin & 1.47 \\
\hline Zinc oxide & 2.02 & Vinyl resin & 1.48 \\
\hline Zinc sulfide & 2.37 & Acrylic resin & 1.49 \\
\hline $\mathrm{TiO}_{2}$ (rutile) & 2.73 & Styrene butadiene resin & 1.53 \\
\hline \multicolumn{3}{|c}{${ }^{*}=$ approximate }
\end{tabular}

The refractive index can be described as the degree of bending of light as it passes through a material. This value is a dimensionless value and is typically referenced to light traveling in a vacuum. Larger refractive indexes reflect a greater degree of bending of light. The refractive index of pigments and film formers are presented in Table 6 . In the 
case of paint, the interface is between that of the pigment and binder material, not air except when formulating at high volume solids. As a result, the actual refractive index difference is lower as typical film formers have a refractive index around 1.5, which is similar to that of extender materials. It is unsurprising that the high refractive index of $\mathrm{TiO}_{2}$ is desired in paint, as there are currently no practical alternatives commercially available.

\subsection{Benefits in Paint}

In addition to contributing to hiding power through its optical properties, $\mathrm{TiO}_{2}$ is also used in paint for UV absorption and anti-microbial properties. These intrinsic properties are additional reasons why $\mathrm{TiO}_{2}$ has not been replaced.

\subsubsection{UV Absorber}

UV absorption is one mode of action as a light stabilizer. Other modes include radical interceptors, quenching agents, and hyrdoperoxide decomposers (Brock et al., 2010). Most polymers, including paints, are susceptible to degradation due to UV light. UV light is also damaging to biological systems. The degradation is due to the generation of propagating radicals. Rutile $\mathrm{TiO}_{2}$ absorbs more UV light than anatase $\mathrm{TiO}_{2}$, as shown in Figure 5 (DuPont, 2007). Recall that the absorbance is inversely related to the reflectance, which is localized scattering. It is also important to note that the optimum particle size for UV light absorbance varies over different wavelengths (Wicks et al., 2007). Despite being a UV absorber, as mentioned earlier, $\mathrm{TiO}_{2}$ is also prone to generate radicals when reacted with UV light and water leading to a process called chalking. The overall photocatalytic reaction is presented in Figure 2. Chalking is the process of the degradation of the binder and exposure of the pigment that is no longer bound. Again, the 
surface treatment of $\mathrm{TiO}_{2}$ particles is performed to decrease the photoactivity, slowing down the reaction.

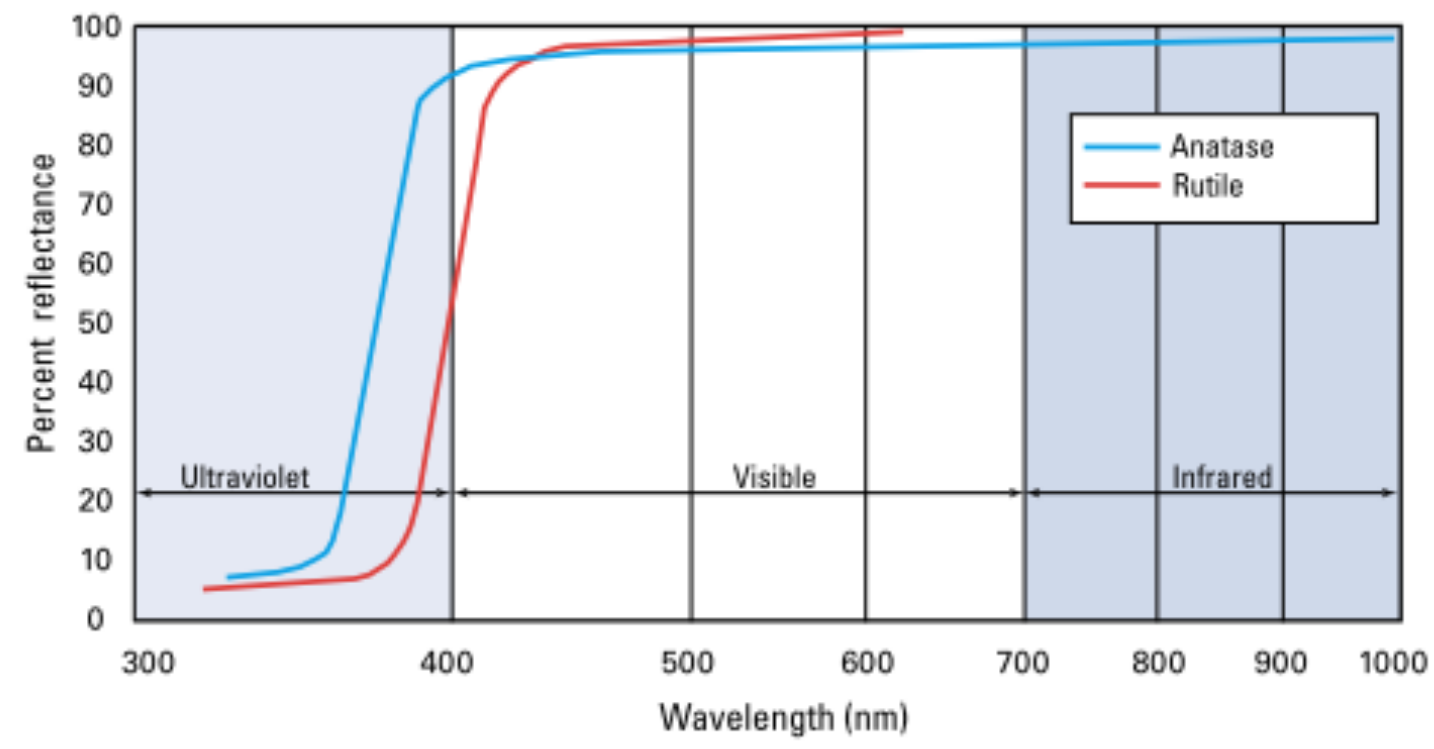

Figure 5: Reflectance of $\mathrm{TiO}_{2}$ Pigment at Various Wavelengths (DuPont, 2007)

\subsubsection{Antimicrobial Properties}

Biocides are needed in coating formulations to control bacteria growth for a variety of reasons, which affect paint application and durability. Reasons include smell and pressure due to gas generation, degradation of the cellulose derivatives in paint, as well as blotchy discoloration on applied paint. $\mathrm{TiO}_{2}$ is not used as a biocide, but has some antimicrobial properties due to the photocatalytic reaction mentioned earlier (Chung, Lin, Tsou, Shi, \& He, 2008; Xing et al., 2012). 


\section{Calcium Carbonate}

Filler or extender particles such as calcium carbonate $\left(\mathrm{CaCO}_{3}\right)$ primary serve as replacement for the binder material. Reasons include the lower cost of filler materials or formulation above critical pigment volume concentration (Section 4.3).

Table 7: Physical Properties of Calcium Carbonate

\begin{tabular}{|l|r|}
\hline Property & $\mathrm{CaCO}_{3}$ (calcite) \\
\hline Refractive Index & 1.63 \\
\hline Density (g/cm ${ }^{3}$ ) & 2.7 \\
\hline Mohs' hardness & 3 \\
\hline Melting Point $\left({ }^{\circ} \mathbf{C}\right)$ & 1339 \\
\hline
\end{tabular}

The primary difference between pigments and fillers are the difference in cost. Fillers can also be thought of poorly functioning pigments. It is unsurprising that fillers are poorly optically active. The physical properties of $\mathrm{CaCO}_{3}$ are presented in Table 7 . $\mathrm{CaCO}_{3}$ is an example of a filler material and it is unsurprising that the refractive index of $\mathrm{CaCO}_{3}$ is significantly lower than $\mathrm{TiO}_{2}(\mathrm{RI}=2.73)$. Some naturally available forms of $\mathrm{CaCO}_{3}$ include chalk, calcite, and aragonite (Brock et al., 2010). Chalk and calcite are used as filler material. Chalk is a natural $\mathrm{CaCO}_{3}$ up to $1 \mu \mathrm{m}$ in diameter from the shells and skeletons of small organisms (Brock et al., 2010). Calcite is a natural $\mathrm{CaCO}_{3}$ derived from limestone and is generally $2-3 \mu \mathrm{m}$ in diameter, commonly used in paint formulations (Brock et al., 2010). Smaller particles (as small as $0.6 \mu \mathrm{m}$ ) are also possible in synthetic form as precipitated calcium carbonate. 


\section{Packing and Scattering Theory}

The refractive index is one way of expressing light scattering performance. In the case of $\mathrm{TiO}_{2}$, a number of factors, including particle size, particle size distribution, shape, and dispersion affect the scattering power (E. Thiele \& French, 1998). Additionally, aggregation and flocculation alter the scatter performance.

\subsection{Mie Theory}

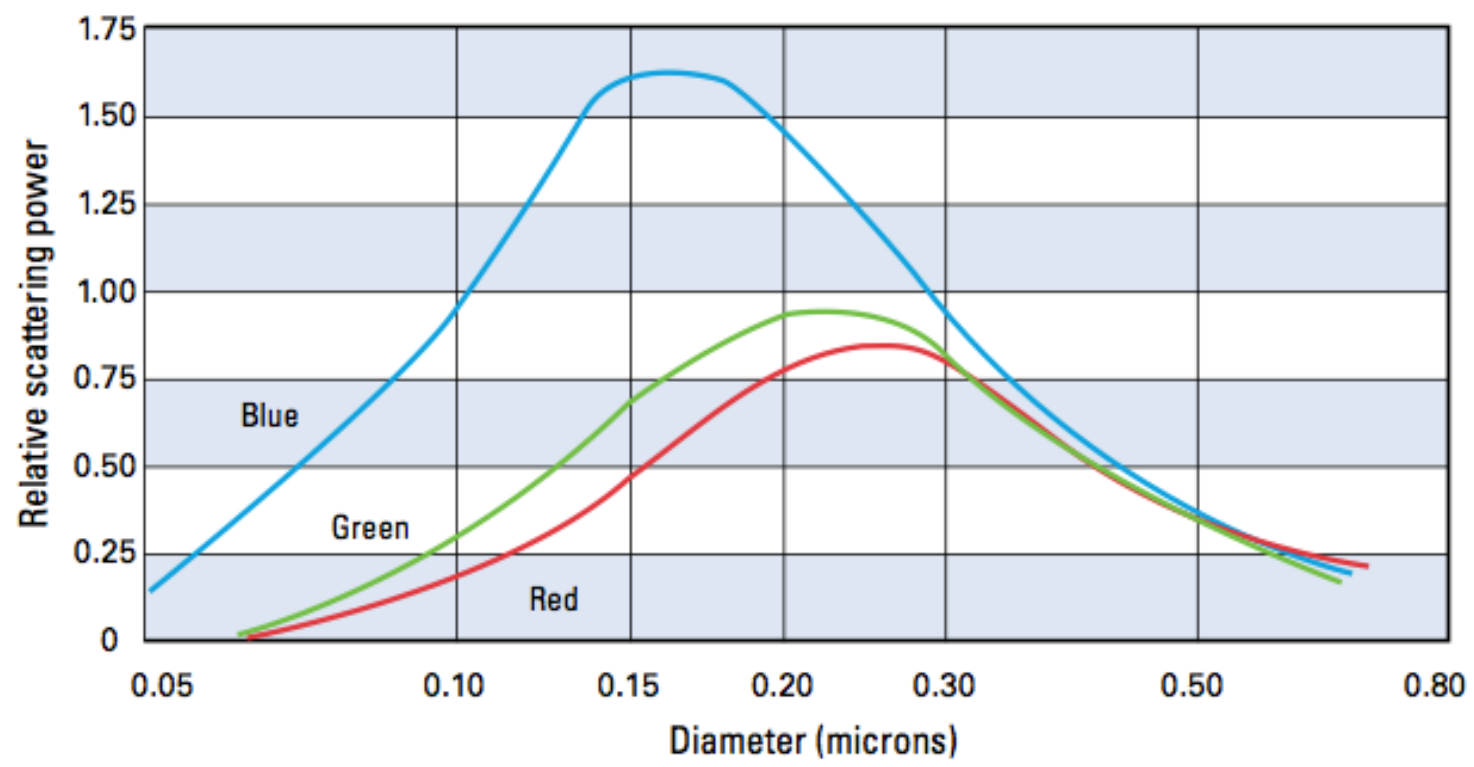

Figure 6: Relative Scattering Power of $\mathrm{TiO}_{2}$ (DuPont, 2007)

The basic foundation to which the scattering ability of $\mathrm{TiO}_{2}$ is understood is based upon Mie theory. Mie first published a paper in 1908 as a first outline, computing light scattering using Maxwell's electromagnetic theory (Hergert \& Wriedt, 2012). Mie theory estimates a general and quantitative model of scattering and absorption of an electromagnetic wave based on a model of one particle that is perfectly spherical. Further refinements have been made to this model to include anisotropic spheres as well as coated spheres (Hergert \& Wriedt, 2012). Shown in Figure 6 is the relative scattering 
power relationship to size at three colors. The optimum size at which $\mathrm{TiO}_{2}$ particles scatter light is around 0.2-0.3 $\mu \mathrm{m}$ depending on its wavelength. It is unsurprising that $\mathrm{TiO}_{2}$ pigments are produced at this size order.

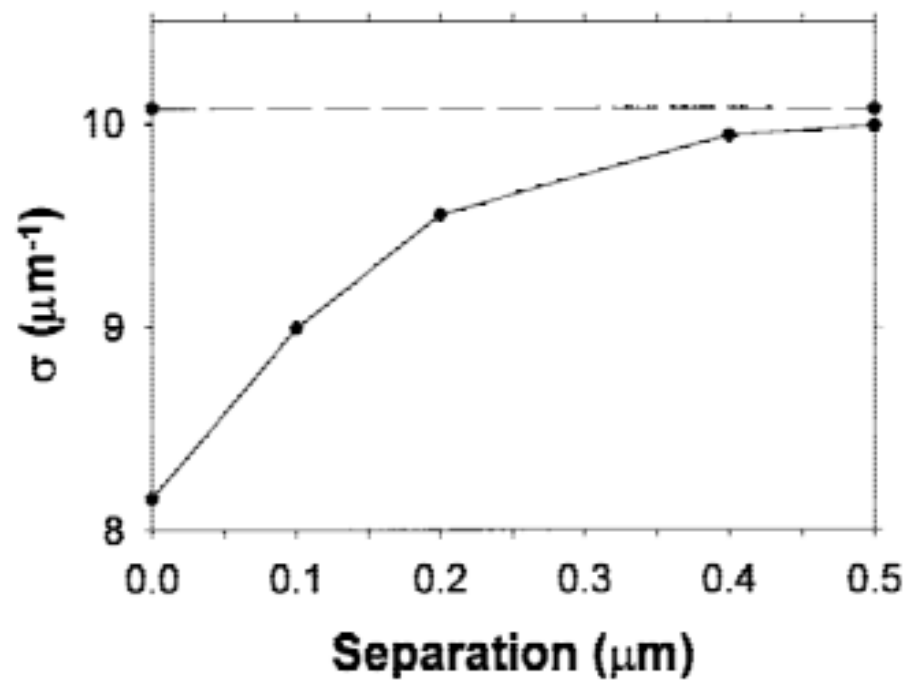

Figure 7: Model of Scattering Loss of Rutile $\mathrm{TiO}_{2}$ (E. S. Thiele \& French, 1998)

On a macroscopic scale, white paint contains more than one $\mathrm{TiO}_{2}$ particle, which renders limitations to Mie theory. In a paint system, $\mathrm{TiO}_{2}$ particles are in abundance with a phenomenon called crowding which reduces the scattering ability per particle. The loss of scattering is explained by overlap of optical cross-sections (J. Braun et al., 1992; Winkler, 2003). As $\mathrm{TiO}_{2}$ particles pack closer together, the available exposed surface area decreases, which lowers scattering efficiency per particle. The crowding effect is well established and has been modeled. Shown in Figure 7 is a model of the scattering power relationship to particle separation distance. There is up to a $20 \%$ loss in scattering power as a result of the crowding effects. In essence the flocs of $\mathrm{TiO}_{2}$ particles can be thought of as one larger particle, which results in dramatically decreased scattering. Much of the 
work presented here has a central theme revovled around reducing the crowding effects of $\mathrm{TiO}_{2}$.

\subsection{Kubelka-Munk Theory}

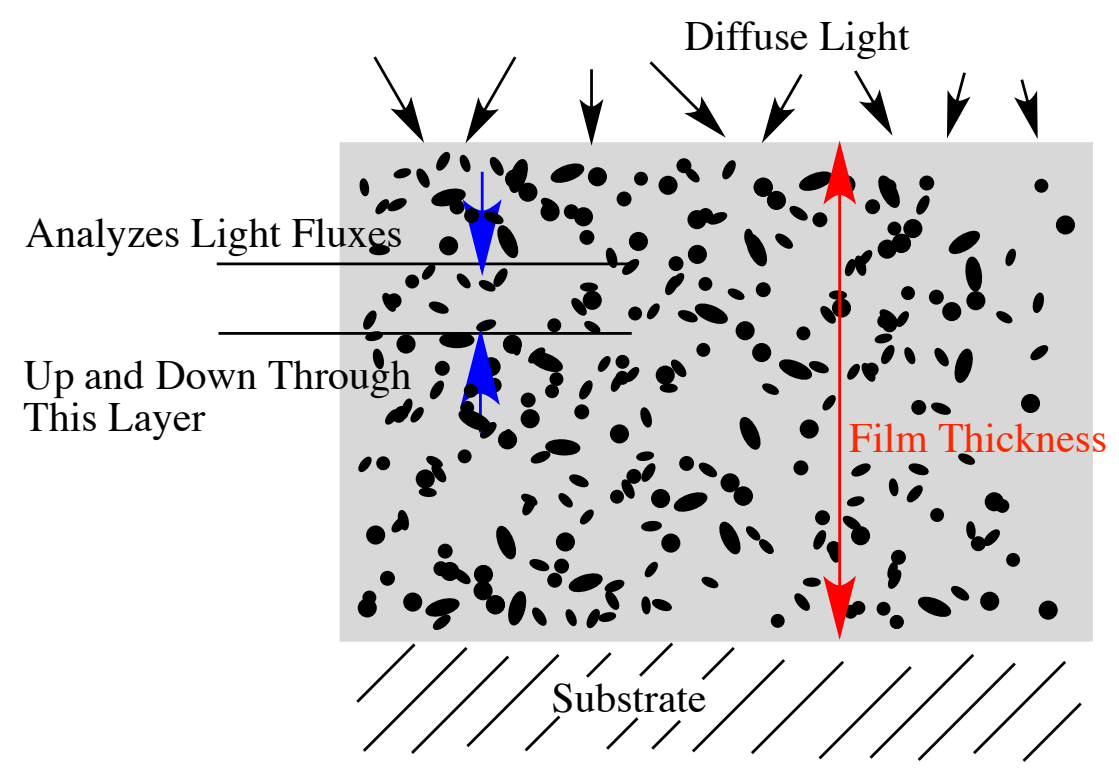

Figure 8: Kubelka-Munk Model

Kubelka-Munk theory is a macroscopic approach to light scattering, where as Mie theory is a microscopic approach. Kubelka and Munk published a set of equations relating contrast ratio, brightness, and quantity of light-scattering material in pigmented film (DuPont, 2002). Kubelka-Munk theory considers the absorption and scattering of light by thin films based on their reflectivites. Shown in Figure 8 is a physical model of Kubelka-Munk theory. The physical model of the theory considers a thin slice of a film and the light passing through it. Kubelka-Munk theory is only descriptive and makes no assumptions concerning the mechanistic reasons for light absorption or light scattering (Winkler, 2003). 


$$
R=\frac{\frac{\left(R_{g}-R_{\infty}\right)}{R_{\infty}}-R_{\infty}\left(R_{g}-\frac{1}{R_{\infty}}\right) e^{S X\left(\frac{1}{R_{\infty}}-R_{\infty}\right)}}{\left(R_{g}-R_{\infty}\right)-\left(R_{g}-\frac{1}{R_{\infty}}\right) e^{S X\left(\frac{1}{R_{\infty}}-R_{\infty}\right)}}
$$

Figure 9: Kubelka-Munk Equations

The Kubelka-Munk equation is shown in Figure 9. The Kubelka-Munk equation expresses the reflectance, $\mathrm{R}$, by considering the background (typically black) reflectance, $\mathrm{R}_{\mathrm{g}}$, the scattering power, $\mathrm{SX}$, and the reflectance of a thick film, $\mathrm{R}_{\infty}$, such that the reflectance does not change. The SX term itself is dimensionless but is a product of the scattering coefficient, $\mathrm{S}$, and the amount of scattering material or thickness, X. The S term is constant for each coating formulation. Altering the amount of coating changes the $\mathrm{SX}$ value. The $\mathrm{X}$ term can be expressed in units of film thickness or coverage area, making the units of $\mathrm{S}$ the reciprocal of $\mathrm{X}$ (e.g. $\mathrm{mil}^{-1}$ or $\left.\mathrm{ft}^{2} / \mathrm{gal}\right)$. The $\mathrm{X}$ term can also be referred to as the spread rate.

Kubelka-Munk relationships can be graphically represented with opacity charts by interrelating reflectances over a black and white substrate, $\mathrm{R}_{\infty}$, and $\mathrm{SX}$. These Kubelka-Munk relationships were first plotted by hand in the late 1930s (Biermann, 1995). Computers can now generate these Kubelka-Munk relationships for more precise calculations. An example of an opacity chart is presented in Figure 10. The reflectances over a black and white substrate can be measured to give corresponding SX and $\mathrm{R}_{\infty}$ values from the opacity chart. The $\mathrm{R}_{\infty}$ associated for each formulation is considered constant and does not change. The SX values can be interpolated at various contrast ratios, increasing as the contrast ratio increases due to a larger quantity $(\mathrm{X})$ used. Since 
the scattering coefficient is constant, the $\mathrm{X}$ value can be estimated at different contrast ratios.

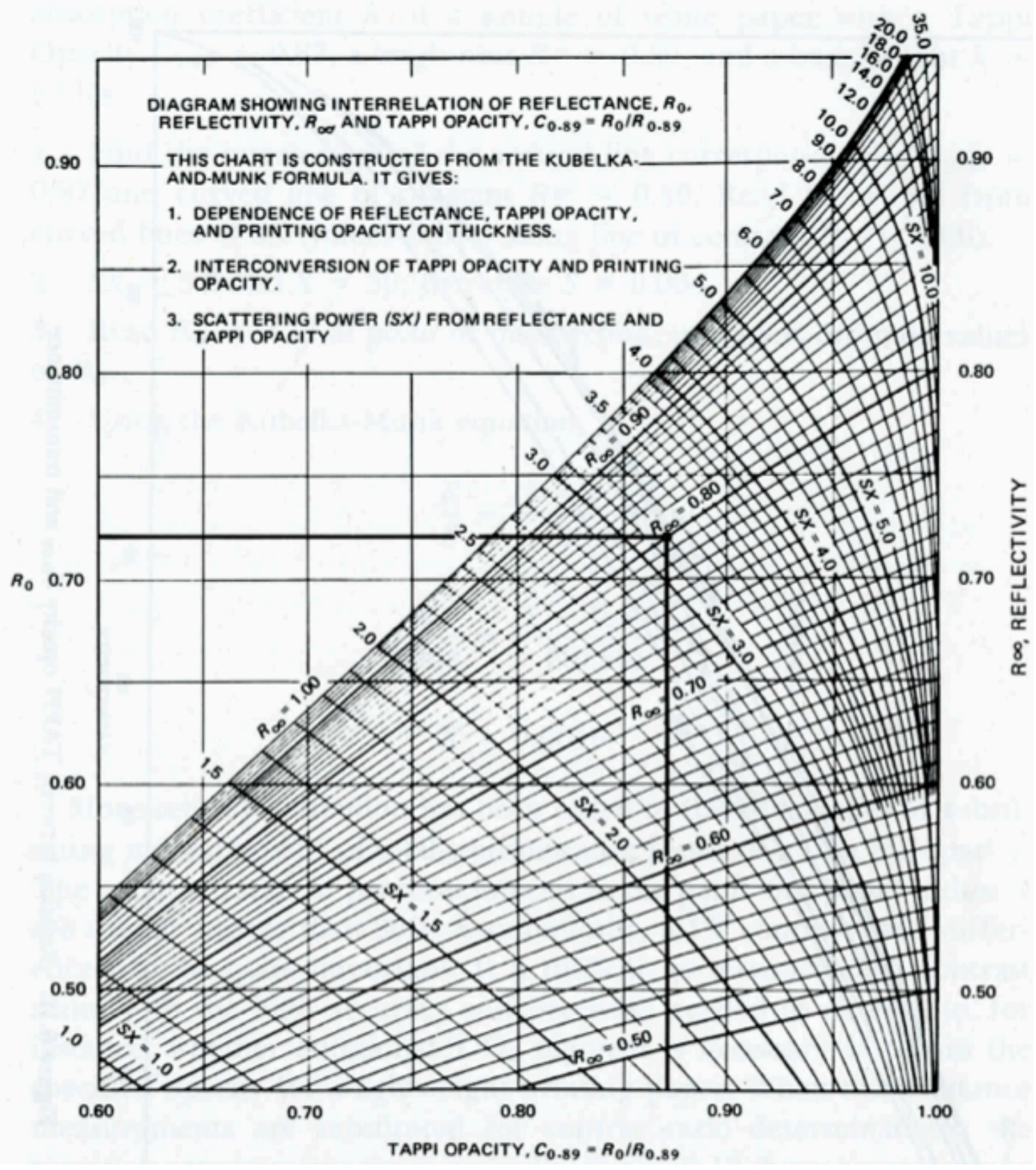

Figure 10: Kubelka-Munk Opacity Chart (Hunter \& Harold, 1987) 


\subsubsection{Contrast Ratio}

The purpose of a white paint is to cover or hide the underlying substrate. This can be measured subjectively by 'eyeballing' how well the paint 'hides'. The hiding power of paint can also be described in a quantitative manner through its contrast ratio. The contrast ratio is the measurement of the hiding of paint without distinction between contributions from light scattering and absorption (J. H. Braun, 1993). The contrast ratio is expressed as the quotient of reflectance of a film (paint) measured over a black and white substrate, performed on an opacity drawdown chart. This value can be expressed as a whole number or as a decimal with a maximum value of 100 or 1 . The reflectance value is defined as the $\mathrm{Y}$ tristimulus value. Complete hiding is a common term that refers to a contrast ratio of 0.98 or greater.

\subsection{Pigment Volume Concentration}

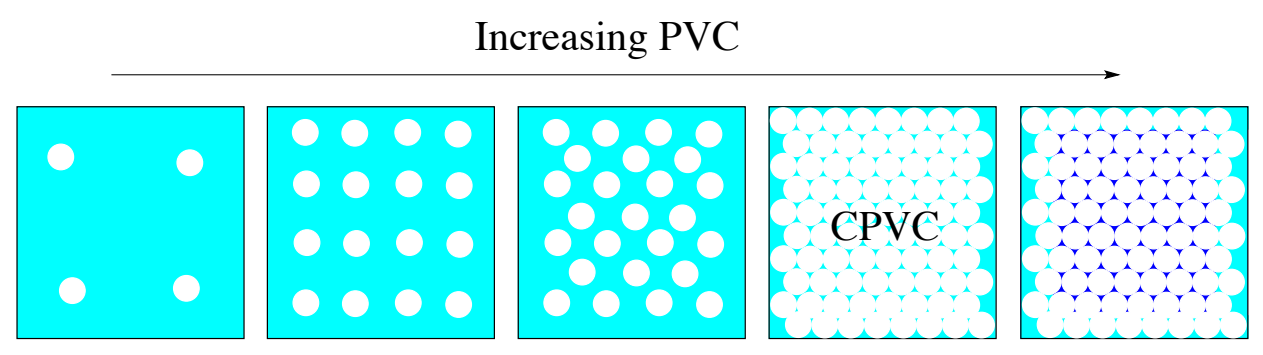

Figure 11: Model of System with Increasing PVC

Pigment volume concentration (PVC) is the most widely accepted quantitative description of paint film composition (J. H. Braun, 1993). PVC is expressed as volume percentage of the pigments and fillers to that of the volume of the dry film expressed as a whole number. Volume is used rather than weight because pigments scatter based on 
volume. PVC values are quantifiable between $0-100$, but these values do not necessarily carry over to other pigment-resin systems.

Shown in Figure 11 is a 2D simple model of a coating with increasing PVC. This simple model assumes uniform sized $\mathrm{TiO}_{2}$ spherical particles (white spheres) surrounded by the binder material (teal). At low $\mathrm{PVC}, \mathrm{TiO}_{2}$ particles scatter light at near their maximum ability. As additional $\mathrm{TiO}_{2}$ is added to the system, binder is replaced by the $\mathrm{TiO}_{2}$ particles. A consequence of the replacement of binder with $\mathrm{TiO}_{2}$ particles is that the $\mathrm{TiO}_{2}$ interparticle distance begins to decrease, lowering scattering efficiency. The scattering efficiency continues to decrease until the particles are essentially touching each other, at which point it reaches the critical pigment volume concentration (CPVC). CPVC is defined qualitatively as the point at which there is just enough binder material to fully envelop the pigment particles. Above CPVC, there is insufficient binder material to envelop the pigment particles, which results in air voids (blue). The $\mathrm{TiO}_{2}$ particles continue to have decreased scattering efficiency due to crowding effects, but there is a greater refractive index difference between $\mathrm{TiO}_{2} /$ air $\left(2.73\right.$ and 1.00) than $\mathrm{TiO}_{2} /$ binder (2.73 and 1.5), which improves opacity. Above CPVC, these air voids begin to form an interconnecting network. Changes in the film properties are most apparent when compared below and above CPVC. Mechanical and chemical properties deteriorate as PVC increases. 


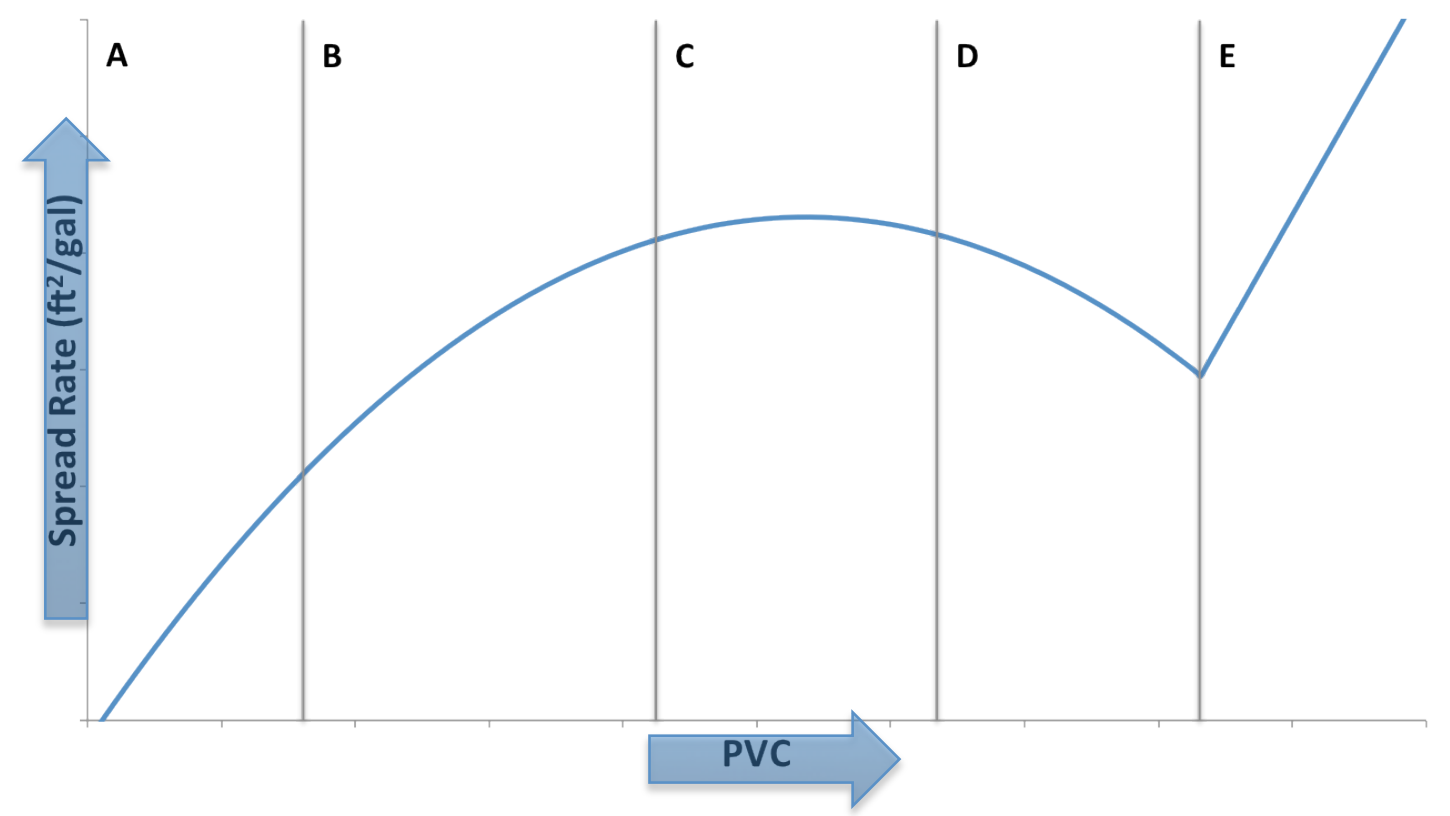

Figure 12: Typical PVC Effect on Spread Rate

Since complete hiding is typically desired in a paint application, the contrast ratio is not an effective method to quantify paint performance. The spread rate is an alternative scale that can be used to estimate the paint performance in a quantifiable manner for application purposes. The units of spread rate are typically $\mathrm{ft}^{2}$ per gallon. Spread rate values typically reflect paint films at complete hiding. It is unsurprising that the quantity of pigment affects the spread rate of paint due to their optical properties. The spread rate generally increases with PVC, but this generalization is not completely true. A typical spread rate to PVC relationship with $\mathrm{TiO}_{2}$ is presented in Figure 12. This figure can be broken down into 5 parts. $\mathrm{As}_{\mathrm{TiO}_{2}}$ is first incorporated into a paint formulation (region A), there is maximum scattering effect, which can be observed by comparing the slope. This simply means that the $\mathrm{TiO}_{2}$ particles are spaced apart and have maximum scattering. With additional $\mathrm{TiO}_{2}$ incorporated (region $\mathrm{B}$ ), crowding effects become apparent with decreased scattering efficiency. The spread rate continues to increase, but not to the 
degree as in region A. Notice that the slope begins to decrease from region A into region B. The spread rate apexes in region $\mathrm{C}$ as addition of $\mathrm{TiO}_{2}$ has negligible effects on the spread rate. Again, this is due to crowding effects. Further addition of $\mathrm{TiO}_{2}$ results (region D) in lower spread rate due to crowding of multiple $\mathrm{TiO}_{2}$, which can be thought of as a larger particle. Regions A-D is the consequence of lower scattering efficiency as the $\mathrm{TiO}_{2}$ particles pack closer together. Despite having maximum scattering efficiency in region $\mathrm{A}$, the spread rate value is low because the $\mathrm{TiO}_{2}$ particles are spaced 'far' apart. The result is that additional paint is needed to achieve the desired hiding effect. The CPVC point begins in region $\mathrm{E}$ and is characterized with a dramatic increase in the spread rate slope, which often exceeds that of region A. The increase in spread rate is due to the introduction of a secondary network of air voids due to the insufficient binder coverage. Specifically, the spread rate increase is the result of an increased refractive index difference between the pigment and its surrounding medium, specifically pigmentair and binder-air interfaces. Light scattering results from the refractive index difference as well as the number of surface interfaces.

The sample model provided above is an example of a one pigment using the same resin system. In the case of pigment blends, this simple model still applies even in the case that pigment blends contain different particle sizes. Void space will always be present as pigments are packed together. The voids contain either air or binder, or other particles when using pigment blends. The void space of packed pigments depends on the pigment size. Larger particles form larger voids and vice versa. In the case of different sized particles, the smaller sized particles are able to pack themselves in the void spaces. 
Paints can vary in PVC as certain PVC ranges are better fit for different applications. Paints are generally not formulated above CPVC with solely $\mathrm{TiO}_{2}$. Reasons include the price of $\mathrm{TiO}_{2}$ pigment and diminished paint properties above CPVC. Additionally, fillers are typically used to reduce the crowding effects of $\mathrm{TiO}_{2}$. Examples of diminished properties include lower gloss and tensile strength as well as being more porous and higher susceptibility to rusting. The property changes all converge around CPVC (Asbeck, 1992). CPVC values vary dramatically with the primary factors due to pigment type, particle size, and pigment flocculation (Wicks et al., 2007). The general trend is that CPVC increases with increased particle size and wider particle size distribution. Flocculated pigments tend to have low CPVC values due to trapping of solvents with the pigment while in the binder, which will then evaporate, forming air voids (Wicks et al., 2007). There are multiple methods to determine CPVC. In many cases, accuracy and/or precision are poor due to the method of measurement. Additionally, CPVC typically varies depending on the method. Examples of these methods include tinting, measuring film density, or calculation from oil absorption tests.

\subsubsection{Oil Absorption}

Oil absorption (OA) tests can be performed as a method to calculate CPVC. The OA of a pigment is the grams of linseed oil per $100 \mathrm{~g}$ of pigment needed to form a pastelike texture. ASTM methods D281 and D1483 both provide similar methods to determine the OA value of a pigment or pigment blend. Both methods use linseed oil and a spatula to incorporate the pigment and linseed oil until a paste is formed. The equation used to relate OA and CPVC is shown in Figure 13. CPVC is expressed as $\mathrm{mL}$ of pigment per 
$100 \mathrm{~mL}$ of film, $\varrho$ is the density of the pigment, OA is oil absorption value, and 93.5 is a factor that take into account the density of linseed oil in $\mathrm{g} / \mathrm{mL}$ per $100 \mathrm{~mL}$ of film.

$$
\mathrm{CPVC}=\frac{1}{1+\frac{\mathrm{OA}^{*} \mathrm{Q}}{93.5}}
$$

\section{Figure 13: Equation Relating OA and CPVC}

OA tests and the calculations are useful despite the lack of accuracy and precision in some cases. These OA tests assume that the wetting properties of linseed oil are similar to that of the paint system and that any flocculation that occurs in the OA test is carried over to the paint system (Brock et al., 2010). Additionally, when working with pigment blends, OA and CPVC estimates cannot be accurately made due to packing dynamics that result from different sized particles. The void space of packed pigments depends on the pigment size, assuming they are all the same shape. If smaller materials are able to fit in the voids, the available surface area increases. 


\section{Materials and Methods}

All materials were obtained from commercially available sources. Physical properties were obtained for the prepared materials by use of a CEM microwave oven to obtain weight solids for slurries $\left(\mathrm{TiO}_{2}\right.$ and $\left.\mathrm{CaCO}_{3}\right)$ and use of an oven, set to $105^{\circ} \mathrm{C}$ for 72 hours in the case of the masterbatch. A VMA-Getzmann Dispermat was used to blend and mix the materials. Density was measured in weight per gallon using a $8.3 \mathrm{~mL}$ U.S. (Baltimore) Midget Cup.

\subsection{Material Formulations}

To simplify and ensure consistency in paint formulation, it was decided beforehand to keep the volume solids of the individual components for the white paint formulations equal to one another. The ingredients that made up the white paints came from a masterbatch and slurries of $\mathrm{TiO}_{2}$ and $\mathrm{CaCO}_{3}$ in different ratios. The masterbatch includes the film formers and additives for the paint system. Slurries contain pigments in a dispersed aqueous form. The pigments were prepared in slurry form, then diluted to the same volume solids level to that of the masterbatch.

Table 8: Physical Properties of Pigments and Extenders used in this Study

\begin{tabular}{|l|c|c|c|c|}
\hline Pigment Material & $\begin{array}{c}\text { R-741 Slurry } \\
\text { R-931 }\end{array}$ & $\begin{array}{c}\text { R-746 Slurry } \\
\text { R-706 }\end{array}$ & Omyacarb 15 & Omyacarb UF \\
\hline Median Particle Size $(\boldsymbol{\mu m})$ & 0.36 & 0.55 & 15 & 0.70 \\
\hline Min TiO $\mathbf{~}_{\mathbf{2}}$ by weight $(\%)$ & 80 & 93 & $\mathrm{~N} / \mathrm{A}$ & $\mathrm{N} / \mathrm{A}$ \\
\hline Pigment Density $(\mathbf{g} / \mathrm{mL})$ & 3.84 & 4.10 & 2.70 & 2.70 \\
\hline
\end{tabular}

A summary of the pigment and extender physical properties used in the PVC ladder study are presented in Table 8. White paints were made into PVC ladders with varying concentrations of $\mathrm{TiO}_{2}$ and $\mathrm{CaCO}_{3}$. A PVC ladder is a study conducted through 
formulation of white paints with increasing PVC. R-741 and R-746 (DuPont) slurries of $\mathrm{TiO}_{2}$ were made into separate PVC ladders and compared to one another. Additional PVC ladders were made containing R-746 with either Omyacarb 15 or Omyacarb UF (Omya) slurry in varying concentrations. R-741 and R-746 slurries contain R-931 and R706 (DuPont) grades of $\mathrm{TiO}_{2}$ pigment, as appropriate. These $\mathrm{TiO}_{2}$ grades are differentiated from each other by their surface treatment and median particle size. R-931 pigments contain $80 \%$ weight solids of $\mathrm{TiO}_{2}$ with a median particle size of $0.55 \mu \mathrm{m}$, whereas R-706 pigments contain $93 \%$ weight solids $\mathrm{TiO}_{2}$ with a median particle size of $0.36 \mu \mathrm{m}$. Omyacarb UF contains $\mathrm{CaCO}_{3}$ particles with particle sizes on the order of $\mathrm{TiO}_{2}$ particles $(0.70 \mu \mathrm{m})$, whereas Omyacarb 15 particles are significantly larger than that of the $\mathrm{TiO}_{2}$ particles $(15 \mu \mathrm{m})$.

Table 9: Solids Content of Masterbatch

\begin{tabular}{|l|c|c|}
\hline Masterbatch & TFW-182 & $\begin{array}{c}\text { TFW-182 with } \\
\text { Acrysol RM-8W }\end{array}$ \\
\hline Density (Ib/gal) & 8.63 & 8.66 \\
\hline Weight Solids (\%) & $25.48 \%$ & $24.22 \%$ \\
\hline Density of solids (Ib/gal) & 8.55 & 9.75 \\
\hline Volume Solids (\%) & $23.61 \%$ & $21.49 \%$ \\
\hline
\end{tabular}

The masterbatch used for this study was an internal formulation from DuPont, designated as TFW-182 Emulsion Gloss Masterbatch. Additional thickener, Acrysol RM8W (Dow), was incorporated into the masterbatch due to initial concerns of pigment settling, due to the low solids of the masterbatch, especially of concern at high $\mathrm{TiO}_{2} \mathrm{PVC}$ due to the pigment density. The Acrysol RM-8W thickener was initially prepared by $50 \%$ dilution by weight in distilled water. Following preparation $4.4 \%$ by weight of the diluted Acrysol RM-8W thickener solution was added to the masterbatch. The additional 
thickener was incorporated into the masterbatch using a VMA-Getzmann Dispermat dropwise with a pipet, and then mixed at 1000 RPM for 10 minutes. TFW-182 utilized an acrylic latex polymer as the binder material in the paint formulation. This masterbatch contained film formers as well as additives for the white paint. This premade masterbatch was used to minimize the variation in the paint components due to the number of paint samples that were to be made. A summary of the solids and density values for the TFW182 masterbatch is shown in Table 9. The masterbatch with added thickener the material used in making the white paints. The volume solids were found by calculating for the solids density from the bulk density and weight solids.

$\mathrm{TiO}_{2}(\mathrm{R}-741$ and $\mathrm{R}-746)$ was already available in slurry form (72-77\% weight solids) and were diluted with distilled water such that the volume solids was equal to that of the masterbatch, which was $21.49 \%$ volume solids. The slurry was diluted as each PVC ladder was prepared to avoid settling of the $\mathrm{TiO}_{2}$ particles. $\mathrm{TiO}_{2}$ particles would settle out if the $\mathrm{TiO}_{2}$ slurries were diluted in bulk beforehand, as $\mathrm{TiO}_{2}$ has a higher density than the water content of the diluted slurry (78.51\% volume solids). The dilutions were determined through a series of calculations similar to the masterbatch in finding density and weight solids and converting to a volume basis.

$\mathrm{CaCO}_{3}$ extenders (Omyacarb 15 and Omyacarb UF) were prepared into slurry form. The extender slurry was made in a high-speed Dispermat mixer with a grind at $78 \%$ weight solids and letdown to $72 \%$ weight solids in distilled water. Added to the Omyacarb slurries was a dispersant, Tamol 1124 (Dow), at $2.2 \%$ by volume. The extender slurry was eventually diluted with distilled water such that the volume solids were equal to that of the masterbatch $(21.49 \%$ volume solids $)$. Dilutions were performed 
as each PVC ladder was made to avoid settling of the extender particles in the slurry due to the absence of thickener in the slurry.

\subsection{Paint Preparation}

\begin{tabular}{|c|c|c|c|c|c|c|c|c|c|c|}
\hline & \multicolumn{9}{|c|}{ OmyaCarb 15} \\
\hline & & 0 & 5 & 10 & 15 & 20 & 25 & 30 & 35 & 40 \\
\hline \multirow{11}{*}{ 은 } & 0 & $x$ & $x$ & $x$ & $x$ & $x$ & $x$ & $x$ & $x$ & $x$ \\
\hline & 5 & $x$ & $x$ & $x$ & $x$ & $x$ & $x$ & $x$ & $x$ & $x$ \\
\hline & 10 & $x$ & $x$ & $x$ & $x$ & $\mathrm{x}$ & $x$ & $x$ & $x$ & $x$ \\
\hline & 15 & $x$ & $\mathrm{x}$ & $x$ & $x$ & $x$ & $\mathrm{x}$ & $x$ & $x$ & $x$ \\
\hline & 20 & $x$ & $\mathrm{x}$ & $x$ & $x$ & $\mathrm{x}$ & $x$ & $x$ & $x$ & $x$ \\
\hline & 25 & $x$ & $x$ & $x$ & $x$ & $x$ & $x$ & $x$ & $x$ & $x$ \\
\hline & 30 & $x$ & $x$ & $x$ & $x$ & $\mathrm{x}$ & $x$ & $x$ & $x$ & $x$ \\
\hline & 35 & $x$ & $x$ & $x$ & $x$ & $x$ & $x$ & $x$ & $x$ & \\
\hline & 40 & $x$ & $x$ & $x$ & $x$ & $x$ & $x$ & $x$ & & \\
\hline & 45 & $x$ & $\mathrm{x}$ & & $x$ & $\mathrm{x}$ & $x$ & & & \\
\hline & 50 & $x$ & $x$ & & & & & & & \\
\hline
\end{tabular}

\begin{tabular}{|c|c|c|c|c|c|c|c|c|c|c|}
\hline & \multicolumn{9}{|c|}{ OmyaCarb UF } \\
\hline & & 0 & 5 & 10 & 15 & 20 & 25 & 30 & 35 & 40 \\
\hline \multirow{11}{*}{ 은 } & 0 & $x$ & $x$ & $x$ & $x$ & $x$ & $x$ & $x$ & $x$ & $x$ \\
\hline & 5 & $x$ & $x$ & $x$ & $x$ & $x$ & $x$ & $x$ & $x$ & $x$ \\
\hline & 10 & $x$ & $x$ & $x$ & $x$ & $x$ & $x$ & $x$ & $x$ & $x$ \\
\hline & 15 & $x$ & $x$ & $x$ & $x$ & $x$ & $x$ & $x$ & $x$ & $x$ \\
\hline & 20 & $x$ & $x$ & $x$ & $x$ & $x$ & $x$ & $x$ & $x$ & $x$ \\
\hline & 25 & $x$ & $x$ & $x$ & $x$ & $x$ & $x$ & $x$ & $x$ & $x$ \\
\hline & 30 & $x$ & $x$ & $x$ & $x$ & $x$ & $x$ & $x$ & $x$ & $x$ \\
\hline & 35 & $x$ & $x$ & $x$ & $x$ & $x$ & $x$ & $x$ & $x$ & \\
\hline & 40 & $x$ & $x$ & $x$ & $x$ & $x$ & $x$ & $x$ & & \\
\hline & 45 & $x$ & $x$ & $\mathrm{x}$ & $x$ & $x$ & $x$ & & & \\
\hline & 50 & $x$ & $x$ & $x$ & & & & & & \\
\hline
\end{tabular}

Figure 14: Visual Representation of Paint Samples Made

White paints were formulated into PVC ladders as 3-component systems which contained TFW-182 with Acrysol RM-8W (masterbatch), R-746 $\mathrm{TiO}_{2}$ slurry, and either Omyacarb 15 or Omyacarb UF (extender) slurry. Additionally, white paints in 2component systems were made in conjunction for use as reference systems which contained the modified masterbatch and either $\mathrm{TiO}_{2}$ or $\mathrm{CaCO}_{3}$ slurry. These $\mathrm{PVC}$ ladders were formulated with varying $\mathrm{PVC}$ levels of $\mathrm{TiO}_{2}$ and/or $\mathrm{CaCO}_{3}$ (pigments), but can be thought of as $\mathrm{TiO}_{2}$ PVC ladders while keeping extender concentration constant. Additional PVC ladders were made with masterbatch and one pigment (R-746, R-741, Omyacarb 15, and Omyacarb UF. It is important to mention that PVC is an alternative notation for concentration, and that PVC itself can refer to the pigment and/or extender. Presented in Figure 14 is a visual representation of the paint or coating samples that were made. Boxes marked in orange indicate the $\mathrm{TiO}_{2}$ and/or $\mathrm{CaCO}_{3} \mathrm{PVC}$ used for each 
sample. The PVC for a each particular formulation is the sum of the Omyacarb and $\mathrm{TiO}_{2}$ PVC values.

Paints were formulated to $50 \mathrm{~mL}$ or $100 \mathrm{~mL}$ samples in $2 \mathrm{oz}$ or $4 \mathrm{oz}$ glass jars, respectively. Jars were first filled in the following order: masterbatch, $\mathrm{TiO}_{2}$ slurry, and finally the extender slurry. The glass jars were sealed with a lid and a plastic seal, placed between the jar opening and lid to prevent the paint from settling around the lid. Samples were placed in a Red Devil Shaker and shaken 10 minutes each side to ensure mixture of the paints for a total time of 20 minute shaking per paint sample. Density was measured for each paint sample and weight solids were obtained periodically to compare to calculated values.

\subsection{Spread Rate Procedure}

\subsubsection{Weighed Drawdown}

Weighed drawdowns were prepared to measure the performance of each paint sample. Paint sample drawdowns were prepared in replicates of 4 for each paint sample. Drawdowns were performed on an automatic drawdown machine with a drawdown bar film applicator with a thickness of 4 mils (0.004 inches) on special cut Leneta Opacity 14-H charts. Each Leneta chart contains 2 sets of alternating white and black backgrounds, giving a total of 4 squares. Paints were stirred slowly with a pipette prior to each drawdown, and then applied onto the Leneta chart with the paint pushed into the end of the drawdown bar. The paint was pushed to the far end of the drawdown bar to ensure the paint coverage area on each Leneta chart were similar to one another, having covered an area of 54.25 in $^{2}$ per drawdown. Additionally, each drawdown was individually 
weighed, such that drawdowns for each paint sample were within \pm 0.05 grams of each other and left to dry overnight in the horizontal position for further analysis.

\subsubsection{Contrast Ratio Measurements}

A Hunterlab LabScan XE Spectrophometer loaded with Hunterlab Easymatch QC Software 3.9.0 was used to measure the light reflectance of the drawdowns to obtain their contrast ratio values. A $44 \mathrm{~mm}$ port size was used under D65 illuminant when obtaining measurements. The Y tristimulus values were used to measure the reflectance values over the black and white backgrounds. Together, these values determine the contrast ratio for the dry paint. The reflectance of the special cut Leneta Opacity 14-H charts were taken into account by measuring the reflectance over the white background of 8 randomly selected charts per box.

Contrast ratio was measured for the drawdowns that were left overnight to dry from the previous day by measuring the light reflectance values or Y tristimulus value of the coating over the black and white backgrounds. One measurement was made for each of the 4 backgrounds per opacity chart -2 values each for the black and white backgrounds for each drawdown for the particular paint. The Y tristimulus values were averaged for each black and white substrate

Additional contrast ratio measurements were performed towards the end of the ladder study to determine whether or not the formulated paint was above CPVC.

Drawdown charts were coated with mineral oil with a paint roller over the drawdown and left to level horizontally for 20 minutes. Oiled contrast ratio measurements were obtained in the same manner by measuring the light reflectance over the black and white backgrounds and compared to previous measurements. Selection of drawdown charts was 
based on PVC ladders to which the CPVC range was not easily distinguished based on spread rate values. Due to the destructive nature of the oiled contrast ratio measurements, repeating of this test was avoided as necessary.

\subsubsection{Spread Rate Calculation}

The Spread Rate Program v2.1 (DuPont) was used to generate spread rate values for each paint sample. This program utilizes Kubelka-Munk relationships to extrapolate and interpolate the $\mathrm{X}$ value. Input variables needed to calculate spread rate include the paint density, $\mathrm{TiO}_{2}$ content, reflectance over white, reflectance over black, substrate reflectance, drawdown weight, and drawdown coverage area. The $\mathrm{TiO}_{2}$ content was calculated based on the quantity of slurry added and the volume of paint made for each paint sample. Output data of concern is the spread rate value at complete hiding. Shown in Figure 15 is a screenshot of the Spread Rate Program used to calculate the spread rate for the measured paint samples. Additional output data, such as actual scattering (S) and thickness $(\mathrm{X})$ values for the drawdowns as is as and $\mathrm{S}$ and $\mathrm{X}$ values extrapolated at complete hiding are provided. Additionally, there is an additional parameter to calculate these values at $\mathrm{R}_{\infty}$. For simplicity and practical application, the additional output data is not used for the purposes of this study. 


\begin{tabular}{|c|c|c|c|c|c|c|c|}
\hline \multicolumn{5}{|c|}{ SR Spread Rate Calculator } & \multicolumn{3}{|c|}{ 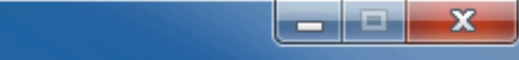 } \\
\hline \multicolumn{4}{|l|}{ - Paint Properties- } & \multicolumn{4}{|c|}{ 「as Drawn Down- } \\
\hline \multicolumn{4}{|c|}{ Study $\quad$ TFW' 182 PVC LADDER 40 PVC OUF } & CRatio & 0.7231 & $\mathrm{R}$ inf & ${ }^{\times N O T E}{ }^{\times}$ \\
\hline \multicolumn{4}{|l|}{ Sample $5 \mathrm{PVC}$} & $S x$ & 1.61 & $X$ [mils] & 2.86 \\
\hline \multicolumn{4}{|c|}{ Description $5 \mathrm{PVC}$} & $\mathrm{S}[1 / \mathrm{mil}]$ & 0.5625 & $\times\left[g / m^{\wedge} 2\right]$ & 3.14 \\
\hline \multicolumn{3}{|c|}{ Paint Density [lbs/gal] } & 9.668 & $\mathrm{~S}\left[\mathrm{~m}^{\wedge} 2 / \mathrm{g}\right]$ & 0.5131 & S Rate [ft^2/gal] & 560.4 \\
\hline \multicolumn{4}{|c|}{ Ti02 Content [lbs/gal] } & \multicolumn{4}{|c|}{ at Complete Hiding [CR = 0.98] } \\
\hline \multicolumn{4}{|c|}{ - Reflectance Readings } & R over Black & 0.98 & $X[$ mils] & 27.48 \\
\hline \multirow{2}{*}{$\begin{array}{r}\text { R o White } \\
0.8569\end{array}$} & \multirow{2}{*}{\multicolumn{2}{|c|}{$\begin{array}{l}\text { R o Black } \\
0.6196\end{array}$}} & \multirow{2}{*}{$\begin{array}{r}\text { R Substrate } \\
0.8015\end{array}$} & R over White & 1 & $X\left[g / m^{\wedge} 2\right]$ & 30.13 \\
\hline & & & & $\mathrm{sx}$ & 15.458 & $S$ Rate $\left[\mathrm{tt}^{\wedge} 2 / \mathrm{gal}\right]$ & 58.37 \\
\hline \multicolumn{4}{|c|}{ DrawDown Properties- } & \multicolumn{4}{|c|}{- Target $R$ infinity } \\
\hline Weight [grams] & 2.948 & Area $\left[\mathrm{in}^{\wedge} 2\right]$ & 54.2 & ГR Infinity & 0.9200 & $5 x$ & \\
\hline \multicolumn{2}{|l|}{ Calculate } & Zoom t & & CRatio & & $X$ [mils] & \\
\hline \multicolumn{2}{|l|}{ Add to List } & Change I & faults & R over Black & & $X\left[g / \mathrm{m}^{\wedge} 2\right]$ & \\
\hline \multicolumn{2}{|l|}{ Print } & Ex & & R over White & & $S$ Rate [ $\left[\mathrm{t}^{\wedge} 2 / \mathrm{gal}\right]$ & \\
\hline \#|Study & Sample & Descripti & & & Density [ [L & bs/gall & Ti02 Conte \\
\hline \multirow[t]{2}{*}{1} & & & & & & & \multirow{2}{*}{$m^{\prime}$} \\
\hline & & & & & & & \\
\hline
\end{tabular}

Figure 15: Spread Rate Program v.2.1 (DuPont) Screenshot

Scatter plots were generated using a combination of the contrast ratio and spread rate values against total PVC. A statistical package, Origin Pro v9, was used to model best fit lines and polynomials in order to find estimated CPVC values. Additional oiled contrast ratio tests were performed to ascertain whether a particular PVC value was above or below CPVC for each paint system (at constant $\mathrm{CaCO}_{3} \mathrm{PVC}$ ).

\subsection{Oil Absorption}

Oil absorption tests were also performed for $\mathrm{TiO}_{2}$ and $\mathrm{CaCO}_{3}$ pigment grades used in the slurry solutions. These oil absorption (OA) values are another way to determine relative CPVC values of a pigment system. OA tests were performed using the 
R-706 and R-931 pigment grades of $\mathrm{TiO}_{2}$ and Omyacarb UF and Omyacarb 15 pigment grades of $\mathrm{CaCO}_{3}$. Additional OA tests were performed with pigment blends containing R706 with Omyacarb UF and 15.

Oil absorption tests were performed according to ASTM Method D281-12, Standard Test Method for Oil Absorption of Pigments by Spatula Rub-Out. Oil absorption tests were performed in triplicates for each pigment sample. Pigment was weighed out in varying amounts (between 1-2 grams) on waxed weighing paper and placed on a glass plate. A burette was filled with linseed oil and added to the pigment sample in a drop wise manner. A spatula was used to incorporate the linseed oil into the pigment. The OA test for each sample was complete when enough oil was applied to and incorporated into the pigment sample with a consistency of a stiff, putty-like paste that does not break or separate. The volume of linseed oil required to wet the pigment was recorded, with pigment mass taken into account to obtain an OA value. A different quantity of pigment was used for each subsequent $\mathrm{OA}$ test to test for repeatability. OA values are constant, ignoring flocculation effects, thus OA tests with different quantities of pigment should provide similar OA values.

\subsubsection{Blend Preparation}

Pigment blends were prepared for $\mathrm{TiO}_{2} / \mathrm{CaCO}_{3}$ pigment mixtures. Pigments used for blending include R-706 $\mathrm{TiO}_{2}$ with Omyacarb 15 and Omyacarb $\mathrm{UF} \mathrm{CaCO}_{3}$ separately. Pigments were added appropriately into a test tube as 5 gram pigments blends, scaled to volume ratios shown in Table 10. Test tubes were sealed with parafilm. Blending or mixing of the pigments were performed by shaking and tapping the test tube for approximately 2 minutes each. 
Table 10: Pigment Blend Formulations

\begin{tabular}{|r|r|r|r|}
\hline \multicolumn{2}{|c|}{ Volume \% } & \multicolumn{2}{c|}{ Mass (g) } \\
\hline Omyacarb 15 & \multicolumn{1}{|c|}{ R-706 } & Omyacarb 15 & \multicolumn{1}{c|}{ R-706 } \\
\hline $0 \%$ & $100 \%$ & 0.00 & 5.00 \\
\hline $20 \%$ & $80 \%$ & 0.71 & 4.29 \\
\hline $40 \%$ & $60 \%$ & 1.53 & 3.47 \\
\hline $60 \%$ & $40 \%$ & 2.48 & 2.52 \\
\hline $80 \%$ & $20 \%$ & 3.62 & 1.38 \\
\hline $100 \%$ & $0 \%$ & 5.00 & 0.00 \\
\hline & & & \\
\hline Volume \% & \multicolumn{2}{|c|}{ Mass (g) } \\
\hline Omyacarb UF & R-706 & Omyacarb UF & R-706 \\
\hline $0 \%$ & $100 \%$ & 0.00 & 5.00 \\
\hline $20 \%$ & $80 \%$ & 0.71 & 4.29 \\
\hline $40 \%$ & $60 \%$ & 1.53 & 3.47 \\
\hline $60 \%$ & $40 \%$ & 2.48 & 2.52 \\
\hline $80 \%$ & $20 \%$ & 3.62 & 1.38 \\
\hline $100 \%$ & $0 \%$ & 5.00 & 0.00 \\
\hline
\end{tabular}




\section{Results and Discussion}

\subsection{Contrast Ratio}

Table 11: Averaged Contrast Ratio - Omyacarb 15 (a) and Omyacarb UF (b)

\begin{tabular}{|c|c|c|c|c|c|c|c|c|c|c|}
\hline & \multicolumn{9}{|c|}{ Omyacarb 15 PVC } \\
\hline & & 0 & 5 & 10 & 15 & 20 & 25 & 30 & 35 & 40 \\
\hline \multirow{11}{*}{$\begin{array}{l}\frac{1}{a} \\
0 \\
\frac{1}{N} \\
\dot{1}\end{array}$} & 0 & 0.022 & 0.031 & 0.035 & 0.041 & 0.046 & 0.052 & 0.055 & 0.068 & 0.088 \\
\hline & 5 & 0.815 & 0.727 & 0.713 & 0.723 & 0.711 & 0.737 & 0.695 & 0.669 & 0.649 \\
\hline & 10 & 0.906 & 0.853 & 0.846 & 0.840 & 0.814 & 0.825 & 0.797 & 0.771 & 0.756 \\
\hline & 15 & 0.909 & 0.892 & 0.890 & 0.883 & 0.862 & 0.858 & 0.829 & 0.815 & 0.805 \\
\hline & 20 & 0.926 & 0.914 & 0.902 & 0.899 & 0.877 & 0.867 & 0.847 & 0.841 & 0.842 \\
\hline & 25 & 0.936 & 0.920 & 0.912 & 0.904 & 0.886 & 0.876 & 0.873 & 0.882 & 0.889 \\
\hline & 30 & 0.940 & 0.925 & 0.913 & 0.900 & 0.892 & 0.897 & 0.900 & 0.912 & 0.932 \\
\hline & 35 & 0.940 & 0.922 & 0.918 & 0.917 & 0.920 & 0.926 & 0.929 & 0.935 & \\
\hline & 40 & 0.939 & 0.929 & 0.936 & 0.938 & 0.942 & 0.946 & 0.948 & \multirow{3}{*}{\multicolumn{2}{|c|}{ Above CPVC }} \\
\hline & 45 & 0.953 & 0.948 & & 0.959 & 0.957 & 0.956 & & & \\
\hline & 50 & 0.965 & 0.960 & & & & & & & \\
\hline
\end{tabular}

(a)

\begin{tabular}{|c|c|c|c|c|c|c|c|c|c|c|}
\hline & \multicolumn{9}{|c|}{ Omyacarb UF PVC } \\
\hline & & 0 & 5 & 10 & 15 & 20 & 25 & 30 & 35 & 40 \\
\hline \multirow{11}{*}{$\begin{array}{l}\frac{1}{a} \\
0 \\
\dot{N} \\
\dot{\alpha}\end{array}$} & 0 & 0.022 & 0.024 & 0.031 & 0.043 & 0.054 & 0.075 & 0.095 & 0.103 & 0.138 \\
\hline & 5 & 0.815 & 0.725 & 0.720 & 0.718 & 0.724 & 0.714 & 0.719 & 0.706 & 0.723 \\
\hline & 10 & 0.906 & 0.849 & 0.846 & 0.842 & 0.840 & 0.822 & 0.824 & 0.861 & 0.866 \\
\hline & 15 & 0.909 & 0.894 & 0.892 & 0.890 & 0.885 & 0.870 & 0.885 & 0.898 & 0.928 \\
\hline & 20 & 0.926 & 0.916 & 0.911 & 0.908 & 0.902 & 0.910 & 0.918 & 0.933 & 0.952 \\
\hline & 25 & 0.936 & 0.921 & 0.921 & 0.917 & 0.913 & 0.935 & 0.943 & 0.954 & 0.959 \\
\hline & 30 & 0.940 & 0.928 & 0.924 & 0.928 & 0.937 & 0.954 & 0.959 & 0.965 & 0.967 \\
\hline & 35 & 0.940 & 0.926 & 0.931 & 0.945 & 0.954 & 0.966 & 0.968 & 0.973 & \\
\hline & 40 & 0.939 & 0.938 & 0.951 & 0.960 & 0.965 & 0.971 & 0.971 & \multirow{3}{*}{\multicolumn{2}{|c|}{ Above CPVC }} \\
\hline & 45 & 0.953 & 0.953 & 0.975 & 0.968 & 0.971 & 0.975 & & & \\
\hline & 50 & 0.965 & 0.966 & 0.981 & & & & & & \\
\hline
\end{tabular}

(b)

The reflectance values of the paints over a black and white substrate are the basis

for the values in this report. As a quotient, these values give the contrast ratio for the

prepared paint samples. The contrast ratio value, averaged from the drawdowns, for each

pigment combination at formulated concentrations is presented in Table 11. Two types of 
pigments $-\mathrm{TiO}_{2}(\mathrm{R}-746)$ and $\mathrm{CaCO}_{3}($ Omyacarb 15 and Omyacarb UF) were used in the paint system. It is reasonable in wanting to know which pigment is responsible in the increase of the contrast ratio for hiding purposes. Going down each column corresponds to an increase in $\mathrm{TiO}_{2} \mathrm{PVC}$ and across each row an increase in $\mathrm{CaCO}_{3} \mathrm{PVC}$ for each Omyacarb grade.

The general observable trend is that the contrast ratio increases with increasing PVC regardless of the pigment type. For each PVC ladder, the increase to $5 \mathrm{PVC}^{\mathrm{TiO}_{2}}$ resulted in an increase of the contrast ratio from close to 0 to at least 0.60 . These results indicate that $\mathrm{TiO}_{2}$ has dramatic effect in influencing the contrast ratio compared to $\mathrm{CaCO}_{3}$. There are some instances where an increased concentration lowers the contrast ratio regardless of pigment type added, which are due to crowding effects.

Highlighted values indicate samples above CPVC. The CPVC cutoff point was determined visually through extrapolation of spread rate values (Section 6.2). Oiled contrast ratio measurements were performed at high PVC due to the difficulty in determining the CPVC cutoff point. A paint formulation was determined to be above PVC if there was a difference between the oiled and unoiled contrast ratios. This is due to the air voids being filled in with oil if above CPVC. The particular contrast ratio differences are provided in Appendix A: Oiled Contrast Ratios.

The contrast ratios for the drawn down paint samples containing Omyacarb 15 can also be visually represented with the plot in Figure 16. The contrast ratio is plotted as a function of $\mathrm{TiO}_{2}(\mathrm{R}-706 / \mathrm{R}-746)$ and Extender (Omyacarb 15) PVC. A similar plot was made for Omyacarb UF, providing similar results is provided for reference in Appendix B: Pigment Contrast Ratio Plot. As mentioned from the data from Table 11, the contrast 
ratio dramatically increases at increasing $\mathrm{TiO}_{2} \mathrm{PVC}$. The increase is due to the high refractive index of $\mathrm{TiO}_{2}$. The values at $0 \mathrm{TiO}_{2} \mathrm{PVC}$ represent the contrast ratios of masterbatch itself and of the extenders. At each particular PVC value, there is a small range in the contrast ratio, which shows dependence, especially when compared to that of the extender. The narrow range indicates that the contrast ratio can potentially be modeled as a function of $\mathrm{TiO}_{2} \mathrm{PVC}$.

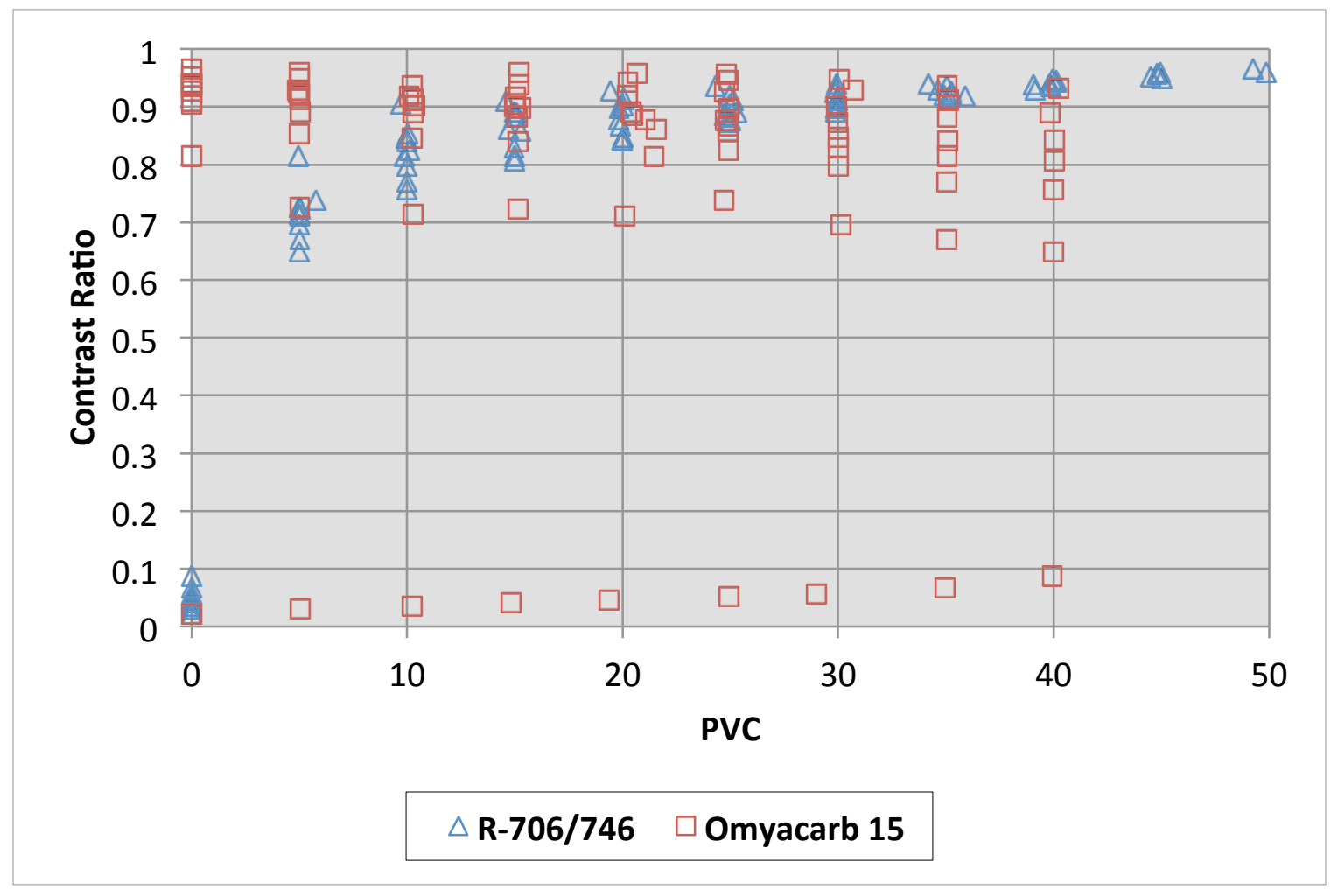

Figure 16: Contrast Ratios with Paints containing Omyacarb 15

There are few arguments to support that the contrast ratios depends on the extender PVC. The main point being that there is a dramatic range of contrast ratios at each PVC value. Even if the contrast ratio values below 0.50 are ignored, the contrast ratio range increases at increasing PVC. The only distinctive trend is at low contrast ratio. 
These values contain no $\mathrm{TiO}_{2}$ and gradually increase. This large range indicates that the contrast ratio is sensitive to the $\mathrm{TiO}_{2}$ concentration.

\subsection{Spread Rate}

The primary question is to consider the effects of Omyacarb on the light scattering properties of $\mathrm{TiO}_{2}$. Since the scattering value, S, derived from Kubelka-Munk relationships is not necessarily representative of practical performance; spread rate values are used as a means to measure the degree of light scattering.

\subsection{1 $\mathrm{TiO}_{2}$ grades}

Spread rate defined in this context the area coverage in square feet for a gallon of paint. The actual spread rate values are derived from Kubelka-Munk relationships, which are then extrapolated to complete hiding, which is a contrast ratio of 0.98 . Spread rates values were plotted for two grades of $\mathrm{TiO}_{2}(\mathrm{R}-746$ and R-741) in Figure 17 and modeled as a function of PVC. In this case, $\mathrm{TiO}_{2}$ and total PVC are equal to one another. It is unsurprising that both plots exhibit similar features to that of the example in Figure 12. The spread rate models can be broken into 2 functions - a parabolic function up to CPVC and linear function above CPVC. The parabolic function relates to the $\mathrm{TiO}_{2}$ crowding effects and the linear function relates to the presence of air voids. The spread rate values for R-746 are greater than R-741 below CPVC due to the higher $\mathrm{TiO}_{2}$ content. At $5 \mathrm{PVC}$, the spread rate values are nearly identical to one another despite the fact R-741 contains less $\mathrm{TiO}_{2}$. This point is not believed to be an outlier, but a limitation of the parabolic model. R-741 pigments have a porous surface as a result of the surface treatment performed. As a result, crowding effects are reduced due to the 'thick' shell, which increases the interparticle distance of the $\mathrm{TiO}_{2}$ compounds. The impact of increased 
interparticle distance is that the scattering efficiency increases, which is reflected upon the spread rate.

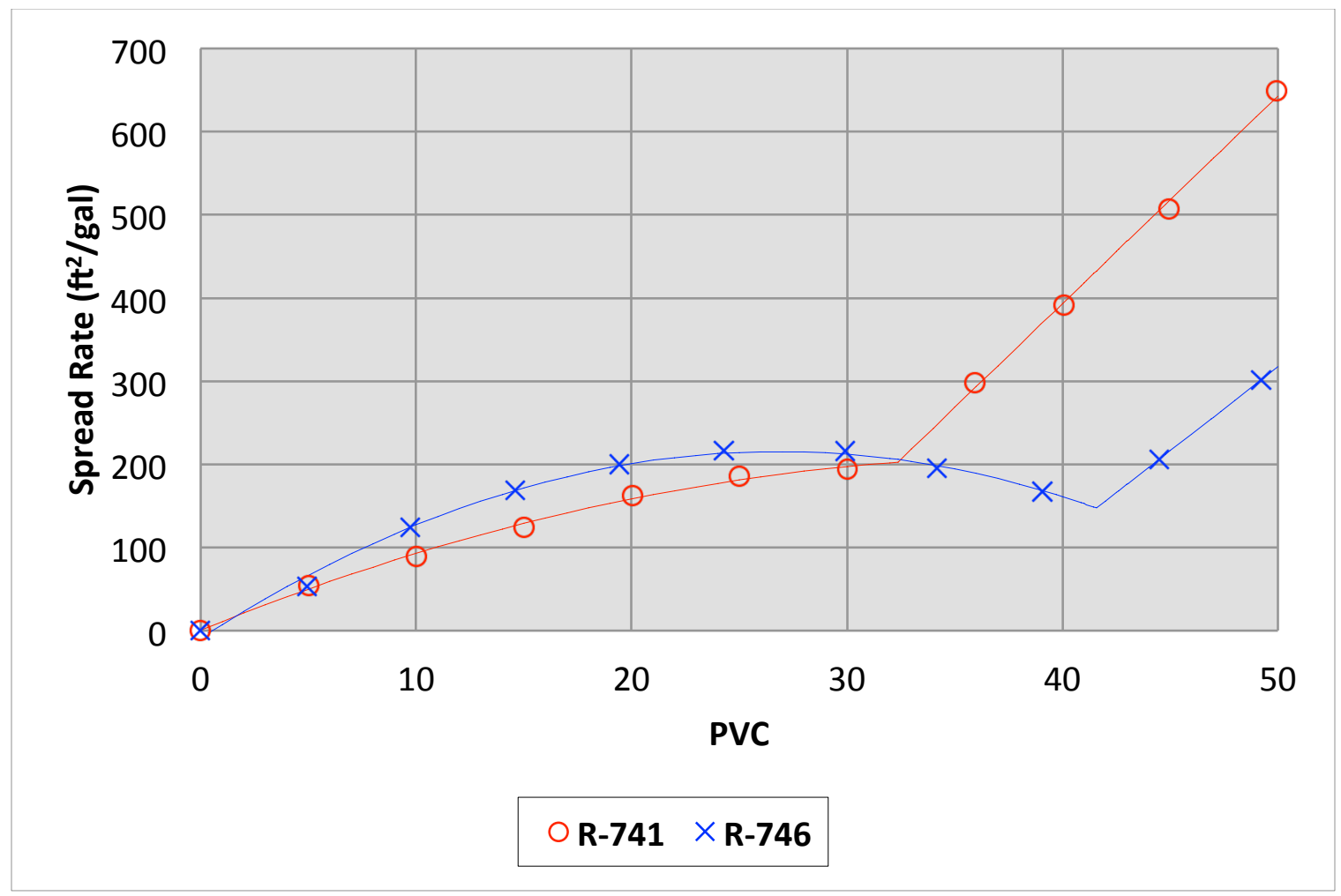

Figure 17: Spread Rate Comparison between $\mathrm{TiO}_{2}$ grades

The CPVC for R-741 is much lower than expected, as larger particles tend to have higher CPVC values. The thick shell implies that the actual $\mathrm{TiO}_{2}$ particle is smaller than it appears. Again, since the shell is porous, the density is concentrated towards the center of the particle. OA tests and surface area relationships are additional explanations to account for this. Above CPVC, spread rate increases linearly for both $\mathrm{TiO}_{2}$ grades due to the presence of air voids.

In addition to coverage area, the spread rate can be though of in terms of a volume basis. For a given area, a paint providing greater spread rate requires less volume. The spread rate plots throughout this paper are not necessarily indicative of spread rates in 
commercial paints. Rheological factors were not considered in this study, but are believed to influence spread rate values, especially at high PVC levels due to the low volume solids $(21.5 \%)$, which affect the dispersion of the pigments in the paint system.

\subsubsection{Total PVC - Omyacrab 15}

Spread Rate values and models for samples containing Omyacarb 15 are presented relative to the Total PVC (combination of $\mathrm{TiO}_{2}$ and $\mathrm{CaCO}_{3}$ ) in Figure 18. Each curve or model represents a PVC ladder at constant Omyacarb 15 concentration with increasing R-746 concentration. Additionally, interpolated CPVC values are indicated in the figure, based on the intercept of the modeled polynomial and linear functions for each model. The data is plotted relative to Total PVC to study the impact of additional extender to the entire paint system. At low Omyacarb 15 replacement, determination of spread rate values being above or below CPVC was done visually through data comparison. At high Omyacarb 15 replacment, oiled contrast ratio measurements were performed.

It is unsurprising for the most part that spread rates are lower for paints with greater Omyacarb 15 content at a constant Total PVC. This is because $\mathrm{TiO}_{2}$ is replaced with Omyacarb 15 on a volume basis at Total PVC. Since $\mathrm{TiO}_{2}$ is responsible for the increase in the spread rate due to its light scattering ability, it makes sense that less $\mathrm{TiO}_{2}$ results in a lower spread rate. 


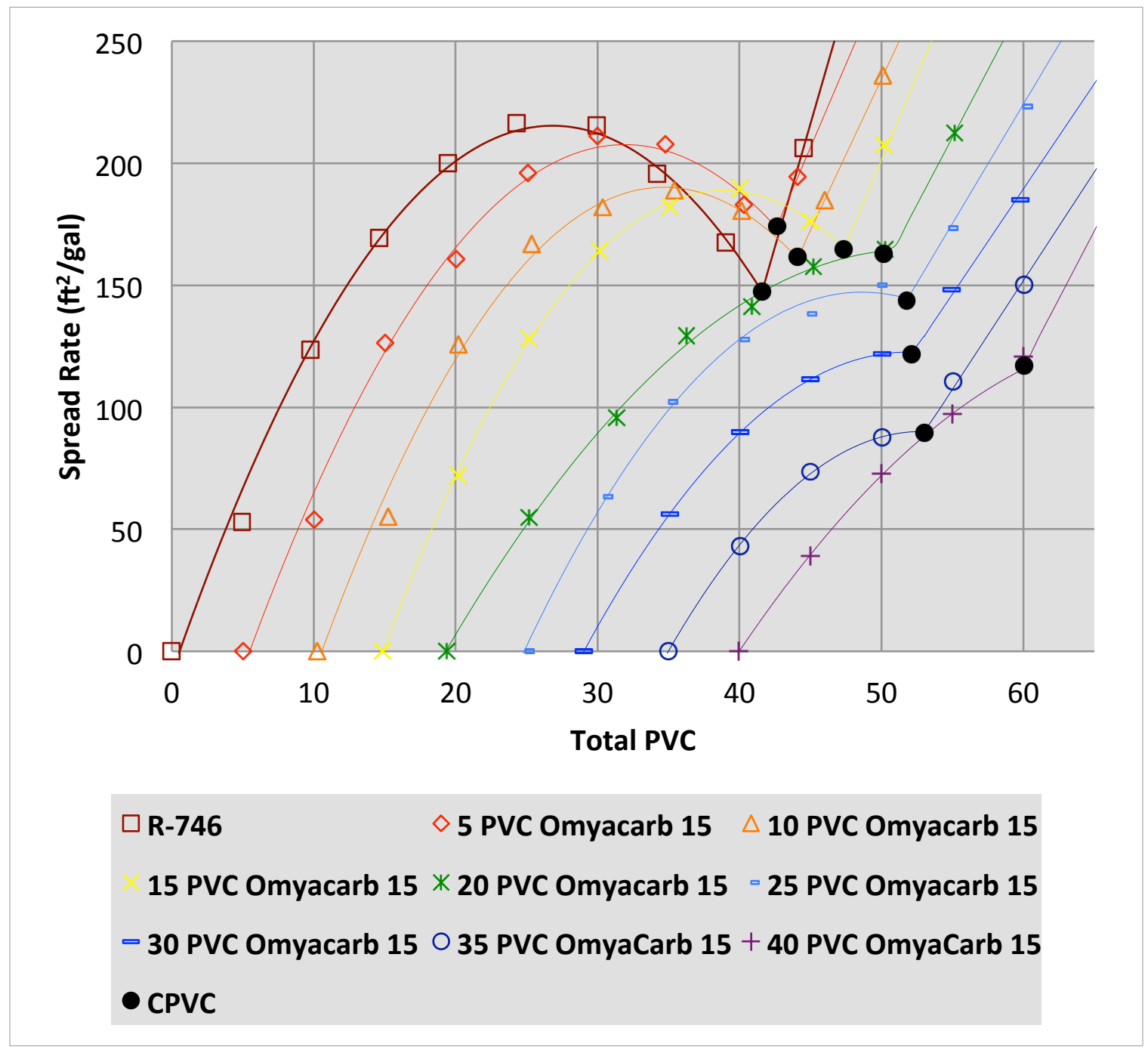

\section{Figure 18: Spread Rate of PVC Ladders containing Omyacarb 15}

In the 30-45 PVC range however, there is some overlap in the spread rate values among the models, deviating from the trend. Roughly $15 \mathrm{PVC} \mathrm{TiO}_{2}$ can be with Omyacarb 15 with comparable if not better spread rate values, just below CPVC. Do note that only spread rate is considered in this analysis. Crowding effects of $\mathrm{TiO}_{2}$ particles has been diminished with partial replacement with Omyacarb 15, while retaining enough $\mathrm{TiO}_{2}$ for light scattering. The replacement of $\mathrm{TiO}_{2}$ particles by a larger particle does not necessarily result in the same volume displacement. Packing efficiency is not $100 \%$, 
which results in the presence of voids. As a result, the $\mathrm{TiO}_{2}$ particles can be thought of as being spaced far enough such that crowding effects are marginally minimized, which can account for the slight increase in spread rate.

Table 12: Omyacarb 15 Replacement CPVC Values

\begin{tabular}{|l|c|c|c|c|c|c|c|c|c|}
\hline Omyacarb 15 PVC & 0 & 5 & 10 & 15 & 20 & 25 & 30 & 35 & 40 \\
\hline CPVC & 41.6 & 42.6 & 44.1 & 47.3 & 50.1 & 51.8 & 52.1 & 53.0 & 60.0 \\
\hline
\end{tabular}

There is a distinct trend in the CPVC values with increased Omyacarb 15 PVC. The actual values are presented in Table 12. This is the result of the packing dynamics of the pigments due to their size difference. Omyacarb 15 is significantly larger than $\mathrm{TiO}_{2}$ pigments used in paint. The difference in size enables $\mathrm{TiO}_{2}$ pigments to pack in the interstitial sites allowing for more packing - increasing available surface area, which results in higher CPVC. The decrease in spread rate is the result of added extender, which itself does not contribute to hiding. Additionally, the packing of $\mathrm{TiO}_{2}$ particles in the interstitial sites can also undergo crowding, which lowers the scattering efficiency of each $\mathrm{TiO}_{2}$ particle.

\subsubsection{Total PVC - Omyacrab UF}

Spread Rate values and models for samples containing Omyacarb UF are presented relative to the Total PVC in Figure 19. This graph was plotted in a similar manner to that of Omyacarb 15 in Figure 18. Determination of whether a spread rate was above or below CPVC was performed in a similar manner as mentioned for Omyacarb 15. 


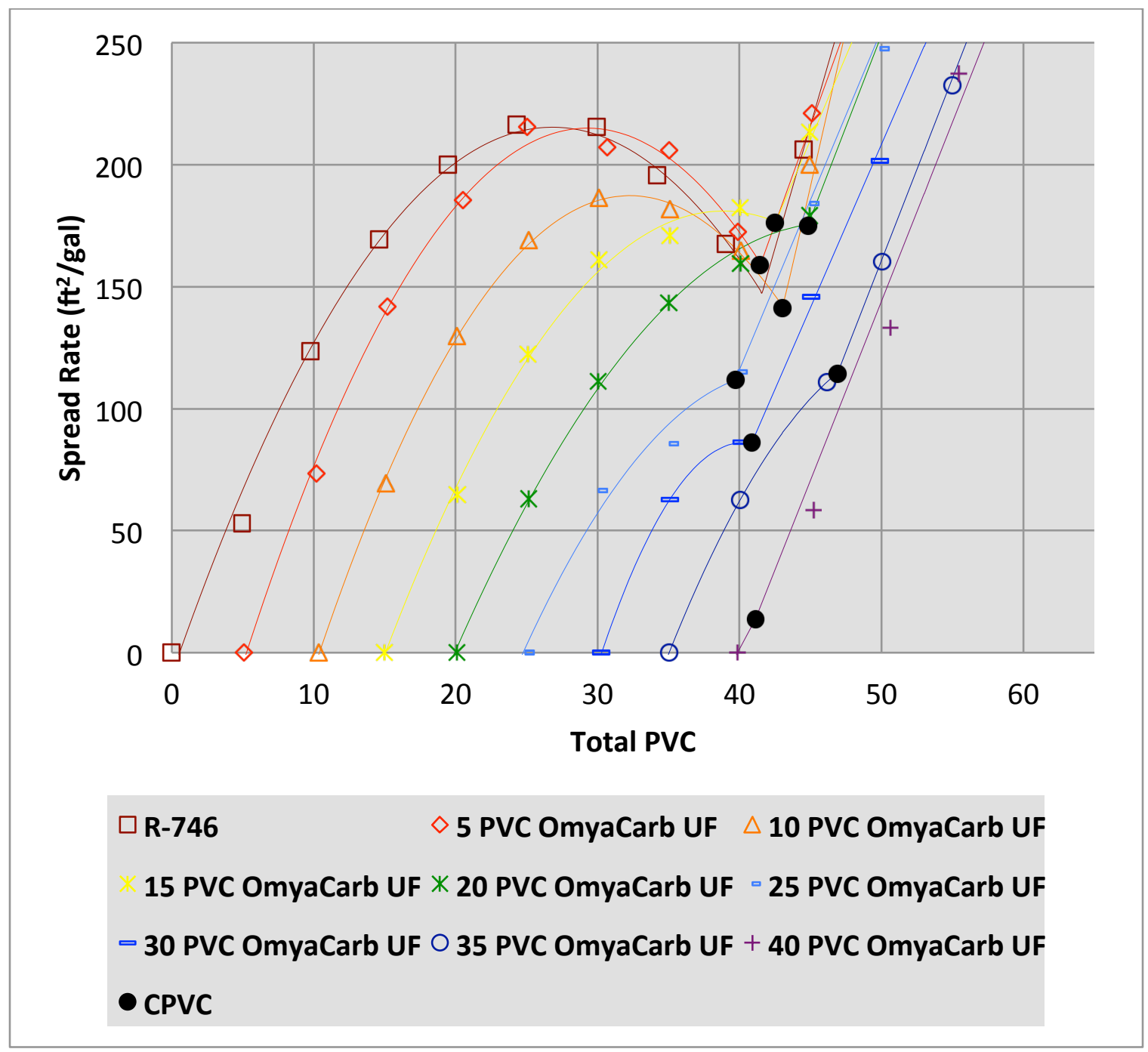

Figure 19: Spread Rate of PVC Ladders containing Omyacarb UF

Similar to the results with Omyacarb 15, an increase in Omyacarb UF PVC generally lowers the spread rate at when at a constant total PVC. One subtle difference with the model (plot) overlaps for Omyacarb UF, are that they are slightly more exacerbated. This is because the particle size difference is not as pronounced between the $\mathrm{TiO}_{2}(0.36 \mu \mathrm{m})$ and Omyacarb UF $(0.70 \mu \mathrm{m})$ particles compared to that of Omyacarb 15 $(15 \mu \mathrm{m})$. The likelihood of crowding in the interstitial sites of Omyacarb UF is lower as the void size is unable to accommodate multiple $\mathrm{TiO}_{2}$ particles without displacement of 
the extender particles. This allows for a more uniform dispersion of the $\mathrm{TiO}_{2}$ particles to reduce crowding effects, which can explain the increase of spread rate with lower $\mathrm{TiO}_{2}$ concentration. The replacement of up to 20 PVC Omyacarb UF below CPVC is rather significant, especially when considering the cost of $\mathrm{TiO}_{2}$.

Table 13: Omyacarb UF Replacement CPVC Values

\begin{tabular}{|l|c|c|c|c|c|c|c|c|c|}
\hline $\begin{array}{l}\text { Omyacarb UF } \\
\text { PVC }\end{array}$ & 0 & 5 & 10 & 15 & 20 & 25 & 30 & 35 & 40 \\
\hline CPVC & 41.6 & 41.5 & 43.0 & 42.5 & 44.8 & 39.7 & 40.9 & 46.9 & 41.1 \\
\hline
\end{tabular}

The CPVC range with for the paint sample containing Omyacarb UF presented in Table 13 are similar to one another unlike Omyacarb 15. Omyacarb UF is of the same size order of typical $\mathrm{TiO}_{2}$ pigment particles. Omyacarb UF essentially replaces $\mathrm{TiO}_{2}$ on a particle basis compared to Omyacarb 15 . The sizes of the void spaces are significantly smaller, which minimize the ability of $\mathrm{TiO}_{2}$ particles to fit and pack in them. As a result, crowding within the voids is unlikely, giving virtually no change to the surface area, which is the result of little to no change in the CPVC.

\subsubsection{Consideration of $\mathrm{TiO}_{2} \mathrm{PVC}$}

Simply stating that the spread rate decreases with additional extenders is misleading. Analysis so far was based on the total PVC. Omyacarb itself contributes little to the increase in spread rate, but influences the spread rate when used in conjunction with $\mathrm{TiO}_{2}$. The particular spread rate values are broken down to the particular concentrations of $\mathrm{TiO}_{2}$ and various Omyacarb grades in Table 14. Spread rate values above CPVC are highlighted because an additional mechanism contributes to the spread rate. Considering the differences in spread rate at constant $\mathrm{TiO}_{2} \mathrm{PVC}$ gives a better 
understanding of light scattering solely due to TiO2. Addition of Omyacarb for the most part did not improve the spread rate below CPVC. The initial addition of Omyacarb at low $\mathrm{TiO}_{2}$ concentration actually increased the spread rate. The increase is marginal for Omyacarb 15, but is more significant for Omyacarb UF. Again, this relates to alleviation of crowding as Omyacarb acts as spacers to extend the $\mathrm{TiO}_{2}$ interparticle distance to increase scattering efficiency. This reasoning can also explain why addition of Omyacarb UF results in a greater spread rate than Omyacarb 15. Spread rate plots comparing Omyacarb UF and Omyacarb 15 are provided in Appendix C: Comparison of Spread Rate Plots with Omyacarb Grades.

Table 14: Spread Rate Values - Omyacarb 15 (a) and Omyacarb UF (b)

\begin{tabular}{|c|c|c|c|c|c|c|c|c|c|c|}
\hline & \multicolumn{9}{|c|}{ Omyacarb 15 PVC } \\
\hline & & 0 & 5 & 10 & 15 & 20 & 25 & 30 & 35 & 40 \\
\hline \multirow{11}{*}{ 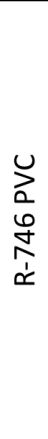 } & 0 & 0.00 & 0.00 & 0.00 & 0.00 & 0.00 & 0.00 & 0.00 & 0.00 & 0.00 \\
\hline & 5 & 53.08 & 54.11 & 55.03 & 72.12 & 54.80 & 63.18 & 56.20 & 43.05 & 38.94 \\
\hline & 10 & 123.57 & 126.13 & 125.78 & 128.32 & 95.79 & 102.34 & 89.94 & 73.62 & 72.83 \\
\hline & 15 & 169.19 & 160.91 & 166.97 & 164.15 & 129.38 & 127.64 & 111.50 & 87.67 & 97.30 \\
\hline & 20 & 200.11 & 196.06 & 181.88 & 182.29 & 141.27 & 138.25 & 121.73 & 110.44 & 120.82 \\
\hline & 25 & 216.59 & 210.99 & 188.88 & 189.76 & 157.79 & 149.84 & 148.10 & 150.28 & 164.41 \\
\hline & 30 & 215.56 & 207.76 & 180.51 & 176.29 & 164.55 & 173.37 & 185.10 & 193.55 & 233.88 \\
\hline & 35 & 195.59 & 182.86 & 184.85 & 207.55 & 212.31 & 223.24 & 234.01 & 244.69 & \\
\hline & 40 & 167.59 & 194.66 & 235.91 & 262.51 & 268.92 & 276.03 & 277.72 & & \\
\hline & 45 & 206.18 & 272.88 & & 344.68 & 326.72 & 316.81 & & \multirow{2}{*}{\multicolumn{2}{|c|}{ Above CPVC }} \\
\hline & 50 & 301.34 & 342.08 & & & & & & & \\
\hline
\end{tabular}

(a)

\begin{tabular}{|c|c|c|c|c|c|c|c|c|c|c|}
\hline & \multicolumn{9}{|c|}{ Omyacarb UF PVC } \\
\hline & & 0 & 5 & 10 & 15 & 20 & 25 & 30 & 35 & 40 \\
\hline \multirow{11}{*}{ 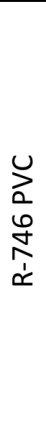 } & 0 & 0.00 & 0.00 & 0.00 & 0.00 & 0.00 & 0.00 & 0.00 & 0.00 & 0.00 \\
\hline & 5 & 53.08 & 73.28 & 69.36 & 64.80 & 63.13 & 66.27 & 62.80 & 62.60 & 58.37 \\
\hline & 10 & 123.57 & 141.61 & 129.75 & 122.38 & 111.35 & 85.72 & 86.12 & 110.89 & 133.27 \\
\hline & 15 & 169.19 & 185.44 & 168.98 & 161.03 & 143.56 & 115.12 & 145.87 & 160.27 & 237.28 \\
\hline & 20 & 200.11 & 215.56 & 186.29 & 170.97 & 159.52 & 184.02 & 201.49 & 232.41 & 319.79 \\
\hline & 25 & 216.59 & 207.23 & 181.56 & 182.37 & 179.00 & 247.52 & 271.43 & 315.58 & 359.91 \\
\hline & 30 & 215.56 & 205.87 & 164.68 & 213.42 & 250.25 & 324.63 & 356.44 & 387.28 & 423.07 \\
\hline & 35 & 195.59 & 172.34 & 200.11 & 272.70 & 329.89 & 410.70 & 417.86 & 454.20 & \\
\hline & 40 & 167.59 & 221.18 & 295.23 & 347.03 & 412.78 & 473.19 & 455.72 & \multirow{3}{*}{\multicolumn{2}{|c|}{ Above CPVC }} \\
\hline & 45 & 206.18 & 289.56 & 473.19 & 414.88 & 475.40 & 525.02 & & & \\
\hline & 50 & 301.34 & 382.19 & 563.50 & & & & & & \\
\hline
\end{tabular}




\subsubsection{Particle Size Effects on Resin Demand}

The paints can be thought of as a 3-part system, represented as a contour plot to relate the spread rate values at varying concentrations of the components. These contour plots for a 3-component system are typically referred to as contour ternary plots. CPVC values can also be compared throughout the PVC ladders to examine the impact of material demand as they are replaced with one another. In this case CPVC values can be compared together to determine the effect on resin demand.

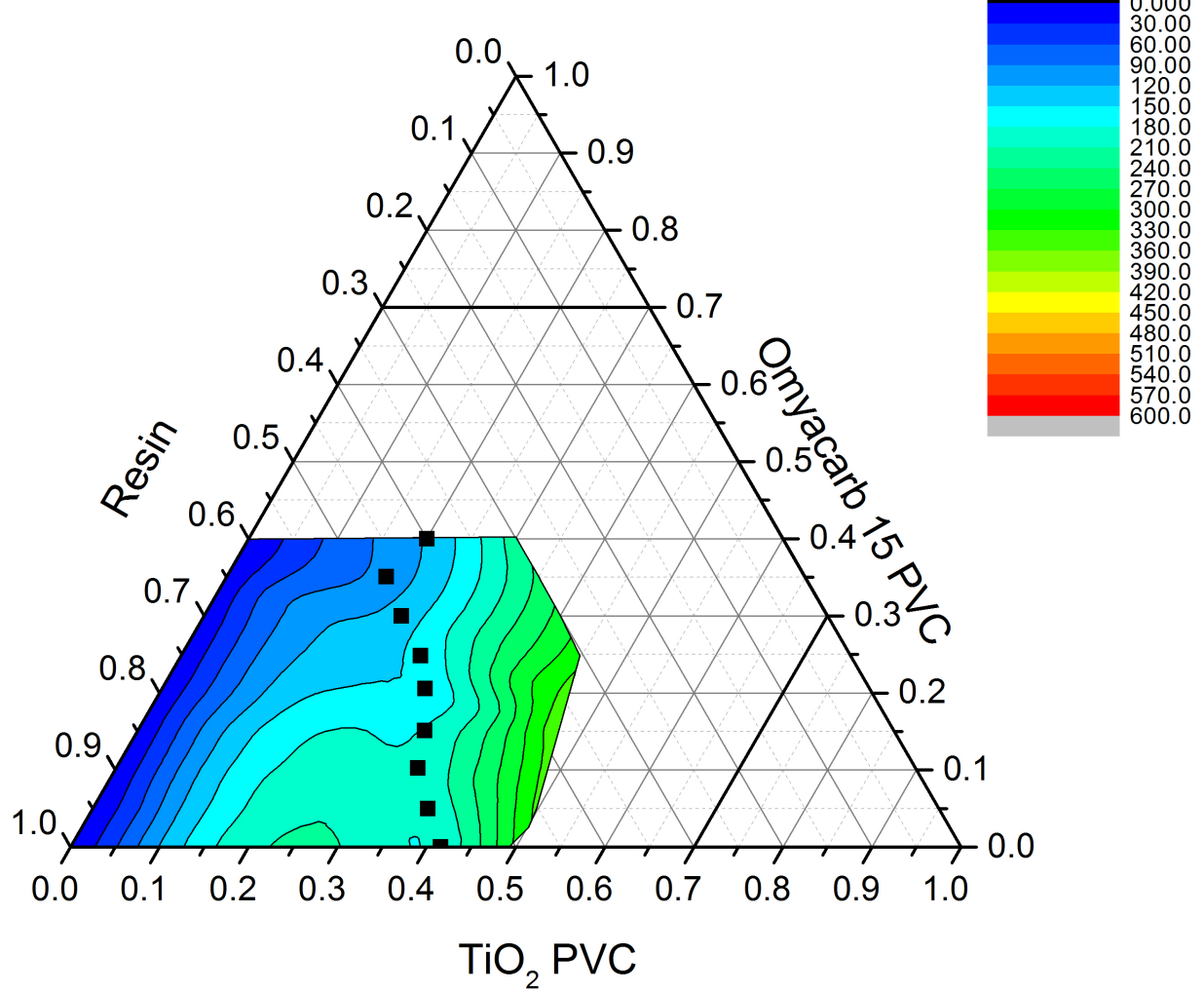

Figure 20: Omyacarb 15 Spread Rate Ternary Plot

The ternary plot with Omyacarb 15 is presented in Figure 20. Increasing PVC of Omyacarb 15 results in a lower resin demand. This can be explained again with packing 
of $\mathrm{TiO}_{2}$ particles within the interstitial voids created with the larger Omyacarb 15 particles. Within these voids, $\mathrm{TiO}_{2}$ particles can undergo crowding effects, which results in the lower spread rates compared to Omyacarb UF. Oil absorption tests support this argument and data. The decreased resin demand has provides a means to reduce materials cost as Omyacarb 15 is cheaper than the resin and $\mathrm{TiO}_{2}$.

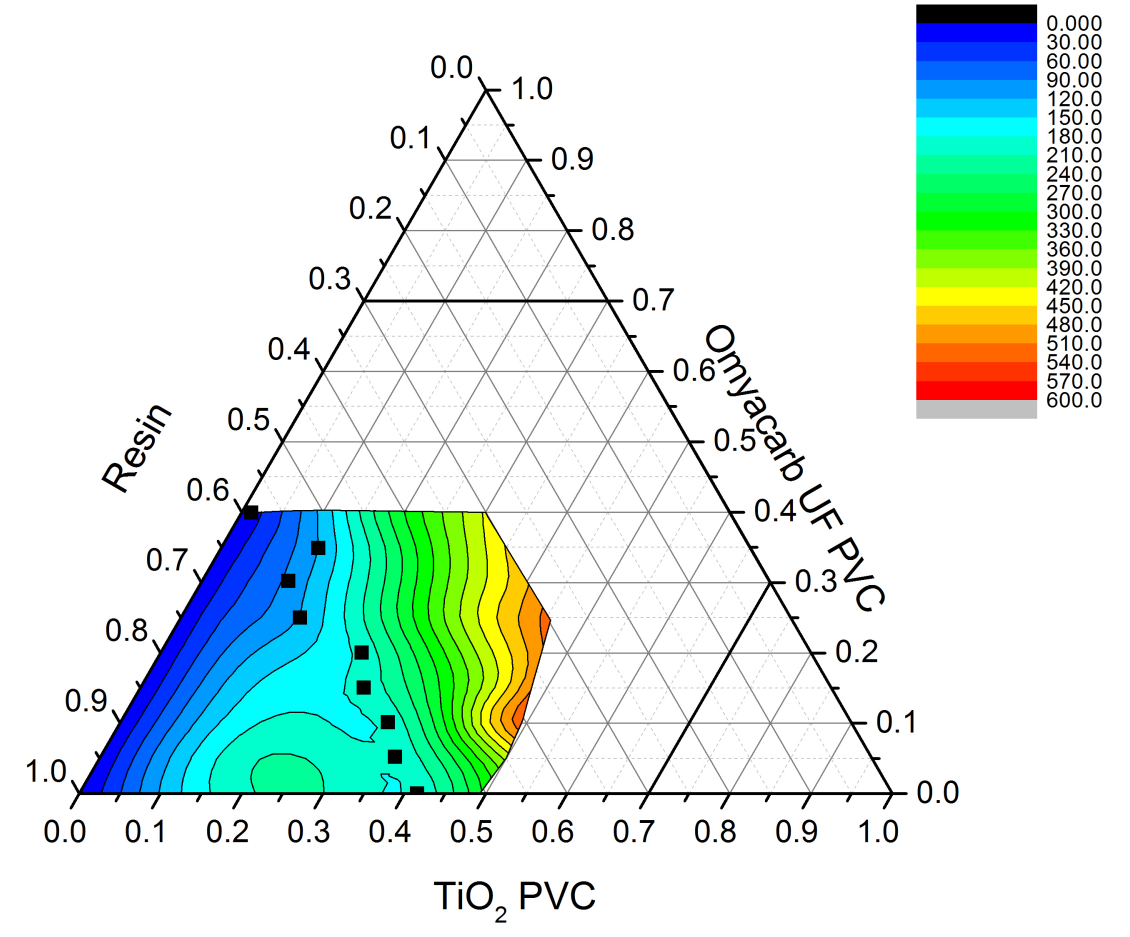

Figure 21: Omyacarb UF Spread Rate Ternary Plot

The ternary plot with Omyacarb UF is presented in Figure 21. Increasing Omyacarb UF PVC results in little to no change in resin demand. Again, since Omyacarb UF and the $\mathrm{TiO}_{2}$ particles are on the same size order, there is little change in volume when they are replaced with one another, thus resulting in little to no change in the resin demand. Unlike Omyacarb 15, there is no change in resin demand with small particles. 
When spread rate is taken into account however, increases are marginal to significant, especially at low $\mathrm{TiO}_{2}$ concentrations.

\subsection{Oil Absorption}

Table 15: Particle OA Values

\begin{tabular}{|l|l|l|}
\hline Particle & Particle Size $(\mu \mathrm{m})$ & OA Value \\
\hline R-706 (R-746) & 0.36 & 28 \\
\hline R-931 (R-741) & 0.55 & 45 \\
\hline Omyacarb UF & 0.70 & 36 \\
\hline Omyacarb 15 & 15.0 & 19 \\
\hline
\end{tabular}

The OA values for the $\mathrm{TiO}_{2}$ and Omyacarb particles are listed in Table 15. The general relationship between OA and particle size is that smaller particles have higher OA values resulting from the increased surface area to volume ratios. This relationship between the $\mathrm{TiO}_{2}$ and $\mathrm{CaCO}_{3}$ pigments was considered separately due to the different chemistries of the particles, which can drastically alter the OA value.

These OA tests were performed on a volume basis then converted to mass, which may have led to inaccurate OA values due to the quantity of pigment used for each test. Regardless of the accuracy of the data, the trends and relationships were of more significant concern to reaffirm the trends exhibited in the spread rate graphs.

The OA values for the different $\mathrm{TiO}_{2}$ particles do not follow the general trend. In the R-931 case, there is a fluffy alumino-silicate surface treatment, which can be though of as a partially porous surface treatment, which actually increases the surface area, causing the OA values to exceed what is expected. Omyacarb OA values conformed to the general relationship as the smaller Omyacarb UF particles was shown to have higher OA values. 


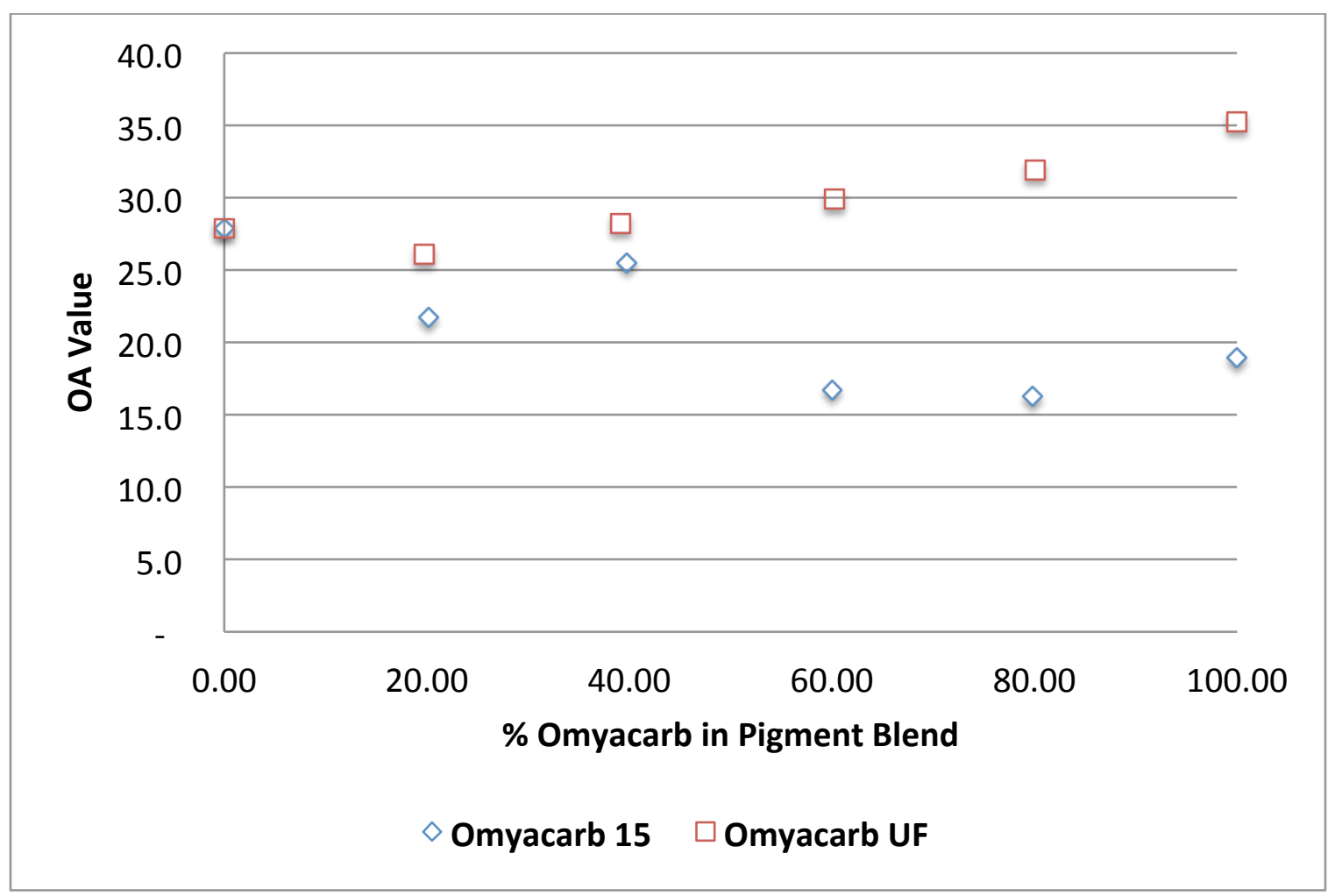

Figure 22: Pigment Blend OA Values

OA Values for the R-706/Omyacarb 15 and R-706/Omycarb UF pigment blends are plotted in Figure 22. Pigment blends containing Omyacarb 15 have particle sizes differences by an order of magnitude whereas blends containing Omyacarb UF have particle sizes on the same order of magnitude.

The Omyacarb UF pigment blend overall has a linear or close to linear relationship to its OA value. Since the particles are on the same size order, there is close to equal replacement of the particles with little to no displacement of the linseed oil. The slight increase in the OA value is result the different materials use in the pigment blend. When these OA values are converted to their CPVC values, they follow a similar trend to the modeled CPVC values. Both cases show little to no change in the CPVC values. The 
initial data point is considered an outlier in this situation due to limitations and variation of obtaining OA values by volume.

The Omyacarb 15 pigment blend does not appear to exhibit a linear relationship. The 40\% Omyacarb 15 data point is considered an outlier. Since the Omyacarb 15 particles are significantly larger in comparison to $\mathrm{R}-706$, the $\mathrm{TiO}_{2}$ particles are able to fit freely in the voids and undergo packing. This void space is therefore occupied when performing OA tests; lowering OA values. This trend is also reaffirmed when OA values are converted to CPVC values, which increase under both cases. 


\section{Conclusion}

The goal of this study was to examine the effect of different sized $\mathrm{CaCO}_{3}$ particles on $\mathrm{TiO}_{2}$ light scattering in coatings. Light scattering can be represented in terms of the contrast ratio and spread rate for each particular paint formulation. The contrast ratio is a direct means to measure light reflectance off a surface, which can result from light scattering off particles in the dry paint. As expected, $\mathrm{TiO}_{2}$ scatters light more than $\mathrm{CaCO}_{3}$ when comparing the contrast ratio. Replacement of $\mathrm{TiO}_{2}$ with $\mathrm{CaCO}_{3}$ reduces the contrast ratio as a result.

The DuPont Spread Rate Program is built upon Kubelka-Munk relationships, which allows extrapolation and interpolation of paint performance at complete hiding. Replacement of $\mathrm{TiO}_{2}$ with resin increases the spread rate of a paint formulation, but only at low levels. Additionally replacement of $\mathrm{TiO}_{2}$ with $\mathrm{CaCO}_{3}$ results in greater spread rate right under CPVC. When comparing replacement with the different Omyacarb grades, the increase is marginal with Omyacarb 15, but rather significant with Omyacarb UF. The initial increase is due to reduced crowding effects among the $\mathrm{TiO}_{2}$ particles as the Omyacarb particles act as spacers to extend the interparticle $\mathrm{TiO}_{2}$ distance, improving scattering which can be expressed as spread rate. Too much Omyacarb 15 recreates crowding within the extender voids. Above CPVC, the spread rate dramatically increases due to the presence of air voids in between the pigment particles.

The CPVC values were extrapolated from the Spread Rate plots showing trends between similar and different sized calcium carbonate particles. Addition of large particles increases the CPVC value, whereas addition of similar sized particle results in 
negligible changes in the CPVC. Again, this is due to the ability of the small particles fitting within the voids formed from the larger particle.

CPVC trends can also relate to the resin demand. Resin demand decreases with additional Omyacarb 15 . If a volume of a large particle replaces many smaller particles such that the volumes are equal, they do not necessarily occupy the same space. There is no real significant change in resin demand with Omyacarb UF. This is due to a substitution of one particle for another, where both occupy roughly the same volume.

The CPVC extrapolations trends among the Omyacarb 15 and UF models can be checked against OA values involving pigment blends. OA values for Omyacarb UF blends correlate with a fairly linear relationship due to being similar sized to $\mathrm{TiO}_{2}$. In the case of Omyacarb 15, the OA values decrease then marginally increase. Again, this is because the voids are big enough such that smaller particles are able to pack inside, displacing the linseed oil to lower the OA value.

This project report can be considered as a first study for the particular grades of $\mathrm{TiO}_{2}$ and $\mathrm{CaCO}_{3}$ used in this study. Additional PVC need to be made with nano-sized $\mathrm{CaCO}_{3}$ extenders in a similar manner such that packing of $\mathrm{TiO}_{2}$ can be studied with particles smaller than the pigment. PVC ladders were only made with the R-706 grade of $\mathrm{TiO}_{2}$ and it would be interesting to see the results if a highly surface treated R-931 grade was used instead. Viscosity was ignored, but could be taken into account, especially at high PVC in future studies. 


\section{References}

Asbeck, W. (1992). A Critical Look at CPVC Performance And Applications Properties. Journal of Coatings Technology, 64(806), 47-58.

Biermann, C. (1995). Construction of opacity charts. Tappi Journal, 78(1), 238-239.

Braun, J., Baidins, A., \& Marganski, R. (1992). TiO2 pigment technology a review. Progress in organic coatings, 20, 105-138.

Braun, J. H. (1993). Introduction to Pigments. Blue Bell, PA: Federation Series on Coatings Technology.

Brock, T., Groteklaes, M., \& Mischke, P. (2010). European Coatings Handbook (2nd ed.). Lamspringe, Germany: Quensen Druck.

Cardinal, C. M., Francis, L. F., \& Scriven, L. E. (2009). Drying and collapse of hollow latex. Journal of Coatings Technology and Research, 6(4), 457-469.

Chung, C.-J., Lin, H.-I., Tsou, H.-K., Shi, Z.-Y., \& He, J.-L. (2008). An antimicrobial $\mathrm{TiO} 2$ coating for reducing hospital-acquired infection. Journal of biomedical materials research. Part B, Applied biomaterials, 85(1), 220-4.

Davis, K. (1982). Chemical of the Month - Titanium Dioxide. Journal of Chemical Education, 59(2), 158-159.

DuPont. (2002). Effective Utilization of Titanium Dioxide. Wilmington, DE: DuPont Titanium Technologies.

DuPont. (2007). DuPont Ti-Pure Titanium Dioxide: Titanium Dioxide for Coatings.

Fasano, D., \& Adamson, L. (2012). Advancements in TiO2 Composite Technology. Paint \& Coatings Industry, 28(8), 28-34.

Gennadios, a., Hanna, M. a., \& Kurth, L. B. (1997). Application of Edible Coatings on Meats, Poultry and Seafoods: A Review. LWT - Food Science and Technology,

Goldschmidt, A., \& Streitberger, H.-J. (2007). BASF Handbook on Basics of Coating Technology. Paderborn, Germany: Bonifatius $\mathrm{GmbH}$.

Hanna, T. R. (2009). Predicting Paint Properties from TiO2 Pigment Properties. JCT Coatings Tech, 6(5), 26-31. 
Hergert, W., \& Wriedt, T. (2012). The Mie Theory. (W. Hergert \& T. Wriedt, Eds.) (1st ed., Vol. 169, pp. 53-71). Berlin, Heidelberg: Springer Berlin Heidelberg. doi:10.1007/978-3-642-28738-1

Hunter, R., \& Harold, R. (1987). The Measurement of Appearance, 2nd Edition (p. 90). New York: John Wiley \& Sons, Inc.

Painter, P. C., \& Coleman, M. M. (2000). Fundamentals of Polymer Science (2nd ed.). Boca Raton, Florida.

Thiele, E., \& French, R. (1998). Light Scattering Properties of Representative, Morphological Rutile Titania Particles Studied Using a Finite Element Method. Journal of the American Ceramic Society, 81(3), 469-479.

Thiele, E. S., \& French, R. H. (1998). Computation of Light Scattering by Anisotropic Spheres of Rutile Titania. Advanced Materials, 10(15), 1271-1276.

Wicks, Z. W., Jones, F. N., Pappas, S. P., \& Wicks, D. A. (2007). Organic Coatings: Science and Technology (3rd ed.). Hoboken, NJ: Wiley.

Winkler, J. (2003). Titanium Dioxide. Hanover, Germany: Vincentz Network.

Xing, Y., Li, X., Zhang, L., Xu, Q., Che, Z., Li, W., Bai, Y., et al. (2012). Effect of TiO2 nanoparticles on the antibacterial and physical properties of polyethylene-based film. Progress in Organic Coatings, 73(2-3), 219-224. 


\section{Appendix A: Oiled Contrast Ratios}

\begin{tabular}{|c|c|c|c|l|l|}
\hline \multicolumn{2}{|c|}{ PVC } & \multicolumn{3}{c|}{ Contrast Ratio } & \multicolumn{2}{c|}{ Status } \\
\hline $\begin{array}{c}\text { Omyacarb } \\
15\end{array}$ & R-746 & Initial & Oiled & Change & Above/Below CVPC \\
\hline 20 & 30 & 0.8949 & 0.8816 & 0.0133 & Below \\
\hline 20 & 35 & 0.9196 & 0.8874 & 0.0322 & Above \\
\hline 25 & 25 & 0.8739 & 0.8618 & 0.0121 & Below \\
\hline 25 & 30 & 0.8971 & 0.8740 & 0.0231 & Above \\
\hline 30 & 20 & 0.8470 & 0.8313 & 0.0157 & Below \\
\hline 30 & 25 & 0.8687 & 0.8454 & 0.0233 & Above \\
\hline 35 & 15 & 0.8188 & 0.8029 & 0.0159 & Below \\
\hline 35 & 20 & 0.8416 & 0.8208 & 0.0208 & Above \\
\hline 40 & 15 & 0.8082 & 0.7906 & 0.0176 & Below \\
\hline 40 & 20 & 0.8522 & 0.8080 & 0.0442 & Above \\
\hline
\end{tabular}

\begin{tabular}{|c|c|l|l|l|l|}
\hline \multicolumn{2}{|c|}{ PVC } & \multicolumn{3}{c|}{ Contrast Ratio } & \multicolumn{1}{c|}{ Status } \\
\hline $\begin{array}{c}\text { Omyacarb } \\
\text { UF }\end{array}$ & R-746 & Initial & Oiled & Change & Above/Below CVPC \\
\hline 20 & 20 & 0.9019 & 0.8963 & 0.0056 & Below \\
\hline 20 & 25 & 0.9158 & 0.9081 & 0.0077 & Below \\
\hline 20 & 30 & 0.9370 & 0.9120 & 0.0251 & Above \\
\hline 25 & 15 & 0.8701 & 0.8618 & 0.0083 & Below \\
\hline 25 & 20 & 0.9110 & 0.8866 & 0.0244 & Above \\
\hline 30 & 10 & 0.8220 & 0.8140 & 0.0080 & Below \\
\hline 30 & 15 & 0.8836 & 0.8589 & 0.0246 & Above \\
\hline 35 & 0 & 0.1032 & 0.0599 & 0.0433 & Above (extender only) \\
\hline 35 & 5 & 0.7054 & 0.6831 & 0.0223 & Below \\
\hline 35 & 10 & 0.8591 & 0.8317 & 0.0275 & Below \\
\hline 35 & 15 & 0.8980 & 0.8545 & 0.0435 & Above \\
\hline 35 & 20 & 0.9317 & 0.8832 & 0.0484 & Above \\
\hline 40 & 0 & 0.1381 & 0.0721 & 0.0659 & Above (extender only) \\
\hline 40 & 5 & 0.7224 & 0.6860 & 0.0364 & Below \\
\hline 40 & 10 & 0.8691 & 0.8062 & 0.0629 & Above \\
\hline 40 & 15 & 0.9310 & 0.8676 & 0.0635 & Above \\
\hline
\end{tabular}


Appendix B: Pigment Contrast Ratio Plot

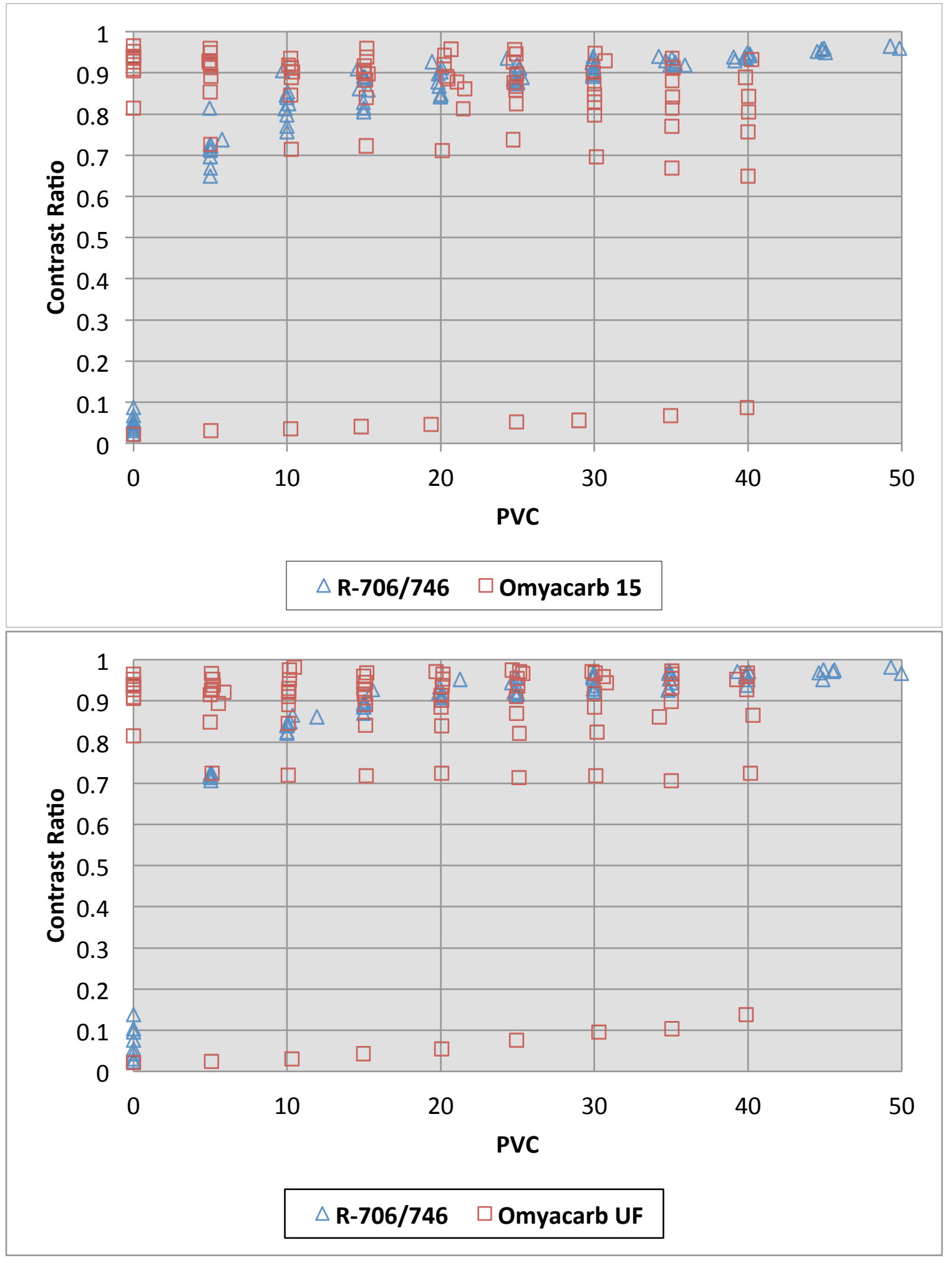


Appendix C: Comparison of Spread Rate Plots with Omyacarb Grades

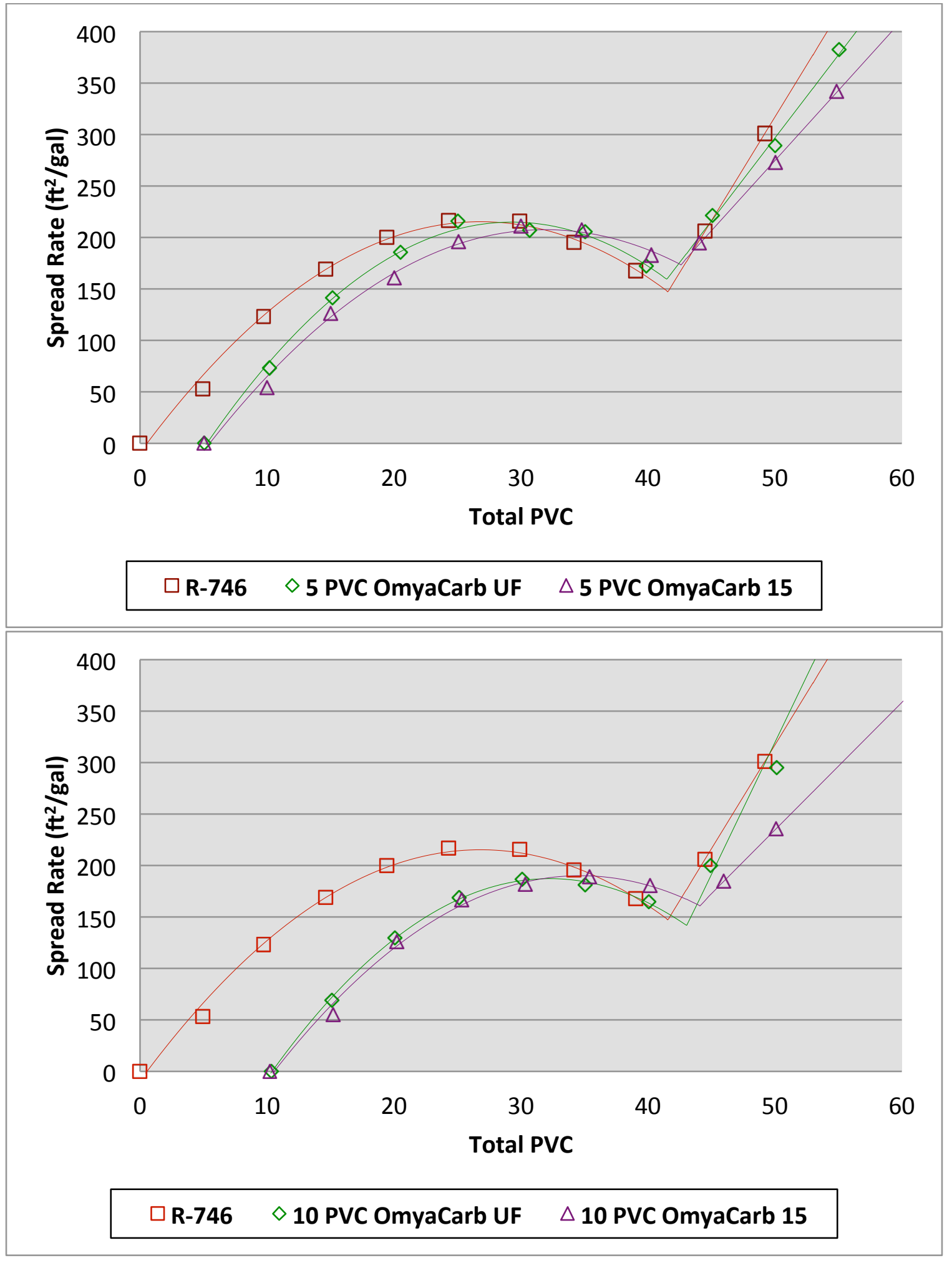



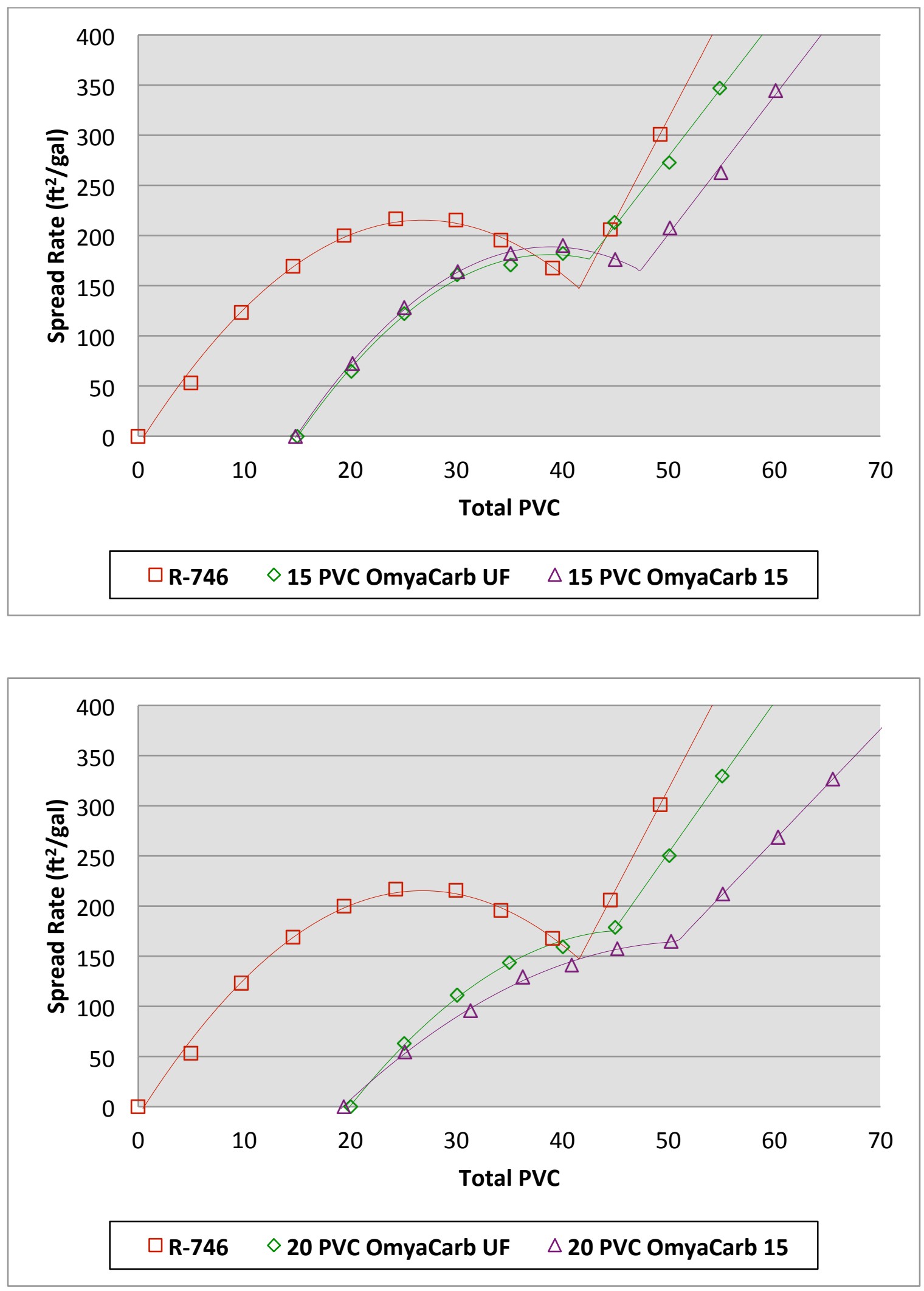

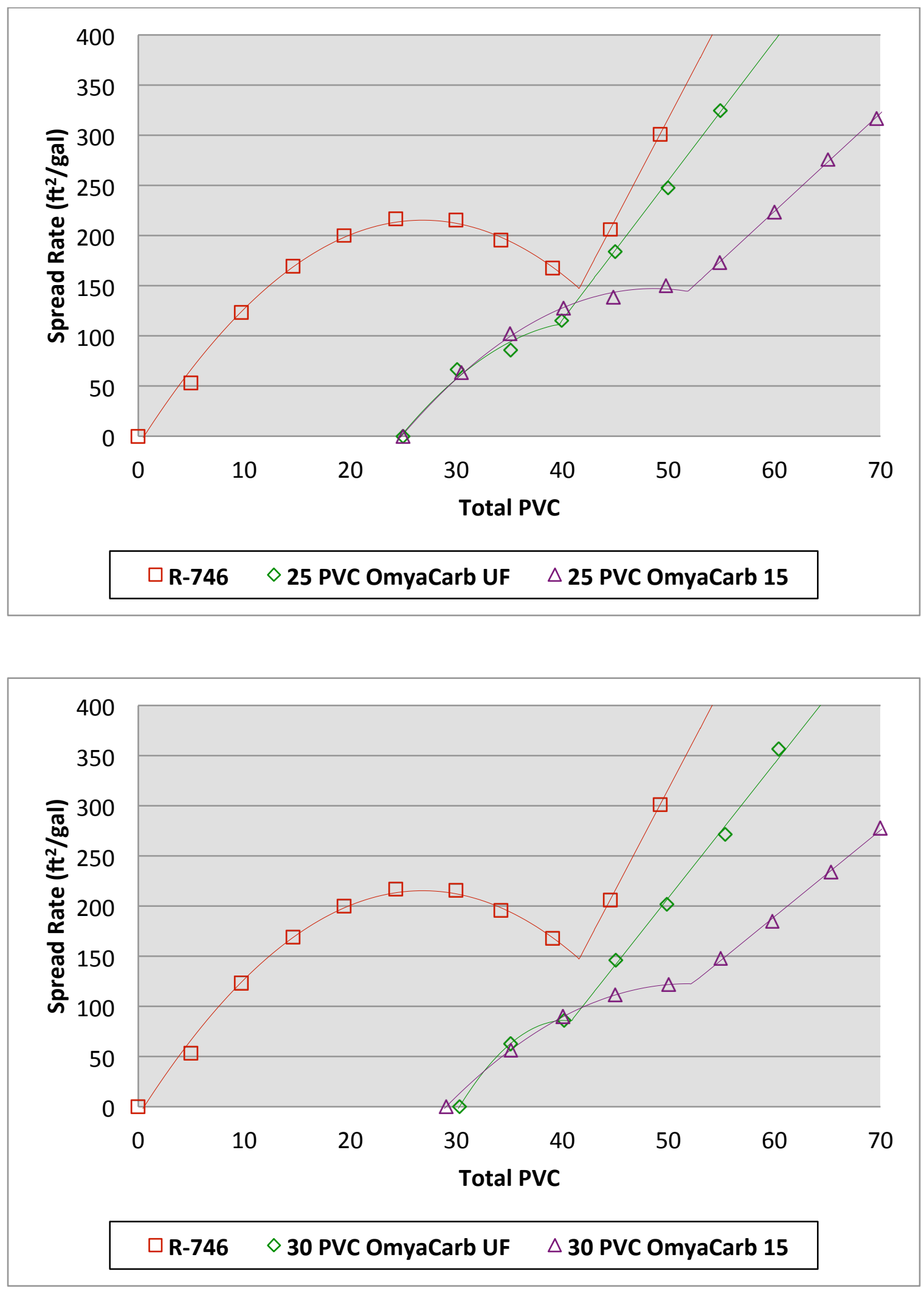

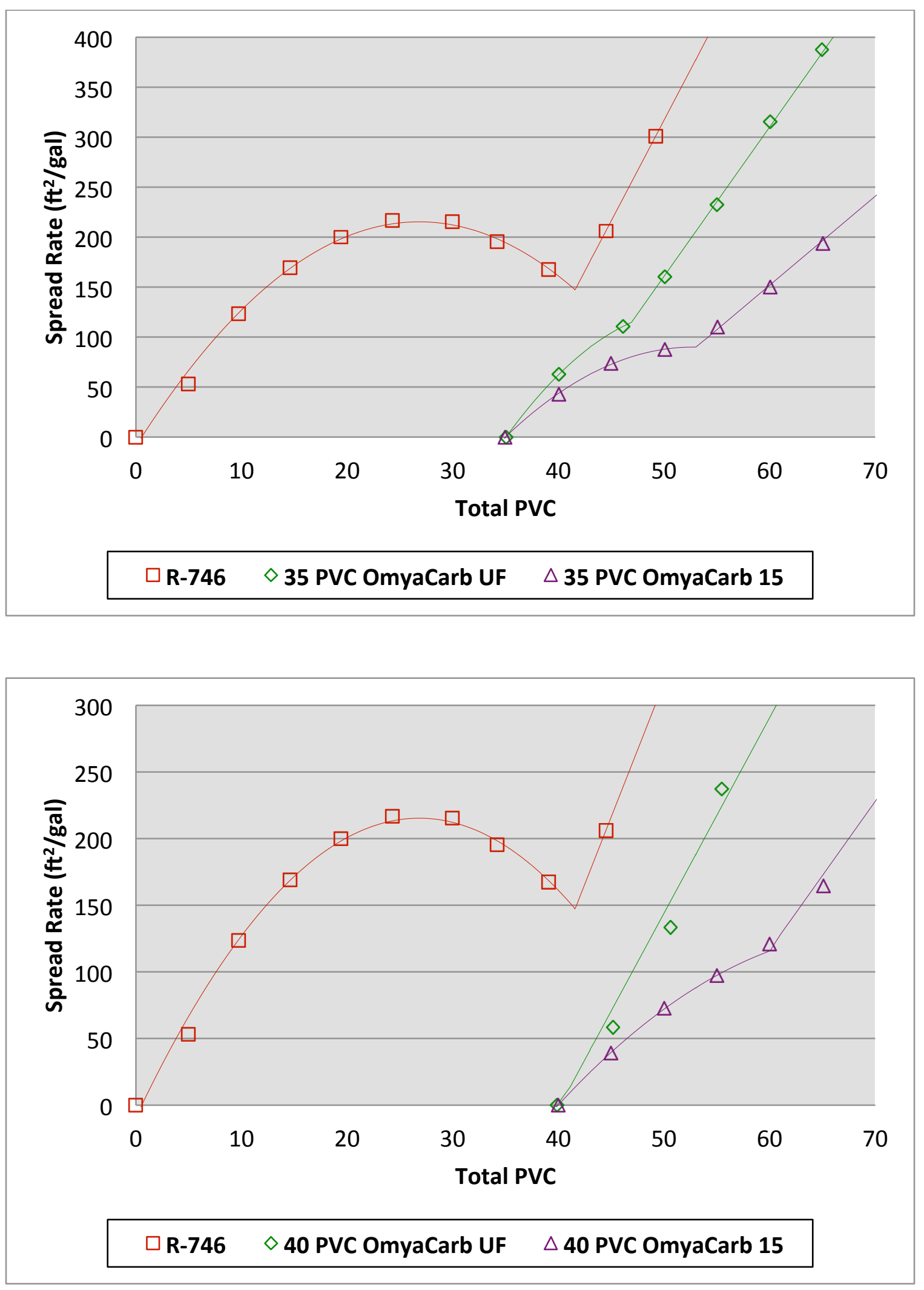


\section{Appendix D: Paint Drawdown Raw Data - $\mathrm{TiO}_{2}$ Only}

\begin{tabular}{|c|c|c|c|c|c|c|c|c|}
\hline $\begin{array}{l}\mathrm{TiO}_{2} \\
\mathrm{PVC}\end{array}$ & $\begin{array}{l}\text { Extender } \\
\text { PVC }\end{array}$ & Resin & $\begin{array}{c}\text { Paint } \\
\text { Density } \\
{[\text { lbs/gal] }}\end{array}$ & $\begin{array}{c}\mathrm{TiO}_{2} \\
\text { Content } \\
{[\text { lbs/gal] }}\end{array}$ & $\begin{array}{c}\mathrm{R} \text { o } \\
\text { White }\end{array}$ & $\begin{array}{c}\text { R o } \\
\text { Black }\end{array}$ & $\begin{array}{l}\text { Weight } \\
\text { [grams] }\end{array}$ & $\begin{array}{c}\text { S Rate } \\
{\left[\mathrm{ft}^{\wedge} 2 / \mathrm{gal}\right]}\end{array}$ \\
\hline \multicolumn{9}{|l|}{ R-746 } \\
\hline 0.00 & 0.00 & 100.00 & & & & & & 0.00 \\
\hline 4.95 & 0.00 & 95.05 & 8.81 & 0.38 & 0.88 & 0.72 & 4.00 & 53.08 \\
\hline 9.72 & 0.00 & 90.28 & 9.10 & 0.72 & 0.90 & 0.82 & 4.16 & 123.57 \\
\hline 14.60 & 0.00 & 85.40 & 9.40 & 1.11 & 0.90 & 0.82 & 3.28 & 169.19 \\
\hline 19.44 & 0.00 & 80.56 & 9.64 & 1.47 & 0.91 & 0.84 & 3.40 & 200.11 \\
\hline 24.30 & 0.00 & 75.70 & 9.89 & 1.84 & 0.92 & 0.86 & 3.52 & 216.59 \\
\hline 29.93 & 0.00 & 70.07 & 10.15 & 2.28 & 0.92 & 0.87 & 3.67 & 215.56 \\
\hline 34.19 & 0.00 & 65.81 & 10.32 & 2.58 & 0.93 & 0.87 & 3.75 & 195.59 \\
\hline 39.05 & 0.00 & 60.95 & 10.52 & 2.94 & 0.93 & 0.87 & 3.81 & 167.59 \\
\hline 44.50 & 0.00 & 55.50 & 10.72 & 3.37 & 0.94 & 0.90 & 3.88 & 206.18 \\
\hline 49.22 & 0.00 & 50.78 & 10.90 & 3.70 & 0.95 & 0.91 & 3.93 & 301.34 \\
\hline \multicolumn{9}{|l|}{ R-741 } \\
\hline 0.00 & 0.00 & 100.00 & & & & & & 0.00 \\
\hline 5.01 & 0.00 & 94.99 & 8.81 & 0.35 & 0.86 & 0.52 & 2.68 & 53.92 \\
\hline 10.01 & 0.00 & 89.99 & 8.98 & 0.88 & 0.87 & 0.69 & 2.79 & 89.60 \\
\hline 15.02 & 0.00 & 84.98 & 9.24 & 1.31 & 0.89 & 0.77 & 2.93 & 123.46 \\
\hline 20.05 & 0.00 & 79.95 & 9.47 & 1.75 & 0.90 & 0.82 & 3.03 & 162.38 \\
\hline 25.01 & 0.00 & 74.99 & 9.71 & 2.19 & 0.91 & 0.84 & 3.12 & 186.20 \\
\hline 30.00 & 0.00 & 70.00 & 9.89 & 2.63 & 0.92 & 0.86 & 3.22 & 193.64 \\
\hline 35.93 & 0.00 & 64.07 & 10.17 & 3.19 & 0.93 & 0.89 & 3.34 & 297.60 \\
\hline 40.07 & 0.00 & 59.93 & 10.33 & 3.50 & 0.94 & 0.91 & 3.32 & 391.74 \\
\hline 44.93 & 0.00 & 55.07 & 10.55 & 3.93 & 0.95 & 0.93 & 3.37 & 506.73 \\
\hline 49.95 & 0.00 & 50.05 & 10.73 & 4.39 & 0.96 & 0.94 & 3.43 & 648.75 \\
\hline
\end{tabular}




\section{Appendix E: Paint Drawdown Raw Data - Omyacarb 15}

\begin{tabular}{|c|c|c|c|c|c|c|c|c|}
\hline $\mathrm{TiO}_{2} \mathrm{PVC}$ & $\begin{array}{l}\text { Extender } \\
\text { PVC }\end{array}$ & Resin & $\begin{array}{c}\text { Paint } \\
\text { Density } \\
\text { [lbs/gal] }\end{array}$ & $\begin{array}{c}\mathrm{TiO}_{2} \\
\text { Content } \\
{[\mathrm{lbs} / \mathrm{gal}]}\end{array}$ & $\begin{array}{c}\mathrm{R} \text { o } \\
\text { White }\end{array}$ & $\begin{array}{c}\mathrm{R} \mathrm{o} \\
\text { Black }\end{array}$ & $\begin{array}{l}\text { Weight } \\
\text { [grams] }\end{array}$ & $\begin{array}{c}\text { S Rate } \\
{\left[\mathrm{ft}^{\wedge} 2 / \mathrm{gal}\right]}\end{array}$ \\
\hline \multicolumn{9}{|l|}{$5 \%$ O15 } \\
\hline 0.00 & 5.04 & 94.96 & & & & & & 0.00 \\
\hline 4.97 & 4.79 & 90.24 & 8.96 & 0.37 & 0.86 & 0.62 & 2.70 & 50.57 \\
\hline 10.02 & 4.53 & 85.45 & 9.20 & 0.74 & 0.88 & 0.75 & 2.80 & 123.72 \\
\hline 14.99 & 4.28 & 80.73 & 9.48 & 1.10 & 0.90 & 0.80 & 2.94 & 167.04 \\
\hline 20.03 & 4.03 & 75.94 & 9.69 & 1.47 & 0.90 & 0.82 & 3.01 & 196.72 \\
\hline 25.03 & 3.78 & 71.19 & 9.95 & 1.84 & 0.91 & 0.83 & 3.10 & 203.20 \\
\hline 30.01 & 3.53 & 66.46 & 10.15 & 2.21 & 0.91 & 0.84 & 3.25 & 204.12 \\
\hline 36.30 & 3.21 & 60.49 & 10.34 & 2.73 & 0.92 & 0.85 & 3.28 & 186.29 \\
\hline 39.97 & 3.03 & 57.00 & 10.50 & 2.94 & 0.92 & 0.86 & 3.30 & 193.73 \\
\hline 45.07 & 2.77 & 52.16 & 10.69 & 3.32 & 0.93 & 0.88 & 3.34 & 246.17 \\
\hline 50.17 & 2.51 & 47.32 & 10.97 & 3.71 & 0.94 & 0.90 & 3.38 & 327.77 \\
\hline \multicolumn{9}{|l|}{ 5PVC O15 } \\
\hline 0.00 & 5.04 & 94.96 & & & & & & 0.00 \\
\hline 5.00 & 5.01 & 89.99 & 8.99 & 0.37 & 0.87 & 0.63 & 2.81 & 54.11 \\
\hline 10.02 & 4.99 & 84.99 & 9.21 & 0.74 & 0.89 & 0.76 & 2.89 & 126.13 \\
\hline 14.98 & 5.04 & 79.98 & 9.51 & 1.10 & 0.90 & 0.80 & 3.02 & 160.91 \\
\hline 20.08 & 5.02 & 74.91 & 9.70 & 1.48 & 0.90 & 0.83 & 3.12 & 196.06 \\
\hline 25.00 & 5.02 & 69.99 & 9.93 & 1.84 & 0.91 & 0.83 & 3.16 & 210.99 \\
\hline 29.84 & 4.95 & 65.22 & 10.15 & 2.21 & 0.91 & 0.84 & 3.30 & 207.76 \\
\hline 35.26 & 5.01 & 59.72 & 10.36 & 2.60 & 0.92 & 0.84 & 3.32 & 182.86 \\
\hline 39.13 & 4.91 & 55.96 & 10.48 & 2.95 & 0.92 & 0.86 & 3.36 & 194.66 \\
\hline 45.04 & 5.02 & 49.94 & 10.93 & 3.33 & 0.93 & 0.88 & 3.36 & 272.88 \\
\hline 49.85 & 4.99 & 45.17 & 11.24 & 3.68 & 0.94 & 0.90 & 3.43 & 342.08 \\
\hline \multicolumn{9}{|l|}{$10 \% \mathrm{O} 15$} \\
\hline 0.00 & 10.24 & 89.76 & & & & & & 0.00 \\
\hline 5.08 & 9.72 & 85.20 & 9.12 & 0.37 & 0.86 & 0.62 & 2.85 & 71.79 \\
\hline 9.96 & 9.22 & 80.82 & 9.32 & 0.73 & 0.88 & 0.74 & 2.94 & 128.77 \\
\hline 14.97 & 8.71 & 76.33 & 9.57 & 1.10 & 0.89 & 0.79 & 3.00 & 169.26 \\
\hline 19.96 & 8.20 & 71.84 & 9.79 & 1.47 & 0.90 & 0.82 & 3.17 & 191.90 \\
\hline
\end{tabular}




\begin{tabular}{|c|c|c|c|c|c|c|c|c|}
\hline $\mathrm{TiO}_{2} \mathrm{PVC}$ & $\begin{array}{l}\text { Extender } \\
\text { PVC }\end{array}$ & Resin & $\begin{array}{c}\text { Paint } \\
\text { Density } \\
{[\text { lbs/gal }]}\end{array}$ & $\begin{array}{c}\mathrm{TiO}_{2} \\
\text { Content } \\
{[\mathrm{lbs} / \mathrm{gal}]}\end{array}$ & $\begin{array}{c}\mathrm{R} \text { o } \\
\text { White }\end{array}$ & $\begin{array}{c}\text { R o } \\
\text { Black }\end{array}$ & $\begin{array}{l}\text { Weight } \\
\text { [grams] }\end{array}$ & $\begin{array}{c}\text { S Rate } \\
{\left[\mathrm{ft}^{\wedge} 2 / \mathrm{gal}\right]}\end{array}$ \\
\hline 25.10 & 7.67 & 67.23 & 10.10 & 1.85 & 0.90 & 0.83 & 3.26 & 209.68 \\
\hline 30.06 & 7.16 & 62.78 & 10.26 & 2.21 & 0.91 & 0.84 & 3.31 & 203.71 \\
\hline 35.26 & 6.63 & 58.11 & 10.36 & 2.60 & 0.91 & 0.84 & 3.28 & 176.22 \\
\hline 39.96 & 6.15 & 53.89 & 10.68 & 2.96 & 0.92 & 0.86 & 3.26 & 213.53 \\
\hline 45.01 & 5.63 & 49.36 & 10.86 & 3.32 & 0.93 & 0.88 & 3.29 & 256.24 \\
\hline \multicolumn{9}{|l|}{ 10PVC O15 } \\
\hline 0.00 & 10.24 & 89.76 & & & & & & 0.00 \\
\hline 4.98 & 10.25 & 84.76 & 9.13 & 0.37 & 0.86 & 0.62 & 2.80 & 55.03 \\
\hline 9.97 & 10.24 & 79.78 & 9.39 & 0.74 & 0.88 & 0.75 & 2.97 & 125.78 \\
\hline 15.06 & 10.27 & 74.67 & 9.68 & 1.11 & 0.89 & 0.79 & 3.13 & 166.97 \\
\hline 20.00 & 10.35 & 69.65 & 9.84 & 1.48 & 0.90 & 0.81 & 3.17 & 181.88 \\
\hline 25.15 & 10.25 & 64.61 & 10.01 & 1.86 & 0.90 & 0.82 & 3.27 & 188.88 \\
\hline 29.92 & 10.25 & 59.83 & 10.23 & 2.21 & 0.91 & 0.83 & 3.35 & 180.51 \\
\hline 35.91 & 10.08 & 54.01 & 10.42 & 2.69 & 0.91 & 0.84 & 3.32 & 184.85 \\
\hline 39.87 & 10.24 & 49.89 & 10.73 & 2.94 & 0.92 & 0.86 & 3.41 & 235.91 \\
\hline \multicolumn{9}{|l|}{$15 \% \mathrm{O} 15$} \\
\hline 0.00 & 14.85 & 85.15 & & & & & & 0.00 \\
\hline 5.00 & 14.10 & 80.89 & 9.23 & 0.37 & 0.86 & 0.61 & 2.88 & 60.68 \\
\hline 10.01 & 13.36 & 76.63 & 9.46 & 0.74 & 0.88 & 0.73 & 2.92 & 120.93 \\
\hline 15.03 & 12.61 & 72.36 & 9.65 & 1.11 & 0.89 & 0.79 & 3.08 & 162.19 \\
\hline 20.00 & 11.88 & 68.12 & 9.85 & 1.47 & 0.89 & 0.81 & 3.17 & 182.37 \\
\hline 24.99 & 11.14 & 63.87 & 10.11 & 1.84 & 0.90 & 0.82 & 3.24 & 195.50 \\
\hline 30.21 & 10.36 & 59.43 & 10.34 & 2.24 & 0.90 & 0.83 & 3.29 & 195.40 \\
\hline 34.95 & 9.66 & 55.40 & 10.48 & 2.58 & 0.91 & 0.83 & 3.29 & 193.73 \\
\hline 39.82 & 8.93 & 51.25 & 10.61 & 2.94 & 0.92 & 0.86 & 3.26 & 243.38 \\
\hline \multicolumn{9}{|l|}{ 15PVC O15 } \\
\hline 0.00 & 14.85 & 85.15 & & & & & & 0.00 \\
\hline 5.07 & 15.14 & 79.79 & 9.25 & 0.37 & 0.85 & 0.62 & 2.90 & 72.12 \\
\hline 9.97 & 15.14 & 74.88 & 9.52 & 0.74 & 0.87 & 0.73 & 2.99 & 128.32 \\
\hline 15.04 & 15.08 & 69.87 & 9.74 & 1.11 & 0.88 & 0.78 & 3.12 & 164.15 \\
\hline 19.83 & 15.28 & 64.89 & 9.96 & 1.47 & 0.89 & 0.80 & 3.21 & 182.29 \\
\hline 24.99 & 15.03 & 59.98 & 10.20 & 1.84 & 0.89 & 0.81 & 3.21 & 189.76 \\
\hline
\end{tabular}




\begin{tabular}{|c|c|c|c|c|c|c|c|c|}
\hline $\mathrm{TiO}_{2} \mathrm{PVC}$ & $\begin{array}{l}\text { Extender } \\
\text { PVC }\end{array}$ & Resin & $\begin{array}{c}\text { Paint } \\
\text { Density } \\
{[\text { lbs/gal }]}\end{array}$ & $\begin{array}{c}\mathrm{TiO}_{2} \\
\text { Content } \\
{[\mathrm{lbs} / \mathrm{gal}]}\end{array}$ & $\begin{array}{c}\mathrm{R} \text { o } \\
\text { White }\end{array}$ & $\begin{array}{c}\text { R o } \\
\text { Black }\end{array}$ & $\begin{array}{l}\text { Weight } \\
\text { [grams] }\end{array}$ & $\begin{array}{c}\text { S Rate } \\
{\left[\mathrm{ft}^{\wedge} 2 / \mathrm{gal}\right]}\end{array}$ \\
\hline 29.97 & 15.00 & 55.03 & 10.27 & 2.21 & 0.90 & 0.81 & 3.19 & 176.29 \\
\hline 35.13 & 15.03 & 49.83 & 10.50 & 2.59 & 0.90 & 0.83 & 3.23 & 207.55 \\
\hline 39.80 & 15.17 & 45.03 & 10.74 & 2.94 & 0.91 & 0.86 & 3.31 & 262.51 \\
\hline 44.93 & 15.21 & 39.87 & 11.05 & 3.31 & 0.93 & 0.89 & 3.45 & 344.68 \\
\hline \multicolumn{9}{|l|}{$20 \% \mathrm{O} 15$} \\
\hline 0.00 & 19.37 & 80.63 & & & & & & 0.00 \\
\hline 5.02 & 18.40 & 76.58 & 9.34 & 0.37 & 0.85 & 0.61 & 2.92 & 64.35 \\
\hline 9.98 & 17.44 & 72.58 & 9.44 & 0.74 & 0.87 & 0.72 & 2.98 & 111.44 \\
\hline 15.04 & 16.46 & 68.50 & 9.73 & 1.11 & 0.89 & 0.78 & 3.11 & 153.92 \\
\hline 20.04 & 15.49 & 64.47 & 9.93 & 1.47 & 0.89 & 0.80 & 3.17 & 173.22 \\
\hline 24.99 & 14.53 & 60.48 & 10.17 & 1.84 & 0.89 & 0.81 & 3.21 & 180.59 \\
\hline 29.99 & 13.56 & 56.45 & 10.28 & 2.20 & 0.90 & 0.81 & 3.21 & 170.97 \\
\hline 35.05 & 12.58 & 52.37 & 10.58 & 2.58 & 0.91 & 0.83 & 3.25 & 199.42 \\
\hline 40.06 & 11.61 & 48.33 & 10.61 & 2.95 & 0.91 & 0.85 & 3.27 & 230.83 \\
\hline 45.01 & 10.65 & 44.34 & 10.84 & 3.31 & 0.92 & 0.88 & 3.27 & 295.23 \\
\hline \multicolumn{9}{|l|}{20 PVC 015} \\
\hline 0.00 & 19.37 & 80.63 & & & & & & 0.00 \\
\hline 5.03 & 20.12 & 74.85 & 9.35 & 0.37 & 0.86 & 0.61 & 3.00 & 54.80 \\
\hline 9.87 & 21.46 & 68.67 & 9.61 & 0.74 & 0.87 & 0.71 & 3.16 & 95.79 \\
\hline 14.69 & 21.55 & 63.76 & 9.91 & 1.11 & 0.88 & 0.76 & 3.28 & 129.38 \\
\hline 19.80 & 21.07 & 59.14 & 9.97 & 1.49 & 0.89 & 0.78 & 3.28 & 141.27 \\
\hline 24.73 & 20.47 & 54.80 & 10.21 & 1.84 & 0.89 & 0.79 & 3.29 & 157.79 \\
\hline 29.88 & 20.38 & 49.74 & 10.33 & 2.21 & 0.89 & 0.80 & 3.26 & 164.55 \\
\hline 34.92 & 20.20 & 44.88 & 10.61 & 2.58 & 0.90 & 0.83 & 3.35 & 212.31 \\
\hline 40.09 & 20.23 & 39.68 & 10.93 & 2.95 & 0.91 & 0.86 & 3.45 & 268.92 \\
\hline 44.79 & 20.69 & 34.53 & 11.31 & 3.34 & 0.92 & 0.88 & 3.64 & 326.72 \\
\hline \multicolumn{9}{|l|}{$25 \%$ O15 } \\
\hline 0.00 & 24.96 & 75.04 & & & & & & 0.00 \\
\hline 5.39 & 23.61 & 70.99 & 9.50 & 0.40 & 0.85 & 0.61 & 3.06 & 65.22 \\
\hline 10.26 & 22.40 & 67.34 & 9.66 & 0.75 & 0.87 & 0.73 & 3.16 & 113.20 \\
\hline 15.17 & 21.17 & 63.65 & 9.87 & 1.12 & 0.88 & 0.77 & 3.22 & 142.80 \\
\hline 20.64 & 19.81 & 59.55 & 10.06 & 1.53 & 0.89 & 0.78 & 3.28 & 157.85 \\
\hline
\end{tabular}




\begin{tabular}{|c|c|c|c|c|c|c|c|c|}
\hline $\mathrm{TiO}_{2} \mathrm{PVC}$ & $\begin{array}{l}\text { Extender } \\
\text { PVC }\end{array}$ & Resin & $\begin{array}{c}\text { Paint } \\
\text { Density } \\
{[\text { lbs/gal }]}\end{array}$ & $\begin{array}{c}\mathrm{TiO}_{2} \\
\text { Content } \\
{[\mathrm{lbs} / \mathrm{gal}]}\end{array}$ & $\begin{array}{c}\mathrm{R} \text { o } \\
\text { White }\end{array}$ & $\begin{array}{c}\text { R o } \\
\text { Black }\end{array}$ & $\begin{array}{l}\text { Weight } \\
\text { [grams] }\end{array}$ & $\begin{array}{c}\text { S Rate } \\
{\left[\mathrm{ft}^{\wedge} 2 / \mathrm{gal}\right]}\end{array}$ \\
\hline 25.36 & 18.63 & 56.01 & 10.19 & 1.88 & 0.89 & 0.79 & 3.20 & 166.29 \\
\hline 30.12 & 17.44 & 52.44 & 10.39 & 2.22 & 0.89 & 0.80 & 3.23 & 168.63 \\
\hline 35.15 & 16.19 & 48.66 & 10.52 & 2.60 & 0.90 & 0.83 & 3.24 & 201.29 \\
\hline 39.71 & 15.05 & 45.24 & 10.68 & 2.96 & 0.91 & 0.85 & 3.27 & 239.80 \\
\hline 45.32 & 13.65 & 41.03 & 10.98 & 3.36 & 0.92 & 0.88 & 3.36 & 304.72 \\
\hline \multicolumn{9}{|l|}{25 PVC O15 } \\
\hline 0.00 & 24.96 & 75.04 & & & & & & 0.00 \\
\hline 5.78 & 24.70 & 69.52 & 9.53 & 0.43 & 0.86 & 0.63 & 3.23 & 63.18 \\
\hline 10.13 & 24.92 & 64.95 & 9.71 & 0.75 & 0.87 & 0.72 & 3.33 & 102.34 \\
\hline 15.26 & 24.86 & 59.87 & 9.90 & 1.13 & 0.88 & 0.76 & 3.31 & 127.64 \\
\hline 19.91 & 24.90 & 55.19 & 10.00 & 1.48 & 0.88 & 0.77 & 3.28 & 138.25 \\
\hline 25.01 & 24.76 & 50.23 & 10.44 & 1.86 & 0.89 & 0.78 & 3.30 & 149.84 \\
\hline 29.87 & 24.94 & 45.19 & 10.54 & 2.20 & 0.89 & 0.80 & 3.34 & 173.37 \\
\hline 35.25 & 24.76 & 39.99 & 10.83 & 2.62 & 0.90 & 0.84 & 3.46 & 223.24 \\
\hline 40.11 & 24.92 & 34.97 & 11.09 & 2.96 & 0.91 & 0.86 & 3.63 & 276.03 \\
\hline 44.80 & 24.82 & 30.38 & 11.50 & 3.33 & 0.92 & 0.88 & 3.76 & 316.81 \\
\hline \multicolumn{9}{|l|}{$30 \% \mathrm{O} 15$} \\
\hline 0.00 & 29.02 & 70.98 & & & & & & 0.00 \\
\hline 5.19 & 27.51 & 67.30 & 9.56 & 0.38 & 0.85 & 0.58 & 2.80 & 59.77 \\
\hline 9.97 & 26.12 & 63.90 & 9.74 & 0.74 & 0.87 & 0.69 & 2.86 & 100.62 \\
\hline 15.08 & 24.64 & 60.28 & 9.90 & 1.11 & 0.88 & 0.73 & 2.90 & 126.96 \\
\hline 20.20 & 23.15 & 56.64 & 10.07 & 1.49 & 0.88 & 0.75 & 2.89 & 140.78 \\
\hline 25.21 & 21.70 & 53.09 & 10.16 & 1.86 & 0.89 & 0.79 & 3.23 & 148.20 \\
\hline 29.99 & 20.32 & 49.70 & 10.31 & 2.21 & 0.90 & 0.79 & 3.34 & 137.22 \\
\hline 35.29 & 18.78 & 45.93 & 10.36 & 2.61 & 0.90 & 0.82 & 3.34 & 174.41 \\
\hline 39.83 & 17.46 & 42.71 & 10.52 & 2.95 & 0.91 & 0.85 & 3.40 & 219.51 \\
\hline \multicolumn{9}{|l|}{30 PVC 015} \\
\hline 0.00 & 29.02 & 70.98 & & & & & & 0.00 \\
\hline 4.99 & 30.13 & 64.88 & 9.64 & 0.37 & 0.86 & 0.60 & 3.26 & 56.20 \\
\hline 10.00 & 30.03 & 59.97 & 9.83 & 0.74 & 0.87 & 0.69 & 3.27 & 89.94 \\
\hline 14.96 & 30.02 & 55.02 & 10.04 & 1.11 & 0.88 & 0.73 & 3.21 & 111.50 \\
\hline 20.01 & 30.02 & 49.98 & 10.25 & 1.47 & 0.88 & 0.75 & 3.27 & 121.73 \\
\hline
\end{tabular}




\begin{tabular}{|c|c|c|c|c|c|c|c|c|}
\hline $\mathrm{TiO}_{2} \mathrm{PVC}$ & $\begin{array}{l}\text { Extender } \\
\text { PVC }\end{array}$ & Resin & $\begin{array}{c}\text { Paint } \\
\text { Density } \\
{[\text { lbs/gal }]}\end{array}$ & $\begin{array}{c}\mathrm{TiO}_{2} \\
\text { Content } \\
{[\mathrm{lbs} / \mathrm{gal}]}\end{array}$ & $\begin{array}{c}\mathrm{R} \text { o } \\
\text { White }\end{array}$ & $\begin{array}{c}\mathrm{R} \mathrm{o} \\
\text { Black }\end{array}$ & $\begin{array}{l}\text { Weight } \\
\text { [grams] }\end{array}$ & $\begin{array}{c}\text { S Rate } \\
{\left[\mathrm{ft}^{\wedge} 2 / \mathrm{gal}\right]}\end{array}$ \\
\hline 24.95 & 29.98 & 45.08 & 10.37 & 1.84 & 0.89 & 0.77 & 3.35 & 148.10 \\
\hline 29.90 & 29.91 & 40.19 & 10.65 & 2.21 & 0.90 & 0.81 & 3.35 & 185.10 \\
\hline 34.63 & 30.70 & 34.66 & 10.81 & 2.57 & 0.91 & 0.84 & 3.52 & 234.01 \\
\hline 39.93 & 30.06 & 30.00 & 11.38 & 2.95 & 0.92 & 0.87 & 3.79 & 277.72 \\
\hline \multicolumn{9}{|l|}{$35 \%$ O15 } \\
\hline 0.00 & 34.96 & 65.04 & & & & & & 0.00 \\
\hline 5.01 & 33.21 & 61.78 & 9.59 & 0.37 & 0.85 & 0.59 & 2.69 & 74.30 \\
\hline 10.02 & 31.45 & 58.53 & 9.78 & 0.74 & 0.87 & 0.69 & 2.79 & 108.07 \\
\hline 15.03 & 29.70 & 55.27 & 9.88 & 1.11 & 0.88 & 0.73 & 2.93 & 129.67 \\
\hline 20.71 & 27.72 & 51.57 & 10.51 & 1.54 & 0.88 & 0.76 & 3.33 & 128.60 \\
\hline 24.89 & 26.25 & 48.85 & 10.21 & 1.87 & 0.89 & 0.78 & 3.12 & 154.15 \\
\hline 30.11 & 24.43 & 45.46 & 10.34 & 1.35 & 0.89 & 0.80 & 3.22 & 186.46 \\
\hline 34.98 & 22.73 & 42.29 & 10.59 & 2.58 & 0.91 & 0.85 & 3.34 & 242.36 \\
\hline 39.97 & 20.99 & 39.05 & 10.88 & 2.96 & 0.92 & 0.88 & 3.32 & 320.55 \\
\hline \multicolumn{9}{|l|}{35 PVC O15 } \\
\hline 0.00 & 34.96 & 65.04 & & & & & & 0.00 \\
\hline 5.02 & 35.02 & 59.96 & 9.74 & 0.37 & 0.86 & 0.57 & 3.29 & 43.05 \\
\hline 9.99 & 35.01 & 55.00 & 9.93 & 0.74 & 0.87 & 0.67 & 3.26 & 73.62 \\
\hline 14.99 & 35.07 & 49.95 & 10.04 & 1.11 & 0.88 & 0.72 & 3.40 & 87.67 \\
\hline 19.98 & 35.10 & 44.93 & 10.71 & 1.48 & 0.88 & 0.74 & 3.56 & 110.44 \\
\hline 24.96 & 35.07 & 39.97 & 10.93 & 1.85 & 0.89 & 0.79 & 3.62 & 150.28 \\
\hline 29.95 & 35.11 & 34.94 & 11.29 & 2.21 & 0.90 & 0.82 & 3.67 & 193.55 \\
\hline 35.04 & 35.05 & 29.92 & 11.34 & 2.59 & 0.91 & 0.85 & 3.71 & 244.69 \\
\hline \multicolumn{9}{|l|}{$40 \% \mathrm{O} 15$} \\
\hline 0.00 & 39.95 & 60.05 & 9.74 & 0.00 & 0.82 & 0.07 & 3.21 & 0.00 \\
\hline 5.03 & 37.94 & 57.03 & 9.74 & 0.37 & 0.85 & 0.54 & 3.21 & 34.46 \\
\hline 10.06 & 35.93 & 54.01 & 9.93 & 0.74 & 0.86 & 0.65 & 3.18 & 70.54 \\
\hline 15.02 & 33.95 & 51.03 & 10.04 & 1.10 & 0.87 & 0.69 & 3.21 & 87.90 \\
\hline 20.02 & 31.95 & 48.03 & 10.71 & 1.47 & 0.88 & 0.73 & 3.19 & 118.99 \\
\hline 25.03 & 29.95 & 45.02 & 10.93 & 1.84 & 0.89 & 0.78 & 3.34 & 156.46 \\
\hline 29.93 & 27.99 & 42.08 & 11.29 & 2.21 & 0.89 & 0.81 & 3.37 & 201.29 \\
\hline 35.20 & 25.88 & 38.91 & 11.34 & 2.60 & 0.91 & 0.84 & 3.49 & 251.96 \\
\hline
\end{tabular}




\begin{tabular}{|r|r|r|r|r|r|r|r|r|}
\hline $\mathrm{TiO}_{2} \mathrm{PVC}$ & $\begin{array}{c}\text { Extender } \\
\text { PVC }\end{array}$ & Resin & $\begin{array}{c}\text { Paint } \\
\text { Density } \\
{[\text { lbs/gal] }}\end{array}$ & $\begin{array}{c}\mathrm{TiO}_{2} \\
\text { Content } \\
\text { [lbs/gal] }\end{array}$ & $\begin{array}{c}\mathrm{R} \mathrm{o} \\
\text { White }\end{array}$ & $\begin{array}{c}\mathrm{R} \text { o } \\
\text { Black }\end{array}$ & $\begin{array}{c}\text { Weight } \\
\text { [grams] }\end{array}$ & $\begin{array}{c}\text { S Rate } \\
{\left[\mathrm{ft}^{\wedge} \text { 2/gal] }\right.}\end{array}$ \\
\hline $40 \mathrm{PVC} \mathrm{O15}$ & & & & & & & & \\
\hline 0.00 & 39.95 & 60.05 & & & & & & 0.00 \\
\hline 5.00 & 40.00 & 55.00 & 9.91 & 0.37 & 0.85 & 0.55 & 3.14 & 38.94 \\
\hline 9.99 & 40.01 & 50.00 & 10.11 & 0.74 & 0.86 & 0.65 & 3.23 & 72.83 \\
\hline 15.00 & 40.04 & 44.97 & 10.24 & 1.10 & 0.87 & 0.70 & 3.24 & 97.30 \\
\hline 19.96 & 40.02 & 40.02 & 10.56 & 1.47 & 0.88 & 0.74 & 3.39 & 120.82 \\
\hline 25.27 & 39.82 & 34.91 & 10.95 & 1.87 & 0.89 & 0.79 & 3.56 & 164.41 \\
\hline 29.88 & 40.24 & 29.88 & 11.15 & 2.21 & 0.90 & 0.84 & 3.78 & 233.88 \\
\hline
\end{tabular}




\section{Appendix F: Paint Drawdown Raw Data - Omyacarb UF}

\begin{tabular}{|c|c|c|c|c|c|c|c|c|}
\hline $\begin{array}{l}\mathrm{TiO}_{2} \\
\mathrm{PVC}\end{array}$ & $\begin{array}{l}\text { Extender } \\
\text { PVC }\end{array}$ & Resin & $\begin{array}{c}\text { Paint } \\
\text { Density } \\
{[\text { lbs/gal] }}\end{array}$ & $\begin{array}{c}\mathrm{TiO}_{2} \\
\text { Content } \\
\text { [lbs/gal] }\end{array}$ & $\begin{array}{c}\text { Ro } \\
\text { White }\end{array}$ & $\begin{array}{c}\mathrm{R} \mathrm{o} \\
\text { Black }\end{array}$ & $\begin{array}{c}\text { Weight } \\
\text { [grams] }\end{array}$ & $\begin{array}{c}\text { S Rate } \\
{\left[\mathrm{ft}^{\wedge} 2 / \mathrm{gal}\right]}\end{array}$ \\
\hline \multicolumn{9}{|l|}{$\begin{array}{l}5 \mathrm{PVC} \\
\text { OUF }\end{array}$} \\
\hline 0.00 & 5.08 & 94.92 & 8.73 & 0.00 & 0.82 & 0.02 & 2.53 & 0.00 \\
\hline 5.07 & 5.13 & 89.81 & 8.95 & 0.37 & 0.85 & 0.62 & 2.64 & 73.28 \\
\hline 10.18 & 5.00 & 84.83 & 9.24 & 0.75 & 0.88 & 0.74 & 2.71 & 141.61 \\
\hline 15.01 & 5.51 & 79.48 & 9.43 & 1.11 & 0.89 & 0.79 & 2.84 & 185.44 \\
\hline 20.05 & 4.98 & 74.97 & 9.70 & 1.48 & 0.90 & 0.82 & 2.96 & 215.56 \\
\hline 24.77 & 5.91 & 69.32 & 9.83 & 1.83 & 0.91 & 0.84 & 3.05 & 207.23 \\
\hline 29.97 & 5.11 & 64.92 & 10.14 & 2.21 & 0.92 & 0.85 & 3.16 & 205.87 \\
\hline 34.80 & 5.09 & 60.12 & 10.37 & 2.57 & 0.92 & 0.85 & 3.18 & 172.34 \\
\hline 39.89 & 5.20 & 54.92 & 10.53 & 2.95 & 0.92 & 0.87 & 3.20 & 221.18 \\
\hline 44.86 & 5.16 & 49.98 & 10.59 & 3.31 & 0.93 & 0.89 & 3.21 & 289.56 \\
\hline 49.98 & 5.10 & 44.92 & 10.78 & 3.69 & 0.94 & 0.91 & 3.24 & 382.19 \\
\hline \multicolumn{9}{|l|}{$\begin{array}{l}10 \mathrm{PVC} \\
\text { OUF }\end{array}$} \\
\hline 0.00 & 10.34 & 89.66 & 8.86 & 0.00 & 0.82 & 0.03 & 2.55 & 0.00 \\
\hline 5.04 & 10.05 & 84.91 & 9.09 & 0.37 & 0.85 & 0.62 & 2.67 & 69.36 \\
\hline 10.04 & 10.05 & 79.91 & 9.38 & 0.74 & 0.88 & 0.74 & 2.81 & 129.75 \\
\hline 15.04 & 10.10 & 74.86 & 9.55 & 1.11 & 0.89 & 0.80 & 2.93 & 168.98 \\
\hline 20.01 & 10.08 & 69.91 & 9.76 & 1.48 & 0.90 & 0.82 & 3.02 & 186.29 \\
\hline 24.95 & 10.14 & 64.91 & 9.96 & 1.84 & 0.91 & 0.84 & 3.13 & 181.56 \\
\hline 29.96 & 10.11 & 59.94 & 10.16 & 2.21 & 0.92 & 0.85 & 3.17 & 164.68 \\
\hline 34.81 & 10.12 & 55.07 & 10.41 & 2.57 & 0.92 & 0.86 & 3.13 & 200.11 \\
\hline 39.99 & 10.16 & 49.85 & 10.55 & 2.95 & 0.93 & 0.88 & 3.14 & 295.23 \\
\hline 44.89 & 10.16 & 44.95 & 10.73 & 3.32 & 0.95 & 0.92 & 3.31 & 473.19 \\
\hline 49.29 & 10.46 & 40.24 & 11.11 & 3.64 & 0.95 & 0.93 & 3.46 & 563.50 \\
\hline \multicolumn{9}{|l|}{$\begin{array}{l}15 \mathrm{PVC} \\
\text { OUF }\end{array}$} \\
\hline 0.00 & 14.96 & 85.04 & 8.99 & 0.00 & 0.82 & 0.04 & 2.74 & 0.00 \\
\hline 5.00 & 15.12 & 79.88 & 9.24 & 0.37 & 0.85 & 0.61 & 2.80 & 64.80 \\
\hline 9.98 & 15.11 & 74.91 & 9.46 & 0.74 & 0.88 & 0.74 & 2.91 & 122.38 \\
\hline 14.98 & 15.09 & 69.93 & 9.73 & 1.10 & 0.89 & 0.79 & 3.05 & 161.03 \\
\hline 20.05 & 15.06 & 64.89 & 9.82 & 1.47 & 0.90 & 0.82 & 3.11 & 170.97 \\
\hline
\end{tabular}




\begin{tabular}{|c|c|c|c|c|c|c|c|c|}
\hline $\begin{array}{l}\mathrm{TiO}_{2} \\
\mathrm{PVC}\end{array}$ & $\begin{array}{r}\text { Extender } \\
\text { PVC }\end{array}$ & Resin & $\begin{array}{r}\text { Paint } \\
\text { Density } \\
{[\mathrm{lbs} / \text { gal }]}\end{array}$ & $\begin{array}{r}\mathrm{TiO}_{2} \\
\text { Content } \\
{[\mathrm{lbs} / \mathrm{gal}]}\end{array}$ & $\begin{array}{r}\text { Ro } \\
\text { White }\end{array}$ & $\begin{array}{r}\text { R o } \\
\text { Black }\end{array}$ & $\begin{array}{l}\text { Weight } \\
\text { [grams] }\end{array}$ & $\begin{array}{r}\text { S Rate } \\
{\left[\mathrm{ft}^{\wedge} 2 / \text { gal }\right]}\end{array}$ \\
\hline 25.01 & 15.03 & 59.96 & 10.10 & 1.84 & 0.91 & 0.83 & 3.16 & 182.37 \\
\hline 29.93 & 15.00 & 55.07 & 10.32 & 2.20 & 0.91 & 0.85 & 3.14 & 213.42 \\
\hline 34.98 & 15.11 & 49.92 & 10.43 & 2.57 & 0.92 & 0.87 & 3.16 & 272.70 \\
\hline 39.84 & 14.99 & 45.17 & 10.60 & 2.93 & 0.93 & 0.89 & 3.21 & 347.03 \\
\hline 44.62 & 15.20 & 40.18 & 10.88 & 3.28 & 0.94 & 0.91 & 3.26 & 414.88 \\
\hline \multicolumn{9}{|l|}{$\begin{array}{l}20 \mathrm{PVC} \\
\text { OUF }\end{array}$} \\
\hline 0.00 & 20.06 & 79.94 & 9.21 & 0.00 & 0.82 & 0.04 & 2.78 & 0.00 \\
\hline 5.02 & 20.09 & 74.89 & 9.35 & 0.37 & 0.86 & 0.62 & 2.88 & 63.13 \\
\hline 10.00 & 20.06 & 69.94 & 9.56 & 0.74 & 0.88 & 0.74 & 2.97 & 111.35 \\
\hline 14.98 & 20.01 & 65.00 & 9.83 & 1.10 & 0.89 & 0.79 & 3.06 & 143.56 \\
\hline 20.00 & 20.08 & 59.92 & 10.02 & 1.47 & 0.90 & 0.81 & 3.10 & 159.52 \\
\hline 24.95 & 20.02 & 55.03 & 10.11 & 1.83 & 0.91 & 0.83 & 3.06 & 179.00 \\
\hline 29.95 & 20.10 & 49.95 & 10.36 & 2.20 & 0.92 & 0.86 & 3.07 & 250.25 \\
\hline 34.90 & 20.15 & 44.95 & 10.68 & 2.56 & 0.93 & 0.89 & 3.10 & 329.89 \\
\hline 39.88 & 20.15 & 39.97 & 11.14 & 2.93 & 0.93 & 0.90 & 3.15 & 412.78 \\
\hline 45.50 & 19.70 & 34.80 & 11.40 & 3.34 & 0.94 & 0.91 & 3.22 & 475.40 \\
\hline \multicolumn{9}{|l|}{$\begin{array}{l}25 \text { PVC } \\
\text { OUF }\end{array}$} \\
\hline 0.00 & 24.96 & 75.04 & 9.32 & 0.00 & 0.82 & 0.06 & 2.84 & 0.00 \\
\hline 5.02 & 25.08 & 69.90 & 9.48 & 0.37 & 0.86 & 0.61 & 2.91 & 66.27 \\
\hline 9.97 & 25.12 & 64.91 & 9.67 & 0.73 & 0.88 & 0.72 & 3.00 & 85.72 \\
\hline 14.98 & 24.95 & 60.07 & 9.87 & 1.10 & 0.89 & 0.77 & 3.01 & 115.12 \\
\hline 20.07 & 24.92 & 55.00 & 10.14 & 1.47 & 0.90 & 0.82 & 3.02 & 184.02 \\
\hline 24.93 & 25.01 & 50.06 & 10.20 & 1.83 & 0.91 & 0.86 & 3.02 & 247.52 \\
\hline 29.91 & 24.96 & 45.12 & 10.42 & 2.20 & 0.93 & 0.88 & 3.10 & 324.63 \\
\hline 34.96 & 25.34 & 39.70 & 10.92 & 2.57 & 0.93 & 0.90 & 3.17 & 410.70 \\
\hline 40.04 & 25.14 & 34.82 & 11.26 & 2.94 & 0.94 & 0.91 & 3.18 & 473.19 \\
\hline 45.61 & 24.65 & 29.74 & 11.54 & 3.35 & 0.94 & 0.92 & 3.29 & 525.02 \\
\hline \multicolumn{9}{|l|}{$\begin{array}{l}30 \mathrm{PVC} \\
\text { OUF }\end{array}$} \\
\hline 0.00 & 30.29 & 69.71 & 9.39 & 0.00 & 0.82 & 0.08 & 2.97 & 0.00 \\
\hline 5.00 & 30.09 & 64.91 & 9.62 & 0.37 & 0.86 & 0.62 & 3.05 & 62.80 \\
\hline 10.00 & 30.16 & 59.85 & 9.84 & 0.74 & 0.88 & 0.72 & 2.98 & 86.12 \\
\hline 14.99 & 30.03 & 54.98 & 10.05 & 1.11 & 0.89 & 0.79 & 3.01 & 145.87 \\
\hline
\end{tabular}




\begin{tabular}{|c|c|c|c|c|c|c|c|c|}
\hline $\begin{array}{l}\mathrm{TiO}_{2} \\
\mathrm{PVC}\end{array}$ & $\begin{array}{l}\text { Extender } \\
\text { PVC }\end{array}$ & Resin & $\begin{array}{c}\text { Paint } \\
\text { Density } \\
{[\mathrm{lbs} / \text { gal }]}\end{array}$ & $\begin{array}{c}\mathrm{TiO}_{2} \\
\text { Content } \\
{[\mathrm{lbs} / \mathrm{gal}]}\end{array}$ & $\begin{array}{c}\text { Ro } \\
\text { White }\end{array}$ & $\begin{array}{c}\text { R o } \\
\text { Black }\end{array}$ & $\begin{array}{l}\text { Weight } \\
\text { [grams] }\end{array}$ & $\begin{array}{c}\text { S Rate } \\
{\left[\mathrm{ft}^{\wedge} 2 / \text { gal }\right]}\end{array}$ \\
\hline 19.84 & 30.01 & 50.15 & 10.27 & 1.47 & 0.91 & 0.83 & 3.04 & 201.49 \\
\hline 24.59 & 30.78 & 44.63 & 10.48 & 1.82 & 0.92 & 0.87 & 3.10 & 271.43 \\
\hline 29.88 & 30.56 & 39.57 & 10.77 & 2.21 & 0.93 & 0.89 & 3.15 & 356.44 \\
\hline 34.83 & 30.04 & 35.13 & 10.97 & 2.58 & 0.94 & 0.91 & 3.27 & 417.86 \\
\hline 39.30 & 29.85 & 30.85 & 11.26 & 2.91 & 0.94 & 0.91 & 3.32 & 455.72 \\
\hline \multicolumn{9}{|l|}{$\begin{array}{l}35 \mathrm{PVC} \\
\text { OUF }\end{array}$} \\
\hline 0.00 & 35.04 & 64.96 & 9.49 & 0.00 & 0.82 & 0.08 & 3.01 & 0.00 \\
\hline 5.06 & 34.98 & 59.96 & 9.54 & 0.36 & 0.86 & 0.61 & 2.99 & 62.60 \\
\hline 11.92 & 34.23 & 53.86 & 9.82 & 0.86 & 0.89 & 0.76 & 3.02 & 110.89 \\
\hline 15.03 & 35.00 & 49.97 & 9.95 & 1.08 & 0.90 & 0.81 & 3.03 & 160.27 \\
\hline 19.95 & 35.05 & 45.00 & 10.05 & 1.43 & 0.91 & 0.85 & 3.09 & 232.41 \\
\hline 25.00 & 35.03 & 39.97 & 10.27 & 1.80 & 0.92 & 0.88 & 3.18 & 315.58 \\
\hline 29.91 & 35.04 & 35.05 & 10.75 & 2.15 & 0.93 & 0.90 & 3.26 & 387.28 \\
\hline 34.90 & 35.02 & 30.09 & 11.05 & 2.51 & 0.94 & 0.91 & 3.42 & 454.20 \\
\hline \multicolumn{9}{|l|}{$\begin{array}{l}40 \text { PVC } \\
\text { OUF }\end{array}$} \\
\hline 0.00 & 39.86 & 60.14 & 9.59 & 0.00 & 0.82 & 0.11 & 2.96 & 0.00 \\
\hline 5.02 & 40.18 & 54.80 & 9.67 & 0.36 & 0.86 & 0.62 & 2.95 & 58.37 \\
\hline 10.35 & 40.29 & 49.36 & 9.80 & 0.74 & 0.88 & 0.77 & 2.95 & 133.27 \\
\hline 15.54 & 39.90 & 44.56 & 10.32 & 1.12 & 0.91 & 0.84 & 3.07 & 237.28 \\
\hline 21.25 & 39.25 & 39.50 & 10.57 & 1.53 & 0.92 & 0.88 & 3.12 & 319.79 \\
\hline 24.85 & 39.95 & 35.20 & 10.66 & 1.78 & 0.93 & 0.89 & 3.15 & 359.91 \\
\hline 29.95 & 39.98 & 30.08 & 11.04 & 2.15 & 0.93 & 0.90 & 3.23 & 423.07 \\
\hline
\end{tabular}

